\title{
CONTROLE QUÍMICO DA REBROTA DO MILHETO USADO COMO COBERTURA VEGETAL PARA SISTEMA DE SEMEADURA DIRETA NO CERRADO
}

\section{LUIZ ALBINO BONAMIGO}

Engenheiro Agrônomo

Orientador: Prof. Dr. ANTÔNIO LUIZ FANCELLI

Dissertação apresentada à Escola Superior de Agricultura "Luiz de Queiroz", da Universidade de São Paulo, para obtenção do título de Mestre em Agronomia, Área de Concentração: Fitotecnia.

PIRACICABA

Estado de São Paulo - Brasil

Fevereiro - 1997 


\section{Dados Internacionais de Catalogaçāo na Publicaçāo (CIP) DIVISÃo DE BIBLIOTECA E DOCUMENTAÇÃO - Campus "Luiz de Queiroz"/USP}

\section{Bonamigo, Luiz Albino}

Controle quimico da rebrota do milheto usado como cobertura vegetal para sistema de semeadura direta no cerrado / Luiz Albino Bonamigo. - - Piracicaba, 1997.

$$
81 \text { p. : il. }
$$

Dissertação (mestrado) - - Escola Superior de Agricultura Luiz de Queiroz, 1997. Bibliografia.

1. Cobertura vegetal 2. Controle quimico 3. Herbicida 4. Milheto (rebrota) 5. Solo de cerrado I. Titulo 


\title{
CONTROLE QUIMICO DA REBROTA DO MILHETO USADO COMO COBERTURA VEGETAL PARA SISTEMA DE SEMEADURA DIRETA NO CERRADO
}

\author{
LUIZ ALBINO BONAMIGO
}

Aprovada em 21.08.1997

Comissão julgadora:

Prof. Dr. Antonio Luiz Fancelli ESALQ/USP

Prof. Dr Ricardo Victória Filho ESALQ/USP

Prof. Dr. Julio Cezar Durigan

FCAVJ/UNESP

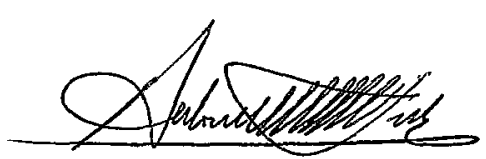

Prof. ANTÔNIO LUIZ FANCELLI

Orientador 
À minha esposa Maísa, compreensão e amor 


\section{AGRADECIMENTOS}

Ao professor Dr. Antônio Luiz Fancelli, pelo apoio e confiança, desde o início, neste trabalho.

Aos meus pais, Nilo José e Ignez, por terem propiciado chegar até aqui.

À CAPES, pela concessão da Bolsa de Estudo.

À colega Liliane Aiko Kobayashi Leonel, pelo inestimável auxílio prestado.

Aos colegas José Antônio Maior Bono e Eny Duboc, pela valiosa contribuição nas análises estatísticas.

Ao colega Dionísio Luiz Pisa Gazziero, pelo crédito inicial de oportunizar os primeiros trabalhos com rotação de culturas.

Ao colega e amigo Francisco $H$. Dübbern de Souza pelo auxílio na elaboração do Summary.

A todos que, direta ou indiretamente, contribuíram para a realização deste trabalho. 


\section{SUMÁRIO}

Página

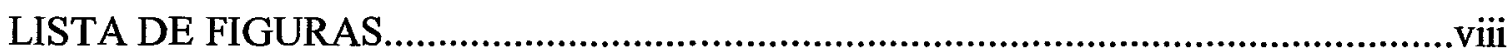

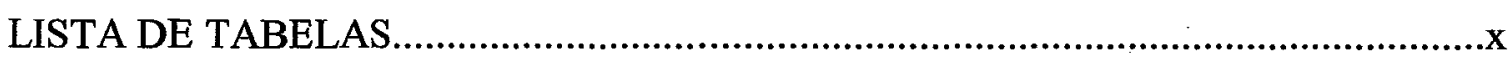

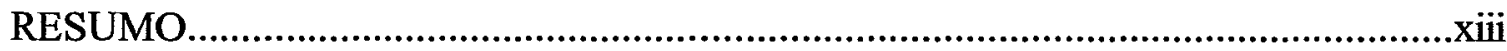

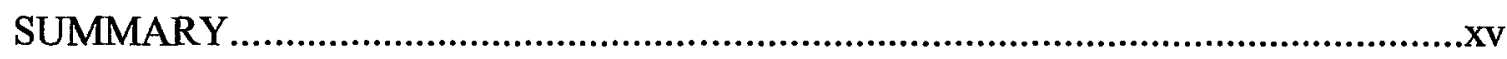

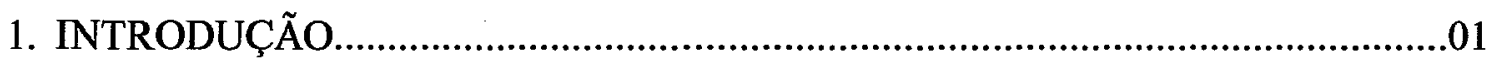

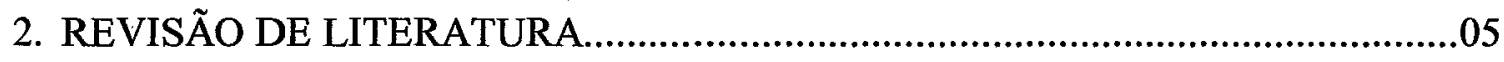

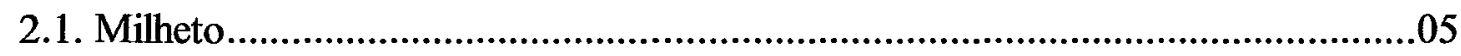

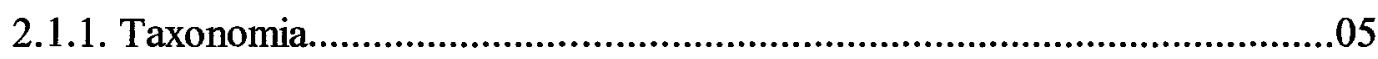

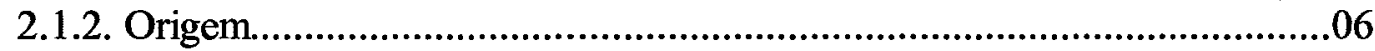

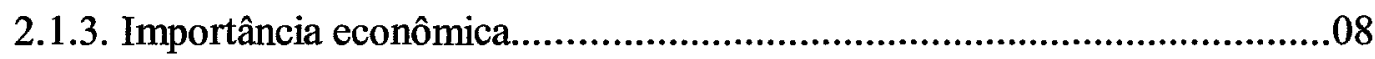

2.1.4. Características morfológicas.......................................................................08

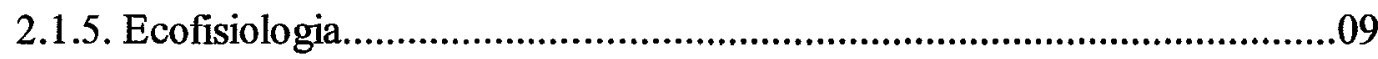

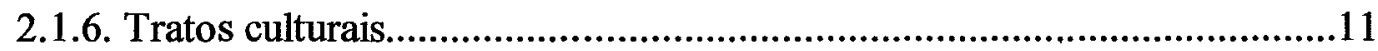

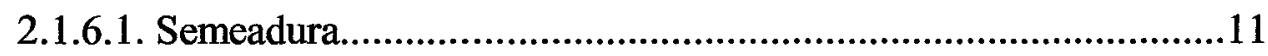

2.1.6.2. Densidade e espaçamento..............................................................11

2.1.6.3. Controle do milheto...................................................................12

2.1.7. Milheto no plantio direto.........................................................................14

2.1.8. Rebrote do milheto..............................................................................15

2.2. Escalas para a avaliação do rebrote de plantas invasoras...................................16

2.3. Herbicida glyphosate.........................................................................................17

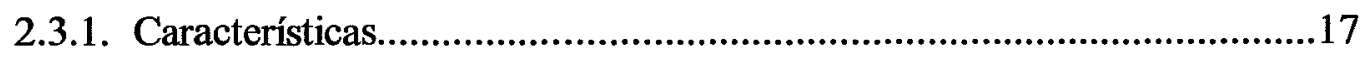

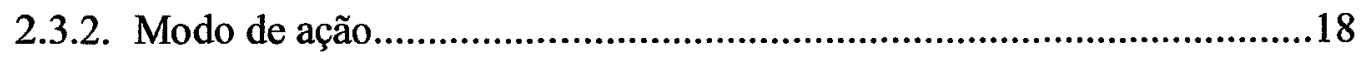

2.3.3. Absorção e translocação......................................................................19

2.3.4. Glyphosate e adjuvantes..........................................................................19

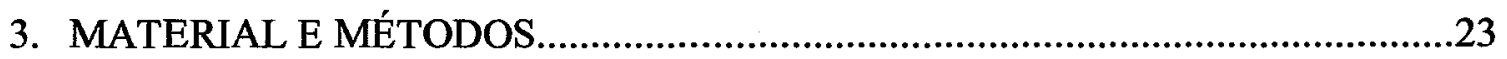

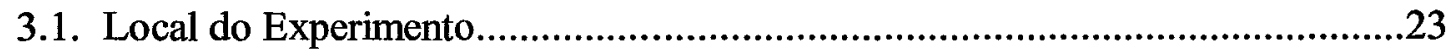

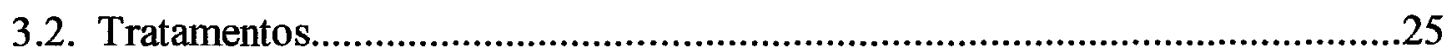


3.3. Instalação e condução dos experimentos............................................................26

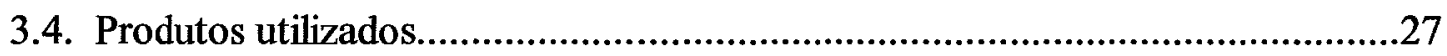

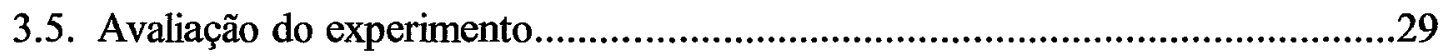

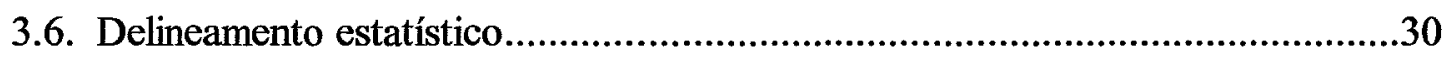

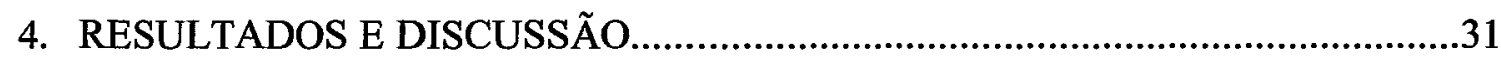

4.1. Ação do glyphosate sozinho ou com adjuvantes sobre o milheto.........................32

4.2. Época de controle do milheto.........................................................................35

4.3. Diferenças de controle do milheto aos 15 e 30 dias, em diversas doses..............38

4.4. Correlação de doses do herbicida em duas épocas sobre o controle do milheto..42

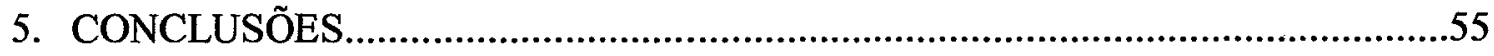

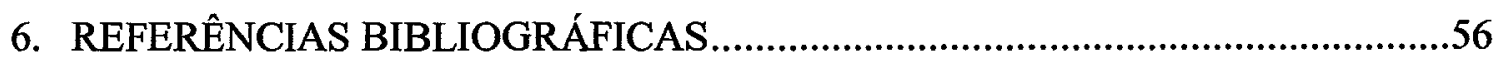

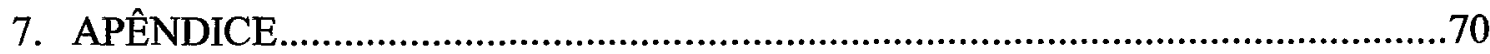




\section{LISTA DE FIGURAS}

Figuras. Página

01. Rolo-faca de levante hidráulico. .26

02. Eficiência de controle do glyphosate com vários adjuvantes na dose de 1,00 1/ha.....39

03. Eficiência de controle do glyphosate com vários adjuvantes na dose de 1,25 1/ha.....40

04. Eficiência de controle do glyphosate com vários adjuvantes na dose de 1,50 1/ha.....40

05 . Eficiência de controle do glyphosate com vários adjuvantes na dose de $1,75 \mathrm{l} / \mathrm{ha} . . . .41$

06. Eficiência de controle do glyphosate com vários adjuvantes na dose de 2,00 1/ha.....41

07. Vista geral do experimento por ocasião da $2^{\mathrm{a}}$. avaliação.....................................46

08. Milheto com dose de $0,251 /$ ha de glyphosate, $2^{\mathrm{a}}$. avaliação ...............................46

09 Milheto com dose de $0,751 /$ ha de glyphosate, $2^{\mathrm{a}}$. avaliação..................................47

10. Milheto com dose de $1,251 /$ ha de glyphosate, $2^{\mathrm{a}}$. avaliação..................................47

11. Milheto com dose de $1,501 /$ ha de glyphosate, $2^{\mathrm{a}}$. avaliação..................................48

12. Milheto com dose de $2,001 /$ ha de glyphosate, $2^{\mathfrak{a}}$. avaliação................................48

13. Eficiência de controle do glyphosate em função de doses aos 15 dias de avaliação...49

14. Eficiência de controle do glyphosate em função de doses aos 30 dias de avaliação...49

15. Eficiência de controle do glyphosate + herbitencil em função de doses aos 15 dias de avaliação.

16. Eficiência de controle do glyphosate + herbitencil em função de doses aos 30 dias de avaliação

17. Eficiência de controle do glyphosate + natur'l óleo em função de doses aos 15 dias de avaliação

18. Eficiência de controle do glyphosate + natur'l óleo em função de doses aos 30 dias de avaliação

19. Eficiência de controle do glyphosate + glicol em função de doses aos 15 dias de avaliação

20. Eficiência de controle do glyphosate + glicol em função de doses aos 30 dias de avaliação. 
(1)

21. Eficiência de controle do glyphosate + assist em função de doses aos 15 dias

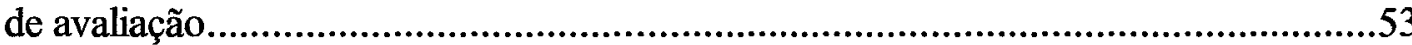

22. Eficiência de controle do glyphosate + assist em função de doses aos 30 dias

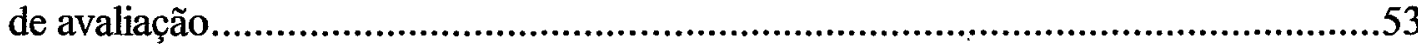


LISTA DE TABELAS

Tabelas

Página

01. Características químicas do solo da Fazenda Bonamigo, Bandeirantes-MS,1989....24

02. Tratamentos com as respectivas doses do ingrediente ativo (i.a.), e do produto comercial no controle do milheto.

03. Escala de avaliação visual usada para determinar a eficiência de controle de plantas daninhas.

04. Análise de variância para eficiência de controle do rebrote do milheto

05. Eficiência de controle do milheto em função do Herbicida Glyphosate em várias doses e diversas misturas.

06. Eficiência de controle do milheto na média de 8 doses em 2 épocas. .35

07. Porcentagem da eficiência de controle do Milheto em função de 2 épocas e 8 doses de herbicida

08. Análise de Regressão Polinomial para Variável Eficiência de Controle na Época 15 dias X Doses

09. Análise de Regressão Polinomial para Variável Eficiência de Controle na Época 30 dias X Doses.

10. Precipitação diária, em mm, ano de 1989, em Bandeirantes - MS

11. Análise de variância fixando o nível glyphosate do fator herbicida e nível 15 dias do fator época.

12. Análise de variância da regressão polinomial para os níveis de doses (glyphosate X 15dias).

13. Equações polinomiais para dados não transformados (glyphosate X 15 dias)..........72

14. Médias ajustadas pelas equações de regressão (glyphosate X 15 dias). 72

15. Análise de variância fixando o nível glyphosate do fator herbicida e nível 30 dias do fator época.

16. Análise de variância da regressão polinomial para os níveis de doses (glyphosate X 30 dias).

17. Equações polinomiais para dados não transformados (glyphosate X 30 dias). 
18. Médias ajustadas pelas equações de regressão (glyphosate X 30 dias). .73

19. Análise de variância fixando o nível glyphosate + herbitencil do fator herbicida e nível 15 dias do fator época

20. Análise de variância da regressão polinomial para os níveis de doses (glyphosate + herbitencial X 15 dias).

21. Equações polinomiais para dados não transformados (glyphosate + herbitencil $\mathrm{X}$ 15dias)

22. Médias ajustadas pelas equações de regressão (glyphosate + herbitencil X 15 dias). 74

23. Análise de variância fixando o nivel glyphosate + herbitencial do fator herbicida $e$ nível 30 dias do fator época.

24. Análise de variância da regressão polinomial para os níveis de doses (glyphosate + herbitencil X 30 dias)

25. Equações polinomiais para dados não transformados (glyphosate + herbitencil $\mathrm{X} 30$ dias).

26. Médias ajustadas pelas equações de regressão (glyphosate + herbitencil X 30 dias). 75

27. Análise de variância fixando o nível glyphosate + natur'l óleo do fator herbicida e nível de 15 dias do fator época.

28. Análise de variância da regressão polinomial para os níveis de doses ( glyphosate + natur'l óleo X 15 dias).

29. Equações polinomiais para dados não transformados (glyphosate+natur'lóleo $\mathrm{X}$ 15dias)

30. Médias ajustadas pelas equações de regressão (glyphosate + natur'lóleo X 15 dias)

31. Análise de variância fixando o nível glyphosate + natur'l óleo do fator herbicida e nível de 30 dias do fator época.

32. Análise de variância da regressão polinomial para os níveis de doses (glyphosate + natur'lóleo X 30 dias).

33. Equações polinomiais para dados não transformados (glyphosate + natur'lóleo X 30 dias) 
34. Médias ajustadas pelas equações de regressão (glyphosate + natur'lóleo

$\mathrm{X} 30$ dias).

35. Análise de variância fixando o nível glyphosate + glicol do fator herbicida e nível 15 dias do fator época. .78

36. Análise de variância da regressão polinomial para os níveis de doses (glyphosate + glicol X 15 dias). .78

37. Equações polinomiais para dados não transformados (glyphosate+glicol X15 dias). 78

38. Médias ajustadas pelas equações de regressão (glyphosate + glicol X 15 dias)........78

39. Análise de variância fixando o nível glyphosate + glicol do fator herbicida e nível 30 dias do fator época.

40. Análise de variância da regressão polinomial para os níveis de doses (glyphosate + glicol X 30 dias)

41. Equações polinomiais para dados não transformados (glyphosate + glicol $\mathrm{X} 30$ dias) .79

42. Médias ajustadas pelas equações de regressão (glyphosate + glicol X 30 dias)........79

43. Análise de variância fixando o nível glyphosate + assist do fator herbicida e nível 15 dias do fator época.

44. Análise de variância da regressão polinomial para os níveis de doses (glyphosate + assist $\mathrm{X} 15$ dias).

45. Equações polinomiais para dados não transformados (glyphosate+assist $\mathrm{X} 15$ dias). .80

46. Médias ajustadas pelas equações de regressão (glyphosate + assist X 15 dias). .80

47. Análise de variância fixando o nível glyphosate + assist do fator herbicida e nível 30 dias do fator época.

48. Análise de variância da regressão polinomial para os níveis de doses (glyphosate + assist $X 30$ dias)

49. Equações polinomiais para dados não transformados (glyphosate + assist X 30 dias).

50. Médias ajustadas pelas equações de regressão (glyphosate + assist X 30 dias). 


\title{
CONTROLE QUímico DA REBROTA DO MILHETO USADO COMO COBERTURA VEGETAL PARA SISTEMA DE SEMEADURA DIRETA NO CERRADO
}

\author{
AUTOR: LUIZ ALBINO BONAMIGO \\ ORIENTADOR: PROF. DR. ANTÔNIO LUIZ FANCELLI
}

RESUMO

O presente trabalho teve o objetivo de avaliar doses crescentes do herbicida glyphosate, associado a diversos adjuvantes, no controle do rebrote do milheto (Pennisetum glaucum), visando redução de custos no sistema de semeadura direta, nas condições do Cerrado.

A pesquisa foi conduzida em área de lavoura, sobre Latossolo Vermelho Escuro, textura média, na Fazenda Bonamigo, município de Bandeirantes, Estado de Mato Grosso do Sul.

Os tratamentos resultaram das combinações de oito doses de glyphosate, desde $90 \mathrm{~g} / \mathrm{ha}$ até $720 \mathrm{~g} / \mathrm{ha}$ do equivalente ácido (e.a.) ou $0,25 \mathrm{l} / \mathrm{ha}$ até $2,00 \mathrm{l} / \mathrm{ha} \mathrm{d}$ produto comercial (p.c.), com acréscimo em cada intervalo de $90 \mathrm{~g} / \mathrm{ha}$ (e.a.) ou 0,25 1/ha (p.c.). Para cada dose o glyphosate, foi testado isoladamente e adicionado de quatro tipos de adjuvantes: óleo mineral "Assist", óleo mineral "Glicol", óleo vegetal "Natur'lóleo" e surfatante "Herbitencil". 
O delineamento experimental adotado foi o de blocos casualizados, com parcelas subdivididas, com três repetições, perfazendo esquema fatorial $8 \times 5 \times 3$, com o fator época em parcelas subdivididas.

Após o uso do rolo-faca na cultura do milheto, foi realizada a aplicação sobre o rebrote com idade de dezesseis dias. Os efeitos dos tratamentos foram avaliados em 2 épocas, 15 e 30 dias após a aplicação dos produtos, usando a escala de notas para avaliação visual do IAPAR.

Os resultados obtidos mostraram que o acréscimo de adjuvantes não trouxe benefício no controle do rebrote do milheto, no volume de calda trabalhado.

O período de ação do glyphosate sobre o milheto abrange 30 dias, necessitando desse período para manifestar todo seu efeito.

A dose adequada, ao controle do rebrote do milheto, foi próxima a $540 \mathrm{~g} / \mathrm{ha}$ (e.a.) ou 1,50 1/h (p.c.), sendo que a menor dose utilizada correspondente a 457 g/ha (e.a.) ou 1,27 1/ha (p.c.), na mistura glyphosate + "Assist", proporcionou controle de $90 \%$.

As equações de regressão obtidas, para o glyphosate e adjuvantes, podem auxiliar no manejo do milheto, que devido as diferentes situações encontradas no Cerrado, necessita de instrumentos de apoio que proporcionem a escolha de doses adequadas a cada situação. 


\section{THE CHEMICAL CONTROL OF MILLET REGROWTH USED AS A COVER CROP FOR NO-TILLAGE SYSTEM UNDER THE BRAZILIAN CERRADO CONDITIONS}

Author: LUIZ ALBINO BONAMIGO

Adviser: PROF. DR. ANTÔNIO LUIZ FANCELLI

\section{SUMMARY}

With the aim of reducing the costs of a no-tillage system with millet as cover crop, a research was conducted to evaluate the comparative effectiveness of several doses of glyphosate, a broad-sprectum, non-selective, post-emergence herbicide, associated or not with different adjuvants, in controlling millet regrowth. The work was carried out under the Brazilian Cerrado conditions, Dark-Red Distrophic Latosol, at Fazenda Bonamigo, located in Bandeirantes, State of Mato Grosso do Sul, Brazil.

Treatments consisted of combinations of eight glyphosate doses and four types of adjuvants, namely, "Assist" mineral oil, "Glicol" mineral oil, "Natur'lóleo" vegetal oil and the surfactant "Herbitencil". Glyphosate doses varied from 90 to $720 \mathrm{~g} / \mathrm{ha}$ (a.e.) or 0,25 to $2,00 \mathrm{l} / \mathrm{ha}$ (c.p.), at $90 \mathrm{~g} / \mathrm{ha}$ or $0,25 \mathrm{l} / \mathrm{ha}$ consecutive increments. The experiment was established in a randomized block design, as a split-plot, in a $8 \times 5 \times 3$ factorial, with three blocks, each with one replications of each treatment. A millet crop was roll-cut and the treatments applied on the 16-day regrowth. Their effects were evaluated 15 and 30 days later, according to a visual scale proposed by IAPAR/BRAZIL. The time of evaluation was considered as main plot for the purpose of statistical analysis of the data. 
Results indicated that no advantages derived from the addition of adjuvants to glyphosate for millet regrowth control. At any of the compared doses, glyphosate needed 30 days to fully manifest its effects. Satisfactory control was achieved with $540 \mathrm{~g} / \mathrm{ha}$ (a.e.) of glyphosate, corresponding to $1.50 \mathrm{l} / \mathrm{ha}$ (c.p.) or with $457 \mathrm{~g} / \mathrm{ha}$ (a.e.) of glyphosate, equivalent to 1,27 1/ha (c.p.), when associated with the adjuvant "Assist".

Millet management may be facilitated by the resulted regression equations which may help choosing the most adequate glyphosate doses and adjuvant for no-tillage system used under a wide range of conditions in the Brazilian Cerrado. 


\section{INTRODUÇÃO}

A área do Cerrado no Brasil é considerada a maior fronteira agrícola contínua do mundo em condições de uso imediato, com uma extensão de 207 milhões de hectares (Resk, 1996), representando 24,3\% do território brasileiro. A utilização de áreas em 1995, estimada por Klink (1996), alcançou 69,5 milhões de hectares; sendo 11,5 milhões em lavouras, 46,4 milhões em pastagens formadas e, ainda, 11,6 milhões de terras abertas não utilizadas.

De acordo com Adámoli et al. (1985), são dois os fatores ecológicos determinantes da ocorrência do cerrado, o clima estacional e a baixa disponibilidade de nutrientes do solo. $\mathrm{O}$ clima caracteriza-se por ter duas estações, uma úmida e outra seca. O período de falta de água varia entre cinco e sete meses em 79,5\% da área. Apesar da grande diversidade de solos, predominam em $76,3 \%$ os solos ácidos, sendo $46 \%$ de Latossolos, 15,1\% de Podzólicos e 15,2\% de Areias Quartzosas.

Essas características são tão salientes que propiciam dúvidas quanto às razões do surgimento dos cerrados. Para Alvim (1996), o fator ambiental fundamental de sua formação é a falta de água, consequiência direta do regime pluvial na estação seca e indireta das limitações químicas ou físicas inerentes dos solos que limitam o desenvolvimento das raízes e, em seqüência, a absorção de água. Enquanto Ker \& Resende (1996) ressaltam que tanto o déficit hídrico como a pobreza química não são propriamente causas, mas servem como mantenedores desse ecossistema, surgido durante a fase mais seca no Brasil, ocorrida entre dez mil e vinte e oito mil anos. 
Em relação à fertilidade do solo no cerrado, a matéria orgânica é o fator de maior importância na sua manutenção e principal responsável pelo fornecimento de cargas negativas, com contribuição média à CTC de $74 \%$, variando de 56 a $91 \%$ nas camadas superficiais (Raij, 1969).

A matéria orgânica como fonte básica de energia para todos os organismos do solo mantém a diversidade dos recursos biológicos do solo (Assad, 1996).

Conforme Igue et al. (1984), a dificuldade de manter a matéria orgânica em níveis razoáveis pode ser explicada pela sua velocidade de decomposição, quatro vezes maior nas regiões tropicais quando comparada com as regiões temperadas.

Segundo Baver citado por Kiehl (1985), a estrutura do solo é a chave da sua fertilidade. Assim, definida pelo arranjo das partículas do solo em agregados, está sujeita a modificações de acordo com o manejo utilizado (Medina, 1972). A importância da matéria orgânica manifesta-se através de suas propriedades físicas e químicas que aumentam a agregação das partículas do solo, influenciando a porosidade (quantidade e distribuição de tamanho dos poros) e o armazenamento da água (Resk,1996).

A ocupação das áreas de Cerrado com a agropecuária, através de métodos tradicionais de manejo do solo, tem levado à diminuição significativa dos teores de matéria orgânica. $\mathrm{Na}$ região de Cerrados do Oeste Baiano as perdas em Areias Quartzosas (AQ), Latossolos Vermelho-Amarelo, textura média (LVm) e textura argilosa (LVa) foram de $0,32 \%, 0,30 \%$ e $0,24 \%$ por ano e, após 5 anos, resultaram em perdas de $73 \%, 68 \%$ e $45 \%$, respectivamente (Resk, 1996).

Portanto, a manutenção da matéria orgânica através de práticas que a favoreçam constitui o objetivo essencial para a conservação da capacidade produtiva dos solos agrícolas do Cerrado (Assad, 1996).

A ocorrência de intensa erosão eólica no inverno e hídrica durante o período de cultivo, agravada pelos freqüentes veranicos que atingem diretamente o rendimento das culturas comerciais no cerrado, em especial a soja e o milho, tem favorecido a divulgação dos conceitos da semeadura direta e sua rápida aceitação pelos agricultores. 
Tal sistema tem demonstrado, em várias circunstâncias, ser economicamente viável e seguro, comparativamente ao sistema tradicional de implantação de culturas.

O uso da semeadura direta tem evoluído substancialmente no Brasil, de 500 mil hectares em 1984 (Derpsch et al., 1991) para mais de 3 milhões de hectares na safra 94/95 (Pereira, 1995), alcançando por volta de 4,5 milhões de hectares na safra 1995/96, dos quais 1,5 milhões de hectares localizados no Cerrado.

Derpsch et al. (1991) afirmam que na semeadura direta observa-se melhor emergência e desenvolvimento das plantas, favorecida pelo maior contato da semente com a terra, ao contrário do solo solto resultante do preparo convencional.

A necessidade da rotação de culturas em plantio direto é ressaltada por Fancelli \& Favarin (1987), que salientam os problemas decorrentes de sua não adoção, como maior ocorrência de pragas e doenças, assim como a seleção e perpetuação de invasoras.

Todavia, a falta de espécies adaptadas ao Cerrado para a semeadura após as culturas de verão, que consigam desenvolver-se no período seco de inverno e/ou durante o curto período de primavera que antecede as culturas de verão, tem sido o fator de maior limitação à expansão do sistema de plantio direto.

Esse fato foi determinante para a implantação do sistema no Cerrado. Nesse contexto, o potencial do milheto para ocupar esse espaço pode ser avaliado em trabalhos como desenvolvidos por Pereira et al. (1987a,b).

Assim, o milheto se destaca como a cultura de maior adaptação e resposta às condições do Cerrado, dando sustentação e estruturação à semeadura direta nessa região, bem como contribuindo para o estabelecimento de bases sólidas para a implantação e consolidação do sistema.

A carência de informações dos diversos usos do milheto no Cerrado determinou a procura por respostas bastantes prementes, tanto para os técnicos como para os agricultores envolvidos com uma agricultura tecnologicamente mais avançada e racional. 
O presente trabalho tem por finalidade avaliar o emprego de diferentes dosagens de glyphosate, associadas a adjuvantes diversos, no controle do rebrote do milheto, visando a redução de custos no sistema de plantio direto ou semeadura direta nas condições do Cerrado. 


\section{REVISÃO DA LITERATURA}

\subsection{Milheto}

\subsubsection{Taxonomia}

O milheto pertence à família Poaceae (Gramineae), subfamília Panicoideae, tribo Paniceae, subtribo Panicinae, gênero Pennisetum, seção Penicillaria ( Jauhar, 1981).

A referida planta está relacionada ao gênero Pennisetum que provém da combinação de duas palavras latinas, penna que significa pena e seta significando pelo, uma referência aos pelos plumosos de algumas espécies, sendo conhecida pelo nome científico de Pennisetum glaucum, P. typhoides, P. americanum.

Vulgarmente é denominado como milheto, milhete, pasto italiano, tifóides, capim charuto, penicilária, gauchinho, pearl millet, mijo menor, mijo negro, bulrush millet, cattail millet, spiked millet, mil aux chandelles, babala ou nyoloti (África do Sul), raa, mungo, gero e maiwa (Nigéria), souna e sanio (Senegal), Kala-sat (Burma), mwele (Leste da África), bajra, bajri, cumbu e sajja (Índia) e dokhan (África Árabe).

$\mathrm{Na}$ literatura científica, encontra-se muitas vezes o milheto referenciado genericamente como millet, que pode ser identificado mais amplamente com o nome de minor millet, sendo que esta designação engloba muitos gêneros como descritos a seguir: 
Minor millets:

Pearl millet: Pennisetum glaucum, P. americanum, P. typhoides

Finger millet ou ragi: Eleusine coracana

Little millet: Panicum miliare, $P$. sumatrense

Proso ou common millet: Panicum miliaceum

Kodo millet: Paspalum scrobiculatum

Fonio: Digitaria exilis ( cultivado na África Central e Ocidental)

Iburus: Digitaria iburus

Tef: Eragrostis tef, Eragrostis abyssinica

Adlay ou job's tear: Coix lachryma-jobi ( cultivado no sudeste da Ásia)

Famine grass: Sporobolus panicoides

Brown top millet: Brachiaria ramosum

Foxtail millet: Setaria italica

Yellow foxtail: Setaria pumila, Setaria glauca

Shama ou jungle rice: Echinochloa colona

Barnyard millet: Echinochloa cruss-galli, Echinochloa utilis, Japanese barnyard millet: Echinochloa frumentacea

\subsubsection{Origem}

Durante o período Chen-Nung, 2700 A.C., foram criados ritos que ressaltavam a importância da agricultura. Assim, enquanto o próprio Imperador Chen-Nung arava e semeava o arroz numa pequena área, os príncipes da Casa Imperial tinham como privilégio o trabalho pessoal do solo e o cultivo do milheto, da soja, do trigo e do sorgo (Rohde, 1995). Estas cinco culturas eram consideradas os $\mathrm{Wu} \mathrm{Ku}$, ou seja, os grãos sagrados da China. 
O provável centro de origem do milheto situa-se na zona do Sahel, no Oeste da África, onde ocorre maior número de formas selvagens e cultivadas. Apenas uma ou duas espécies selvagens foram domesticadas e as outras raças subsequentes evoluíram por seleção em novos ambientes. As variedades utilizadas na África Ocidental possuem espiguetas densamente pilosas, diferentemente das variedades da África Oriental e da Índia, que são glabras ou possuem pequena pilosidade (Purseglove, 1972).

Segundo Andrews \& Kumar (1992), a domesticação envolveu a mudança de poucos genes e ocorreu, possivelmente, há 5000 anos na savana, sul do Saara, espalhando-se pelo leste e sul da África, chegando ao subcontinente Indiano há 3000 anos. O tipo ancestral do milheto assemelha-se ao $P$. violaceum, uma raça ssp monodii, que ainda ocorre na orla sul do Saara.

Uma evidência citogenética apoia a hipótese da África como centro de origem primário do milheto. Como a ocorrência de cromossomos acessórios servem de indicativos dos centros de origem, constatou-se maior frequêencia de cromossomos acessórios nas variedades primitivas em comparação com as variedades comerciais de milheto, onde somente nas variedades oriundas do Sudão e Nigéria foram identificados esses cromossomos (Burton \& Powell, 1968). A Índia é considerada centro de origem secundário do milheto.

Sua introdução na Europa foi realizada através de sementes coletadas na Índia e enviadas à Bélgica por volta de 1566, chegando aos Estados Unidos da América no ano de 1850.

Os primeiros relatos de sua presença no Brasil são provenientes do Rio Grande do Sul, mais especificamente da Estação Zootécnica de Montenegro, datados de 1929, onde foi avaliado por Anacreonte A. Araújo (Medeiros, 1977). 


\subsubsection{Importância econômica}

O milheto é utilizado na África e Índia como cultura de subsistência, servindo principalmente como alimento em regiões marginais para as outras culturas, ocupando uma área de 26 milhões de hectares (Andrews \& Kumar, 1992). Precipitações de apenas $150 \mathrm{~mm}$ anuais, no Sahel, não permitem outro cultivo senão o milheto.

$\mathrm{Na}$ África e Ásia é usado para consumo humano servindo como farinha para panificação e bolos, mingau, e também, como malte para fabricação de cerveja. No Brasil e EUA é utilizado como forragem para os animais.

O milheto tem sido utilizado no controle da erosão eólica, um problema que atinge 430 milhões de hectares em todo mundo (Michels, 1995).

Para Andrews \& Kumar (1992), os maiores avanços na próxima década serão advindos do desenvolvimento e adaptação do milheto como cultura de grãos, nas regiões temperadas, lembrando em alguns aspectos semelhantes a ocupação de espaço que ocorreu com a soja há 40 anos atrás nos EUA.

\subsubsection{Características morfológicas}

O milheto é uma planta anual, de porte alto e ereto, possui colmos cheios, grossos ou delgados, apresenta-se com nós pilosos abaixo da panícula e tem boa capacidade de perfilhamento.

É uma espécie de fecundação cruzada, exibindo completa protogenia. O estigma torna-se receptivo antes que as anteras liberem os grãos de pólen, apresentando um intervalo entre a emergência de todas elas e a antese de 1 a 6 dias (Andrews \& Kumar, 1992), em consequiência, é facilmente contaminado com pólen de outras áreas e espécies. 
Diversas são as denominações da inflorescência: panícula contraída (Alcântara \& Bufarah, 1979; Purseglove, 1972), terminal (Empresa Pernambucana de Pesquisa Agropecuária, 1982; Purseglove, 1972), falsa espiga (Burton \& Powell, 1968; Purseglove, 1972), ou espiga densa (Bogdan, 1977). Cada inflorescência produz entre 500 a 1500 grãos. As espiguetas medem de 4 a $7 \mathrm{~mm}$ e são em número de 1 a 5 . Ocorrem mais comumente aos pares, com um florete inferior macho séssil e um florete bissexual curtamente pedicelado.

Os grãos variam bastante em tamanho e cor, mostrando-se expandidos da lema e pálea na maturidade e, normalmente, ficam livres das glumas na colheita (Burton \& Powell, 1968). O peso de 100 sementes varia de 0,5 a 2,0 gramas. $O$ grão é composto por $75 \%$ de endosperma, $17 \%$ de embrião e $8 \%$ de farelo. O maior valor nutritivo do grão do milheto deve-se à proporção do embrião, duas vezes maior do que o sorgo, e aos seus baixos níveis de polifenóis sem tanino (Andrews \& Kumar, 1992). A referida espécie é diplóide apresentando número cromossômico $2 \mathrm{n}=14$.

\subsubsection{Ecofisiologia}

As temperaturas adequadas para o desenvolvimento do milheto são de $28^{\circ} \mathrm{C}$ para o período diurno e de $20^{\circ} \mathrm{C}$ no período noturno (Burton citado por Duarte, 1980). Porém, para a Empresa Pernambucana de Pesquisa Agropecuária (1982) as ideais durante o dia são, máxima de $40^{\circ} \mathrm{C}$, mínima de $25^{\circ} \mathrm{C}$ e ótima de $35^{\circ} \mathrm{C}$. Salienta-se, ainda, a acentuada suscetibilidade à temperatura inferior a $10^{\circ} \mathrm{C}$.

O milheto tem o ponto de saturação de luz de $80 \mathrm{Klux}$, enquanto na colza é de 60 Klux e no trigo de 50 Klux.

Quanto à eficiência fotossintética, considera-se alta à temperatura de $39^{\circ} \mathrm{C}$, $47,9 \mathrm{mg}$ de $\mathrm{CO}_{2} / \mathrm{dm}^{2}$, próxima ao milho com $45,2 \mathrm{mg}$ de $\mathrm{CO}_{2} / \mathrm{dm}^{2}$. Já a colza e o trigo, a $17,9^{\circ} \mathrm{C}$, têm a capacidade de $35 \mathrm{mg}$ de $\mathrm{CO}_{2} / \mathrm{dm}^{2}$ e $37 \mathrm{mg}$ de $\mathrm{CO}_{2}$, enquanto ambos diminuem para apenas $18 \mathrm{mg}$ de $\mathrm{CO}_{2} / \mathrm{dm}^{2}$ e $23 \mathrm{mg}$ de $\mathrm{CO}_{2}$, respectivamente, com o aumento da 
temperatura para $37^{\circ} \mathrm{C}$ (Zhang \& Han, 1988).

Segundo Burton (1965), os milhetos sensíveis ao fotoperiodismo são de dias curtos e ciclo longo, enquanto que os insensíveis (neutros em relação ao dia) ou de resposta indeterminada ao florescimento são de ciclo curto.

Em fotoperíodos de 12 horas, a espécie floresce precocemente, pois o genótipo e a temperatura não influenciam, ao contrário do que acontece sob períodos longos, de 14 a 16 horas, quando o florescimento é retardado (Bogdan, 1977).

A tolerância à baixa precipitação depende fundamentalmente da rapidez do crescimento e do ciclo precoce (Bogdan, 1977).

$\mathrm{O}$ milheto possui maior tolerância a altos níveis de alumínio tanto no solo como em solução (Buerkert et al., 1995), e também aos solos ácidos e aos solos salinos.

O desenvolvimento em solos arenosos de baixa fertilidade é superior a de qualquer outro cereal, com possível exceção dos milhetos menores (Purseglove, 1972). Nos solos pesados, não mostra igual comportamento, em razão de suas raízes desenvolverem-se superficialmente. Sua eficiência na utilização da água alinha-se entre as maiores das plantas cultivadas ( Empresa Pernambucana de Pesquisa Agropecuária, 1982).

A tolerância à seca deve-se ao rápido crescimento e desenvolvimento associada a uma rápida e profunda penetração das raízes, no entanto, no início do seu ciclo, essa tolerância diminui substancialmente.

A tolerância do milheto à erosão eólica foi avaliada por Michels et al. (1995) os quais demonstraram que a velocidade do vento afeta menos as perdas da área foliar do que o nível do fluxo de areia presente. A ação do vento, sem areia, não interferiu no peso seco das plantas. O milheto apresentou maior resistência aos danos de rajadas de areia do que outras culturas, evidenciando $100 \%$ de sobrevivência quando submetido a diferentes velocidades do vento, tais como: 8,11 ou $14 \mathrm{~m} / \mathrm{s}$, e vento mais areia (fluxo de 8,3, 25,0 ou 41,7 g/m/s). 


\subsubsection{Tratos culturais}

\subsubsection{Semeadura}

No plantio convencional, o solo deve estar bem preparado de modo a evitar o seu polvilhamento, pois com o encrostamento superficial, demonstra dificuldades na emergência. Na semeadura, a profundidade ideal da semente é de até $4 \mathrm{~cm}$ (Sivaprasad \& Sarma, 1987), observando um mínimo de terra cobrindo a mesma.

Conforme Irvine, citado por Duarte (1980), o milheto tem maior capacidade de germinar com menos umidade quando comparada a outras culturas, em geral.

\subsubsection{Densidade e espaçamento}

Quanto à produção de forragem Hart \& Burton (1965), trabalhando com os espaçamentos de 18,61 e $91 \mathrm{~cm}$ entre linhas durante três anos, apontam que na estação de maior precipitação o milheto conduzido com menor espaçamento $(18 \mathrm{~cm})$ proporcionou a maior produção. No ano em que houve precipitações adequadas, ou na média da região de Tifton, Geórgia, USA, as maiores produções foram obtidas nos espaçamentos mais amplos, embora no ano muito seco não fossem detectadas diferenças entre os três espaçamentos estudados. A aplicação de nitrogênio até $448 \mathrm{Kg} / \mathrm{ha}$ aumentou a produção de forragem, o teor de proteína bruta e de vitamina A das plantas de milheto. Mas, nem o espaçamento e nem a adubação de $\mathrm{N}$ tiveram qualquer efeito significativo sobre a digestibilidade da matéria seca.

A população do milheto não interfere na produção total e no teor de proteína bruta na planta (Medeiros \& Saibro, 1973).

Com uma melhor ocupação de espaço, através do aumento da população de 
$148 \mathrm{mil}$ para $330 \mathrm{mil}$ plantas/ha e menor espaçamento entre linhas de $45 \mathrm{~cm}$ para $20 \mathrm{~cm}$, ocorre um aumento significativo da produção (Gholve et al., 1987). Ainda, a semeadura em linha geralmente proporciona melhores resultados do que à lanço (Humphreys citado por Scheffer et al., 1985).

Embora densidades diversas não demonstrem diferenças nos rendimentos de matéria seca, o milheto, quando conduzido em maiores populações, apresenta qualidade da forragem superior, pois mostra uma melhor relação folha:colmo e maior rendimento de proteína/ha (Duarte, 1980; Medeiros, 1977). A dose de rendimento máximo de matéria seca equivalente ao ponto de maior eficiência técnica, foi de $293 \mathrm{Kg} \mathrm{N} / \mathrm{ha}$ e produziu $18,4 \mathrm{t}$ MS/ha (Medeiros \& Saibro, 1973).

\subsubsection{Controle do milheto}

O manejo inadequado das invasoras realizado por agricultores no campo, com um controle tardio das mesmas, especialmente dentro da linha de semeadura, determinou perdas médias de 27 a $36 \%$ no rendimento do milheto. Quando foi controlado precocemente, através da capina ou aplicação em pré-emergência de atrazine ou propazine na dosagem de $0,8 \mathrm{Kg} /$ ha i.a., numa faixa de $20 \mathrm{~cm}$ na linha de semeadura, foram alcançados aumentos de 36 a $50 \%$ com a capina e 33 a 54\% com os herbicidas (Carson, 1987).

O período crítico de competição das invasoras, no milheto, compreende desde a emergência até sete semanas da cultura (Carson, 1987).

Seu emprego na lavoura ocorre, normalmente, de duas maneiras. Como planta cultivada surge, muitas vezes, a necessidade de controle das plantas invasoras, tanto em pré como em pós-emergência. Por outro lado, o milheto pode surgir como infestante após a semeadura das culturais comerciais ou, ainda, ser controlado quando usado como fonte de cobertura para a semeadura direta. 
No caso de utilização em pré-emergência, Gautam \& Kaushik (1992) apontam o uso de atrazine, $0,5 \mathrm{Kg}$ do i.a./ha, como seletivo para o milheto. Também Balyan et al. (1988) utilizando atrazine na mesma dosagem em PPI (pré-plantio incorporado) e em préemergência, em solos tipo areia franca, encontraram seletividade para o milheto, no entanto quando foi realizado o replantio ou onde foi irrigado com $50 \mathrm{~mm}$ de água, o milheto foi significativamente afetado pelo herbicida.

A tolerância do milheto para atrazine em baixas dosagens é confirmada por Ndahi (1984), pois quando em aplicação de $1,5 \mathrm{Kg}$ i.a./ha apresentou fitotoxidade. De acordo com Ferraris \& Norman (1973), a atrazine utilizada na dosagem de 1,0 Kg i.a./ha controlou as plantas invasoras por apenas três semanas.

O herbicida linuron mostrou-se fitotóxico, reduzindo a produção de grãos e a fitomassa do milheto (Choudhary \& Logoke, 1981). Ndahi (1984) observou também que o linuron na dose de 1,6 Kg i.a./ha afetou o milheto, assim como a simazine na dose de $3,0 \mathrm{Kg}$ i.a./ha, reduziu a sua produção.

O herbicida propazine na dose de $0,8 \mathrm{Kg}$ i.a./ha mostrou um bom controle de invasoras e menor dano ao milheto (Choudhary \& Logoke, 1981). Também para Cummins \& Hardcastle (1980), este herbicida não apresentou fitotoxidez ao mesmo e não houve perdas no seu rendimento nas doses de 1,12 até $3,36 \mathrm{Kg}$ i.a./ha. Conforme Ndahi (1984), o milheto tolera o propazine até $1,6 \mathrm{Kg}$ i.a./ha.

No uso em pós-emergência, Cummins \& Hardcastle (1980) testaram, em área de milheto, três herbicidas com o intuito de controlar somente as plantas invasoras. Após um corte visando diminuir a competição das plantas durante o rebrote do milheto, foram aplicados glyphosate na dosagem de 2,24 Kg de i.a./ha, paraquat com 0,56 e 0,84 Kg i.a./ha e dinoseb com 3,36 e 5,6 Kg i.a./ha. O volume de calda utilizado foi de $374 \mathrm{l} / \mathrm{ha}$. Somente o dinoseb mostrou-se seletivo e apresentou bom controle das infestantes, enquanto o paraquat e, especialmente o glyphosate, mostraram-se fitotóxicos reduzindo a área foliar do milheto.

Uma invasora correlacionada com o milheto, de grande ocorrência nos EUA, é o Panicum millaceum conhecido como wild proso millet. Os herbicidas atrazine e simazine não foram eficientes para controlar esta planta (Wilson, 1992). Sua tolerância à atrazine torna seu controle difícil, especialmente na cultura do milho. Fawcett \& Harvey (1988), 
encontraram um bom controle da invasora utilizando sethoxydim em baixa dosagem (56 $\mathrm{g}$ i.a./ha) sem adjuvante. Aplicado em jato dirigido no milho com $40 \mathrm{~cm}$ de altura não provocou injúria ou prejuízo no rendimento da cultura.

\subsubsection{Milheto no plantio direto}

Com a disponibilidade do milheto variedade $\mathrm{BN}-1$, a partir de 1986 , foi superada a dificuldade inicial da implantação do sistema de semeadura direta no Cerrado, fundamentalmente em razão da sua grande produção de massa, ainda que apresente boa adaptação aos solo e clima da região.

A geração de grande quantidade de matéria verde, através de espécie cultivada para esse fim, proporciona vantagens expressivas no sistema agrícola como um todo. A cobertura do solo com palha proporcionou redução de 25 a 30\%, na necessidade da água para o milheto e aumento da produção de forragem verde, de 49,4 para 53,9 t/ha (Bogdan, 1977).

Do ponto de vista da física do solo, a presença de resíduo de culturas sobre a superfície determinou menor resistência mecânica do solo, provavelmente em razão da maior atividade de cupins e deposição de partículas grosseiras na superfície. $O$ uso da palhada aumentou o desenvolvimento radicular do milheto (Buerkert et al., 1995).

Entre os vários aspectos biológicos do sistema agrícola, a comunidade de fungos micorrízicos sofre grandes mudanças com a rotação de culturas. Como exemplo, Hendrix et al. (1995) salientaram que para determinada cultura é possível que diferentes fungos Glomus sejam mutualísticos ou patogênicos. $\mathrm{O}$ aproveitamento dessas características pode propiciar, através de adequada rotação cultural, um aumento da produtividade do solo e tornarem-se um modo fácil e menos dispendioso de desenvolver uma produção sustentável das culturas comerciais.

O fungo micorrízico aumenta, particularmente nas plantas, a capacidade de absorção de íons imóveis, de água e nitrogênio (Hendrix, 1995). O milheto em plantio direto, 
num sistema de rotação com Festuca arundinacea, diminuiu a dominância na comunidade, ao estimular a diversidade e a quantidade dos fungos (Hendrix, 1995).

A ocorrência do nematóide do cisto (Heterodera glycines), em lavouras de soja no Cerrado, tem trazido grandes prejuízos à cultura, especialmente quando conduzidas em monocultivo. Segundo Garcia \& Silva (1996), as áreas com milheto têm apresentado uma supressão do inóculo inicial do nematóide do cisto, em razão de uma maior presença de microrganismo do solo, principalmente como Fusarium solani, Fusarium oxysporum que degradam os ovos e também de Gliocadium sp. e Stagonospora sp., todos eles em maior número por provável estímulo do milheto.

\subsubsection{Rebrote do milheto}

A altura de corte mais adequada para um bom rebrote e maior produção relatada por diversos autores apresenta algumas diferenças. Alguns recomendam como altura ideal de 6 a $10 \mathrm{~cm}$, no entanto, essa medida tem como desvantagem a eliminação da maior parte das gemas basais, enquanto outros adotam o corte a $20 \mathrm{~cm}$, que, ao preservar esses pontos meristemáticos, permite rebrote mais intenso e, conseqüentemente, maior produção de fitomassa.

O milheto Gahi-1, avaliado por Clapp \& Chamblee (1970), após cortes a 8 , 10,15 e $25 \mathrm{~cm}$ de altura, em quatro ocasiões e sempre que as plantas atingiam entre $60 \mathrm{e}$ $90 \mathrm{~cm}$, apresentou um rebrote mais dependente das gemas terminais e menos do perfilhos, pois que os meristemas apicais foram pouco removidos, em todas alturas de corte, diferentemente do capim-sudão e do sorgo. Os perfilhos provenientes das gemas basais foram sempre em maior número em relação aos das gemas axilares. Especialmente após o primeiro corte, o milheto continha dez vezes mais perfilhos basais do que axilares, enquanto para os cultivares e híbridos de sorgo esta relação foi, somente, duas a três vezes maior.

Em estudo do rebrote do milheto sob corte de 10,30 e $50 \mathrm{~cm}$ de altura, 
Ferraris \& Norman (1973) corroboram esta tendência, salientando a maior produtividade e qualidade de forragem à $30 \mathrm{~cm}$ de altura.

\subsection{Escalas para a avaliação do rebrote de plantas invasoras}

Entre as escalas normalmente utilizadas para avaliar níveis de infestações de plantas invasoras e grau de fitotoxicidade da cultura, destacam-se da ALAM e da EWRC (Durigan, 1988), assim como do IAPAR (Pereira, 1989). Esta ao permitir, na avaliação da eficiência do controle das plantas infestantes, maior diferenciação em níveis mais baixos e índices de avaliação com boa distribuição no intervalo de 0 a 100 , facilita melhor a discriminação das doses necessárias dos herbicidas. Essa escala tem sido, também, aplicada na pesquisa com as plantas daninhas de culturas do cerrado do Mato Grosso do Sul pela EMPAER/MS.

A avaliação indireta, através da estimativa visual do controle do milheto, é de rápida execução e de boa representatividade pela obtenção de valores médios para a área da parcela (Sociedade Brasileira da Ciência das Plantas Daninhas, 1995).

$\mathrm{O}$ nível mínimo de controle das plantas invasoras, para interesse prático, considerado pela escala da ALAM, é de 71 a $80 \%$, enquanto na escala da EWRC e do IAPAR considera-se $90 \%$ como suficiente. As espécies infestantes apresentam diferentes capacidades de interferência junto às culturas e o milheto se alinha com as plantas de maior capacidade competitiva, em razão de suas características já citadas. Entre os diversos fatores que atuam nas áreas agrícolas, o sistema radicular das diversas espécies influencia decisivamente na pressão competitiva entre as plantas (Durigan, 1983), na absorção de água e nutrieńtes. Em decorrência de possuir um agressivo sistema radicular, o índice de controle do milheto deve ser mais rígido. Baseado na experiência a campo, foi estipulado como $90 \%$ seu nível mínimo de controle. 


\subsection{Herbicida glyphosate}

Entre os herbicidas de manejo comumente utilizados, o glyphosate, com sua ação sistêmica, proporciona um bom controle das plantas infestantes mais agressivas, quando comparado aos herbicidas com ação de contato. No manejo do milheto, que devido a sua grande capacidade de competição traz dificuldades de ser controlado, o uso de dessecantes com ação de contato pode permitir um maior rebrote da espécie, com a provável necessidade de nova aplicação (seqüencial) ou de utilização de herbicidas aplicados em pós-emergência, elevando os custos de produção das culturas.

\subsubsection{Características}

Considerado como aminoácido fosforado pertencente ao grupo químico derivados de glicina. Denominado quimicamente de sal isopropilamino de $\mathrm{N}$-(fosfonometil) glicina, de fórmula $\mathrm{C}_{3} \mathrm{H}_{8} \mathrm{NO}_{5} \mathrm{P}$. Produto com características polares de grande solubilidade em água, $10000 \mathrm{ppm}$ a $25^{\circ} \mathrm{C}$. Comercialmente é formulado como solução aquosa concentrada de $360 \mathrm{~g} / 1$ de equivalente ácido (Rodrigues \& Almeida, 1995).

Possui um largo espectro de controle. Das 78 piores plantas daninhas do mundo, 76 destas são efetivamente controladas pelo herbicida considerado (Franz, 1985). 


\subsubsection{Modo de ação}

O glyphosate afeta muitos processos internos das plantas, com especial ação na via do ácido xiquímico, causando acúmulo significativo do mesmo. A via do ácido xiquímico forma os aminoácidos aromáticos essenciais para a síntese de proteínas como triptofano, tirosina e fenilalanina, e compostos secundários como flavonóides, antocianinas, auxinas e alcalóides (Hance \& Holly, 1988). Entre as principais conseqüências iniciais desta inibição, observa-se o impedimento da síntese de proteínas e da formação de compostos secundários (Cole, 1985). Também afeta a produção de compostos associados com a defesa e a regularidade do crescimento das plantas (Hance \& Holly, 1988), com reflexo contundentes sobre o metabolismo. Estima-se que de 40 a $60 \%$ do carbono fixado pelas plantas ocorre através do fluxo da via xiquimato (Kishore et al., 1992).

A principal enzima inibida dessa via é a EPSP sintetase (5-enolpiruvato xiquimato-3 fosfato sintetase). Esta enzima catalisa a condensação reversível de xiquimato-3fosfato (S3P) e fosfoenolpiruvato (PEP) para produção de EPSP e fosfato inorgânico (Pi). A inibição é competitiva em relação ao fosfoenolpiruvato (PEP), e não competitiva ao xiquimato-3-fosfato, causando então a acumulação do ácido xiquímico nos tecidos tratados com glyphosate, primariamente nos vacúolos das células (Duke, 1985). A via xiquimato localiza-se, inicialmente, nos plastídeos (Kishore et al., 1992).

O glyphosate pode inibir a síntese da clorofila através da supressão geral de compostos que contêm porfirina (Cole, 1985). Ocorre a acumulação do precursor da clorofila, pois o ácido 5-aminolevulínico (ALA) é inibido. A subsequente conversão de ALA em clorofila não é afetada pelo herbicida (Duke, 1985). Pode ainda agir na formação de cloroplastos, embora o mecanismo envolvido seja pouco conhecido (Deuber, 1992). Há relatos de modificação da ultra-estrutura do cloroplasto e de aberrações cromossômicas (Richard et al., 1979).

Muitos pesquisadores não tem encontrado inibição do transporte de elétrons na fotossíntese, concordando que o glyphosate não tem efeito direto na reação fotoquímica da mesma (Richard et al., 1979; Guimarães, 1981). 
A seletividade do glyphosate aos animais é devido às reações envolvendo EPSP, que ocorrem somente em plantas e microrganismos (Cole, 1985).

\subsubsection{Absorção e translocação}

A penetração do glyphosate na cutícula é pela via hidrofílica. Em condições favoráveis, penetra rapidamente no apoplasto e posteriormente no simplasto. $\mathrm{O}$ movimento apoplástico ocorre entre células e nos tecidos do xilema. É necessário que haja transferência, através das membranas, para o glyphosate entrar no simplasto e mover-se pelo floema (Caseley \& Coupland, 1985). Do parênquima paliçádico atinge os vasos do floema, sendo distribuído às diferentes partes da planta, até atingir o meristema apical, os tubérculos e rizomas (Deuber, 1992).

Guimarães (1981), ao avaliar a absorção do glyphosate pela tiririca, encontrou taxas maiores nos tecidos mais jovens, necessitando de seis horas e doze horas nas plantas novas e nas mais velhas, respectivamente. Contrariamente, a translocação mostrou-se maior nas plantas ou tecidos mais velhos, necessitando de cinco dias para as plantas mais velhas e de quinze dias para as mais novas.

\subsubsection{Glyphosate e adjuvantes}

Adjuvantes segundo Camargo (1986), são materiais adicionados à formulação de defensivos agrícolas, que modificam as características físicas da mistura, facilitando a pulverização e proporcionando a intensificação da sua atividade. Os surfatantes e os óleos minerais e vegetais estão incluídos entre os adjuvantes. 
Os óleos minerais e vegetais, uréia, sulfato de amônio e os protetores de planta e herbicidas são também conhecidos como aditivos.

Os surfatantes podem aumentar a solubilidade do ingrediente ativo, sua retenção, distribuição, secamento e forma de deposição na planta, como também alterar a permeabilidade da cutícula, afetando a absorção da planta. Pouco se conhece sobre suas propriedades físico-químicas e influências sobre a interação entre a superfície foliar e os defensivos aplicados (Knoche \& Bukovak, 1993). Para Turner (1985), o principal efeito dos adjuvantes sobre os herbicidas é reduzir a tensão interfacial e auxiliar na ação de molhamento da calda de pulverização.

O uso de adjuvantes adicionados ao glyphosate em pulverizações, tem mostrado diversidade de comportamento a campo, em função da interação surfatante/ herbicida / planta ser altamente específica (Carvalho, 1989).

Entre muitos fatores, a temperatura e a umidade do ar influenciam decisivamente na absorção dos herbicidas. Conforme estudo de Wills (1978), a absorção e translocação do glyphosate foi afetada primariamente pela umidade relativa. Mantendo a temperatura constante e as mesmas doses do surfatante, ocorre um aumento de três a seis vezes na translocação, quando a umidade relativa varia de 40 para $100 \%$. Na temperatura de $25^{\circ} \mathrm{C}$, ao contrário da mais alta $55^{\circ} \mathrm{C}$, também encontraram maior injúria do herbicida no algodão com o surfatante.

A umidade do solo também pode influenciar na expressão dos efeitos do herbicida sobre a planta. Ahmadi et al., citados por Durigan (1993), não encontraram diferença para as umidades do solo, entre $1 / 8$ e 5 bar, na redução do peso da matéria seca do capim-arroz pulverizado com glyphosate. No entanto, observou-se menor eficiência do herbicida com baixa disponibilidade de umidade (37 bar). Também Carvalho (1985), citando Moosavi-Nia \& Dore, relata a redução da atividade do glyphosate em condições de extremo estresse de umidade do solo.

Outro aspecto a considerar, quanto à adição de óleos na calda de pulverização, refere-se a sua maior eficiência na diminuição da deriva dos produtos pulverizados (Wodageneh \& Matthews, 1981). 
De modo positivo, Nalewaja \& Matysiak (1992a), obtiveram aumento da fitotoxicidade do glyphosate com o acréscimo de surfatantes não iônicos: oxisórbico 20 (polioxietileno,20, monolaurato sorbitan), marca comercial Tween 20; e, orto X-77 (alquil aril polioxietileno, glicol, ácidos graxos livres e isopropanol), marca comercial X-77.

Nalewaja \& Matysiak (1992c), utilizando Tween 20 com glyphosate, verificaram melhor espalhamento e maior contato do mesmo junto às depressões da superfície foliar do trigo, kochia e girassol e, em conseqüência, aumento de sua fitotoxicidade. Também, Knoche \& Burovac (1993) relatam aumento marcantes na absorção do herbicida com o uso de surfatantes não iônicos alinol, nonoxinol e octoxinol.

No controle do capim-colonião (Panicum maximum), Durigan (1992) obteve redução de $0,72 \mathrm{~kg} / \mathrm{ha}$ do equivalente ácido do glyphosate, em relação a dose de $1,80 \mathrm{Kg} / \mathrm{ha}$, quando acrescentou 2,0 1/ha de óleo vegetal.

Por outro lado, no trabalho de Nalewaja \& Matysiak (1992b), ao comparar glyphosate sozinho ou com adjuvante oxysorbic 20 (Tween 20), não foi observado diferença na redução da massa verde de girassol, soja e kochia; mas, quando à calda de aplicação foram adicionados sais antagônicos ao herbicida, o adjuvante não mostrou superar o antagonismo dos sais.

Wyril \& Burnside, citados por Carvalho (1989), relatam que entre diversos surfatantes testados, as aminas etoxiladas foram mais eficientes na expressão da toxicidade do glyphosate.

Carvalho (1989), testou quatro adjuvantes em mistura com herbicidas aplicados em pós-emergência, no controle de quatro espécies de Ipomea, encontrando diferenças conforme os herbicidas e adjuvantes aplicados. Na aplicação de fomesafen e acifluorfen, a adição de Etaldine (não iônico) ou Energic (mistura de iônico e aniônico) mostrou superioridade comparado com Aterbane (mistura de não iônico e aniônico) ou Assist (mistura de óleo mineral e surfatante). Quando utilizado fluoroglicofen, a mistura com Etaldine foi inferior em relação. aos outros três adjuvantes. O herbicida chlorimuron-etil não apresentou diferença de eficiência, na comparação dele sozinho e com os quatro adjuvantes, embora haja a recomendação de acréscimo de óleo mineral emulsionável a $0,05 \% \mathrm{v} / \mathrm{v}$ (Rodrigues \& Almeida, 1995). 
Das informações levantadas sobre o milheto percebe-se a pequena quantidade de trabalhos em nosso país. Com a sua grande expansão ocorrida nos últimos anos no Cerrado, urge a necessidade de mais trabalhos que possibilitem o desenvolvimento de todo o seu grande potencial. Entre as muitas questões que devem ser melhor conhecidas pode-se citar: a ação inibitória diferenciada do milheto sobre as ervas infestantes através da competição e/ou alelopatia, a avaliação do comportamento de variedades e híbridos adaptados e desenvolvidos no Cerrado quanto a produção de fitomassa, ao perfilhamento e a germinação e estabelecimento em condições de estresse hídrico, assim como a identificação de pragas e doenças que ocorrem na cultura e qual a sua posição num sistema de rotação de culturas atuando como reciclador de nutrientes e supressor de doenças. 


\section{MATERIAL E MÉTODOS}

\subsection{Local do Experimento}

A pesquisa foi conduzida em condições de campo, em área de semeadura direta há três anos, sempre com a utilização do milheto como cobertura vegetal, na Fazenda Bonamigo, município de Bandeirantes - MS. Sua localização geográfica é definida pela latitude $19^{\circ} 55^{\prime} 04^{\prime \prime} \mathrm{S}$, longitude $54^{\circ} 21^{\prime} 50$ ' $\mathrm{W}$ (Greenwich) e altitude de $629 \mathrm{~m}$.

Seu clima é Aw, tropical úmido de verão chuvoso e inverno seco, conforme a classificação de Köppen, citado por Ayoade (1986).

O solo da região é do tipo Latossolo Vermelho Escuro, de textura média, com teor de argila entre 24 e $26 \%$ e de areia entre 68 a 70\%. O relevo é suave ondulado, com inclinação entre 2 e $6 \%$ (Mato Grosso do Sul, 1989).

O regime de umidade do solo é ústico, enquanto o regime de temperatura do solo é considerado isohipertérmico, ou seja, com temperatura média anual de $\geq 22{ }^{\circ} \mathrm{C}$ e com $<5^{\circ} \mathrm{C}$ de diferença entre os três meses mais quentes e os três mais frios. A precipitação média anual na propriedade é de $1750 \mathrm{~mm}$. As características químicas do solo estão na Tabela 1. 


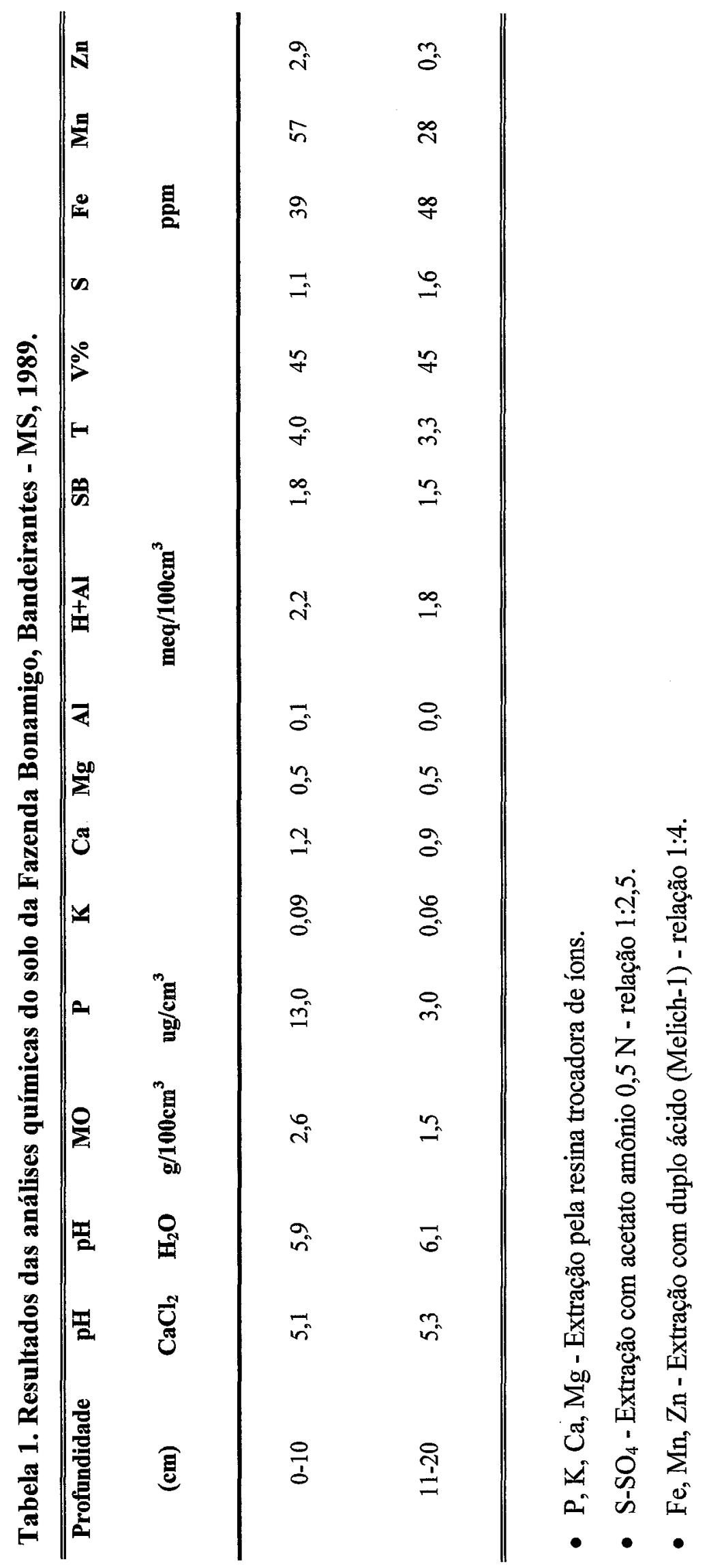




\subsection{Tratamentos}

Os tratamentos estudados resultaram da combinação de diversas doses de glyphosate com e sem adjuvantes conforme apresentado na Tabela 2.

Tabela 2. Herbicida com as respectivas doses do equivalente ácido (e.a.) e produto comercial (p.c.), junto com os adjuvantes, no controle do milheto (Bandeirantes - MS, 1989).

\begin{tabular}{|c|c|c|c|}
\hline TRATAMENTOS & HERBICIDA/ADJUVANTES & DOSE & DOSE \\
\hline N. ${ }^{-}$ & Nome comum/Nome comercial & e.a. (g/ha) & p.c. $($/hia $)+\%$ v/v \\
\hline $\mathbf{0 1}$ & Glvphosate & 90 & 0.25 \\
\hline 02 & Glyphosate + Herbitencil & 90 & $0,25+0,2$ \\
\hline 03 & Glyphosate + Naturlóleo & 90 & $0,25+2,0$ \\
\hline 04 & Glyphosate + Glicol & 90 & $0,25+1,0$ \\
\hline 05 & Glyphosate + Assist & 90 & $0,25+1,0$ \\
\hline 06 & Glyphosate & 180 & 0,50 \\
\hline 07 & Glyphosate + Herbitencil & 180 & $0,50+0,2$ \\
\hline 08 & Glyphosate + Naturlóleo & 180 & $0,50+2,0$ \\
\hline 09 & Glyphosate + Glicol & 180 & $0,50+1,0$ \\
\hline 10 & Glyphosate + Assist & 180 & $0,50+1,0$ \\
\hline 11 & Glyphosate & 270 & 0,75 \\
\hline 12 & Glyphosate + Herbitencil & 270 & $0,75+0,2$ \\
\hline 13 & Glyphosate + Natur'lóleo & 270 & $0,75+2,0$ \\
\hline 14 & Glyphosate + Glicol & 270 & $0,75+1,0$ \\
\hline 15 & Glyphosate + Assist & 270 & $0,75+1,0$ \\
\hline 16 & Glyphosate & 360 & 1,00 \\
\hline 17 & Glyphosate + Herbitencil & 360 & $1,00+0,2$ \\
\hline 18 & Glyphosate + Naturlóleo & 360 & $1,00+2,0$ \\
\hline 19 & Glyphosate + Glicol & 360 & $1,00+1,0$ \\
\hline 20 & Glyphosate + Assist & 360 & $1,00+1,0$ \\
\hline 21 & Glyphosate & 450 & 1,25 \\
\hline 22 & Glyphosate + Herbitencil & 450 & $1,25+0,2$ \\
\hline 23 & Glyphosate + Natur'lóleo & 450 & $1,25+2,0$ \\
\hline 24 & Glyphosate + Glicol & 450 & $1,25+1,0$ \\
\hline 25 & Glyphosate + Assist & 450 & $1,25+1,0$ \\
\hline 26 & Glyphosate & 540 & 1,50 \\
\hline 27 & Glyphosate + Herbitencil & 540 & $1,50+0,2$ \\
\hline 28 & Glyphosate + Natur'lóleo & 540 & $1,50+2,0$ \\
\hline 29 & Glyphosate + Glicol & 540 & $1,50+1,0$ \\
\hline 30 & Glyphosate + Assist & 540 & $1,50+1,0$ \\
\hline 31 & Glyphosate & 630 & 1,75 \\
\hline 32 & Glyphosate + Herbitencil & 630 & $1,75+0,2$ \\
\hline 33 & Glyphosate + Naturlóleo & 630 & $1,75+2,0$ \\
\hline 34 & Glyphosate + Glicol & 630 & $1,75+1,0$ \\
\hline 35 & Glyphosate + Assist & 630 & $1,75+1,0$ \\
\hline 36 & Glyphosate & 720 & 2,00 \\
\hline 37 & Glyphosate + Herbitencil & 720 & $2,00+0,2$ \\
\hline 38 & Glyphosate + Natur'lóleo & 720 & $2,00+2,0$ \\
\hline 39 & Glyphosate + Glicol & 720 & $2,00+1,0$ \\
\hline 40 & Glyphosate + Assist & 720 & $2,00+1,0$ \\
\hline
\end{tabular}




\subsection{Instalação e condução do experimento}

O milheto foi implantado no campo em semeadura direta com a Semeadora TD 300, no dia 26 de agosto de 1989, no espaçamento de $20 \mathrm{~cm}$ entre as linhas e densidade de 40 plantas/ m linear. A variedade utilizada foi BN-1 Africano, cujos tratos culturais foram idênticos àqueles dispensados a uma lavoura comercial.

No milheto com idade de 49 dias após a emergência, em 28 de outubro de 1989, foi passado rolo-faca da marca Norma, com hidráulico, contendo três seções: sendo dois cilindros ou rolos dianteiros laterais e um cilindro traseiro central, que possibilitaram um aumento do peso até $2900 \mathrm{Kg}$. A todos os cilindros foi adicionada água para permitir a regulagem de corte do milheto de modo a seccionar as plantas com o mínimo de revolvimento do solo. As facas tinham disposição em paralelo, com altura de 6 $\mathrm{cm}$ de corte. Sua largura de trabalho foi de $3,30 \mathrm{~m}$ e a velocidade utilizada de $10 \mathrm{Km} / \mathrm{h}$. O implemento pode ser visto na Figura 1.

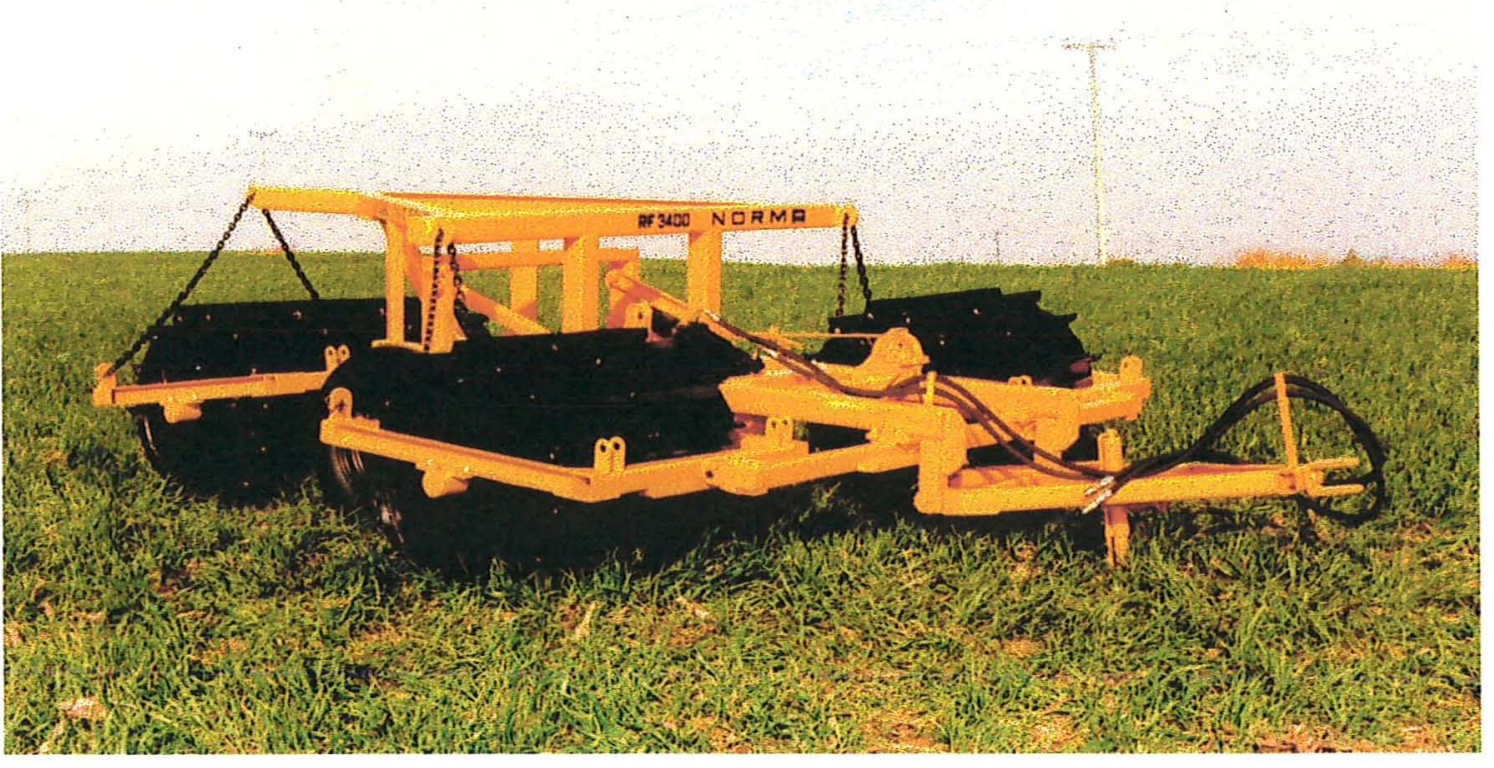

FIGURA 1 - Rolo-faca de levante hidráulico em Bandeirantes - MS, 1989. 
Após 16 dias da rebrota do milheto, em 13 de novembro de 1989, foram aplicados todos os tratamentos, visando ao seu controle.

A aplicação do herbicida com seus adjuvantes foi realizada com um pulverizador costal à pressão constante mantida pelo $\mathrm{CO}_{2}$ comprimido, de $28 \mathrm{lbf} / \mathrm{pol}^{2}$. A barra de pulverização era de 1,5 m de comprimento, equipada com quatro bicos 11004 Albuz série $\mathrm{APG}$, de jato plano, espaçados de $50 \mathrm{~cm}$ cada, com volume de aplicação equivalente a $280 \mathrm{l} / \mathrm{ha}$.

A precipitação pluvial e sua distribuição, no ano de 1989, pode ser vista na Tabela 10 constante do Apêndice.

\subsection{Produtos utilizados}

Objetivando a configuração dos tratamentos estudados, foram empregados os seguintes produtos:

a) Glyphosate

Formulação comercial: Roundup

Grupo químico: derivados de glicina

Formulação: suspensão aquosa concentrada (S.Aq.C)

Composição: 360 gramas de equivalente ácido, $\mathrm{N}$-(fosfonometil) glicina por litro, ou 480 gramas por litro de sal de isopropilamina de glyphosate, e surfatante não iônico, Mon 0818 ( amina graxa etoxilada).

Fórmula molecular: $\mathrm{C}_{3} \mathrm{H}_{8} \mathrm{NO}_{5} \mathrm{P}$

Peso molecular: 169,1

Solubilidade em água: $1 \%$ a $25^{\circ} \mathrm{C}$ ou $10.000 \mathrm{ppm}$

Volatilidade: insignificante 
Densidade: $0,5 \mathrm{mg} / \mathrm{cc}$

Ponto de fusão: $200^{\circ} \mathrm{C}$

Ponto de ebulição: sem determinação

Ponto de vapor: insignificante

b) Herbitencil

Composição: $400 \mathrm{~g} / 1$ de nonil fenol oxietilado e $150 \mathrm{~g} / 1$ de álcool isopropílico

Grupo químico: álcool e fenol

Classe: surfatante espalhante

Formulação: solução aquosa concentrada

c) Natur'lóleo

Composição: $930 \mathrm{ml}$ de óleo vegetal por litro e $70 \mathrm{ml}$ de emulsificante por litro

Classe: surfatante espalhante adesionante

Formulação: concentrado emulsionável

d) Glicol

Composição: óleo mineral, mistura com nonil fenol etoxilado

Classe: adjuvante

Formulação: concentrado emulsionável

e) Assist

Composição: $756 \mathrm{~g} / \mathrm{l}$ óleo mineral, mistura de hidrocarbonetos parafinicos, cicloparafínicos e aromáticos saturados e insaturados, provenientes da destilação do petróleo

Classe: adjuvante

Formulação: concentrado emulsionável 


\subsection{Avaliação do experimento}

Os efeitos dos diversos tratamentos foram avaliados em duas épocas, aos 15 e 30 dias após a aplicação dos produtos mencionados, usando a escala de avaliação visual do IAPAR, conforme citado por Pereira (1989), a qual está descrita na Tabela 3.

Tabela 3. Escala de notas para a avaliação visual do controle das plantas daninhas.

\begin{tabular}{lc}
\hline \hline Eficiência de controle & Controle (\%) \\
\hline Excelente & 100 \\
& 90 \\
Boa & 80 \\
Aceitável & 70 \\
Moderada & 60 \\
& 50 \\
Deficiente & 40 \\
& 30 \\
Fraca & 20 \\
Muito fraca & 10 \\
Inexpressiva a nula & 0 \\
\hline \hline
\end{tabular}

Fonte: IAPAR, citado por Pereira (1989). 


\subsection{Delineamento estatístico}

$\mathrm{O}$ delineamento experimental utilizado foi o de blocos casualizados, com parcelas subdivididas, em três repetições, perfazendo esquema fatorial $8 \times 5 \times 3$, com o fator época em parcelas subdivididas. As análises realizadas no fatorial foram:

a) 8 doses

b) 3 blocos

c) 5 combinações do herbicida e adjuvantes

O tamanho da parcela foi de $3 \times 5 \mathrm{~m}$ com área total de $15 \mathrm{~m}^{2}$, e a aplicação realizada em $2 \times 5 \mathrm{~m}$, com área útil de $10 \mathrm{~m}^{2}$. Em cada unidade experimental deixou-se uma faixa como testemunha para auxiliar na avaliação dos tratamentos.

De acordo com a Sociedade Brasileira da Ciência das Plantas Daninhas (1995), o uso de testemunhas laterais pode reduzir o coeficiente de variação possibilitando altos níveis de precisão na estimativa das porcentagens de controle. 


\section{RESULTADOS E DISCUSSÃO}

As dosagens testadas, as duas épocas avaliadas, assim como a interação entre esses dois fatores, apresentou significância a nível de $1 \%$, conforme o quadro de análise de variância. Os dados de porcentagem de controle do milheto foram transformados em arco seno da raiz de $\mathrm{x} / 100$ para a análise estatísticas dos dados.

Tabela 4. Análise de Variância para eficiência de controle do rebrote do milheto.

\begin{tabular}{|c|c|c|c|c|c|}
\hline $\begin{array}{l}\text { CAUSAS DA } \\
\text { VARIAÇÃO } \\
\end{array}$ & GL & $\begin{array}{c}\text { SOMA DE } \\
\text { QUADRADOS }\end{array}$ & $\begin{array}{c}\text { QUADRADOS } \\
\text { MÉDIOS }\end{array}$ & $\begin{array}{c}\text { VALOR DE } \\
\text { F } \\
\end{array}$ & PROB $>$ F \\
\hline $\begin{array}{c}\text { Blocos } \\
\text { Dosagens } \\
\text { Herbicida/Adjuvante } \\
\text { Dosagens X } \\
\text { Herbicida/Adjuvante } \\
\end{array}$ & $\begin{array}{r}2 \\
7 \\
4 \\
28\end{array}$ & $\begin{array}{r}\mathbf{2 6 . 2 9 6 9 1 5 6} \\
23799.1773621 \\
\mathbf{8 2 . 1 7 1 9 9 0 6} \\
\mathbf{3 2 5 . 2 3 9 3 2 7 1}\end{array}$ & \begin{tabular}{r|}
13.148578 \\
3399.8824803 \\
20.5429976 \\
11.6156903
\end{tabular} & $\begin{array}{r}0.8226 \\
212.7011 \\
1.2852 \\
0.7267\end{array}$ & $\begin{array}{l}0.5533 \mathrm{~ns} \\
0.0001 * * \\
0.2823 \mathrm{~ns} \\
0.8274 \mathrm{~ns}\end{array}$ \\
\hline Resíduo (A) & 78 & 1246.7771539 & 15.9843225 & & \\
\hline $\begin{array}{c}\text { Parcelas } \\
\text { Época } \\
\text { Dosagens X Época } \\
\text { Herbicida/Adjuvante X } \\
\text { Época } \\
\end{array}$ & $\begin{array}{c}119 \\
1 \\
7 \\
4 \\
\end{array}$ & \begin{tabular}{|r|}
25479.6627493 \\
496.2942522 \\
407.5372606 \\
\\
23.6626615 \\
\end{tabular} & \begin{tabular}{r|}
496.2942522 \\
58.2196087 \\
\\
5.9156654 \\
\end{tabular} & $\begin{array}{r}88.9416 \\
10.4336 \\
1.0602 \\
\end{array}$ & $\begin{array}{l}0.0001 * * \\
0.0001 * * \\
0.3823 \mathrm{~ns} \\
\end{array}$ \\
\hline $\begin{array}{c}\text { Dosagens X } \\
\text { Ferbicida/Adjuvante } X \\
\text { Época } \\
\end{array}$ & 28 & 167.9223283 & 5.9972260 & 1.0748 & $0.3888 \mathrm{~ns}$ \\
\hline Resíduo (B) & 80 & 446.4001012 & 5.5800013 & & \\
\hline Total & 239 & 27021.4793531 & & & \\
\hline
\end{tabular}

Média Geral = 64.511314 $($ dados transformados)

Média Geral $=79.457 \quad$ ( dados originais)

* * F significativo a $1 \%$ de probabilidade

ns F não significativo

Coeficiente de variação (para os dados não transformados) para Parcelas - Dosagens e Herbicida

CV $(A)=4,95 \%)$

Coeficiente de variação (para os dados não transformados) para Sub-Parcelas - Épocas

CV (B) $=3,93 \%$ )

Os resultados apresentados, quanto ao glyphosate, são discutidos no texto, em relação as dosagens do produto comercial (p.c.). 


\subsection{Ação do glyphosate sozinho ou com adjuvantes sobre o milheto.}

As combinações do glyphosate com os adjuvantes, não apresentaram variação significativa no quadro de variância, mas quando feita a comparação das misturas herbicida/surfatante, com o uso da comparação entre as médias através do teste de Tukey, percebe-se na Tabela 5, que glyphosate com a adição de Assist ou Glicol e o glyphosate sozinho mostraram-se superiores a nível de $5 \%$ em relação ao glyphosate com Natur'lóleo ou Herbitencil, analisados como média de todas as dosagens. A eficiência do controle abrange as duas épocas de 15 e 30 dias juntas.

Tabela 5. Eficiência do controle do milheto em função do Herbicida Glyphosate em várias dosagens e diversas misturas em Bandeirantes - MS, 1989.

\begin{tabular}{lc}
\hline \hline Herbicida & Eficiência de controle (\%) \\
\hline Glyphosate + Assist & $81.04 \mathrm{a}$ \\
Glyphosate & $79.27 \mathrm{a}$ \\
Glyphosate + Glicol & $79.17 \mathrm{a} \mathrm{b}$ \\
Glyphosate + Herbitencil & $78.96 \mathrm{~b}$ \\
Glyphosate + Natur'lóleo & $78.96 \mathrm{~b}$ \\
\hline \hline
\end{tabular}

Médias seguidas pela mesma letra não diferem entre si pelo teste de Tukey ao nível de $5 \%$ de significância.

Esses dados mostram que o glyphosate sozinho ou em mistura com os adjuvantes à base de óleo mineral não apresentaram diferença significativa entre si, no controle do rebrote do milheto, diferentemente da adição tanto do Herbitencil como do Natur'lóleo ao herbicida, que demonstraram menor eficiência. Contrariamente, Carvalho (1985), trabalhando com diversos adjuvantes, obteve efeito sinergístico desses quando adicionados ao glyphosate, devido a maior absorção e translocação do produto, por facilitar a sua penetração cuticular. O Natur'lóleo a 1,0\% v/v (1,0 1/ha) proporcionou os melhores resultados no controle da grama-seda (Cynodon dactylon). 
A complexa interação entre ambiente/planta/herbicida/adjuvante pode propiciar resultados diferentes do esperado quando do uso de adjuvantes. $\mathrm{O}$ uso de óleos emulsionáveis, normalmente, não possibilitam redução nas dosagens dos herbicidas, apesar de propiciar melhor eficácia, especialmente em condições adversas (Carvalho, 1989).

Segundo Turner (1985), a pulverização de glyphosate com óleo pode aumentar a absorção do herbicida, mas no todo, tem efeito adverso sobre a sua atividade, talvez porque as moléculas do herbicida são imobilizadas dentro das micelas formadas pelo ingrediente ativo e surfatante.

A aplicação de herbicidas pós-emergentes é influenciada por fatores ambientais como temperatura e umidade relativa do ar, radiação solar e chuva. Carvalho (1989) relata maior quantidade de glyphosate absorvido por Cynodon dactylon, em condições de alta umidade relativa do ar, com maior eficiência no seu controle.

No entanto, Gazziero \& Fleck (1980) enfatizam que, de acordo com a maior eficiência do herbicida sobre a espécie alvo, ou seja, sua especificidade, os fatores ambientais têm diminuída sua influência.

As condições climáticas, após a instalação do experimento, não foram favoráveis ao desenvolvimento do milheto, como pode ser visto na tabela 10 , constante no Apêndice. Não houve ocorrência de chuva desde a aplicação do produtos até a primeira avaliação de controle das plantas, no dia 29 de novembro.

$\mathrm{O}$ efeito total do herbicida aplicado na folhagem de plantas manifesta-se desde que o alvo seja atingido, seja retido pela folha, haja a absorção e translocação na planta até o seu local de ação, na concentração suficiente e na forma tóxica apropriada para controlar a planta alvo (Victória Filho, 1985). No entanto, as plantas mostram diferentes suscetibilidades ao glyphosate (Nalewaja et al., 1992 b), podendo esse fato ser determinante na expressão da eficiência do herbicida, como no caso do presente trabalho com o milheto.

Diferentes volumes de calda podem apresentar variações quanto à eficiência de adjuvantes no glyphosate. Marochi (1996), utilizando herbicidas sistêmicos 
no manejo de aveia branca, em condições de prolongada seca (75 dias sem chuva), relata que volumes de aplicações elevados influenciaram negativamente os resultados, quando as pulverizações foram realizadas às 6:00 $\mathrm{h}$, na presença de orvalho. Por outro lado, o volume de 67 1/ha de calda foi eficiente, independentemente do horário de aplicação.

Turner \& Loader (1980) observaram que com baixo volume de aplicação, 15 ou 75 1/ha, ocorreu maior concentração do ingrediente ativo nas gotas, aumentando a fitotoxicidade do glyphosate sobre a planta alvo, e os adjuvantes testados não foram eficientes nesta quantidade de calda. Com volumes mais comumente usados, 150 ou 200 1/ha, os mesmos mostraram-se eficientes, aumentando a ação do herbicida, especialmente os catiônicos com balanço hidrofilico-lipofilico (BHL) de grau 17 (de maior predominância hidrofilica), embora na mistura de glyphosate com sulfato de amônio, os surfatantes de características lipofilicas apresentaram maior resposta.

Conforme relato de Carvalho (1985), em testes com altos volumes de aplicação, a máxima retenção encontrada pela Avenua fatua foi de 150 1/ha, provavelmente, devido a melhor retenção na folhagem e maior concentração do herbicida nas gotas. Quando utilizou 100 1/ha sobre outra espécie, Cynodon dactylon, alguns surfatantes aumentaram a fitotoxicidade do glyphosate, mas não se observou efeito marcante da ionogeneidade desses adjuvantes.

De acordo com Turner (1985), a adição de surfatante extra, freqüentemente melhora os efeitos do glyphosate, particularmente quando dosagens baixas do herbicida são usadas, pois a concentração do surfatante formulado de fábrica, pode tornar-se muito baixa para exercer efeito. Contrariamente, dosagens muito altas do herbicida, em baixos volumes de aplicação, pode propiciar muito alta concentração do surfatante. Assim, sua maior ação sobre o glyphosate ocorre em pulverizações de baixas dosagens do herbicida, em médio ou alto volumes de aplicação.

Para Durigan (1993), o acréscimo de um aditivo, colocado sem conhecimento técnico, ao herbicida pode prejudicar a sua ação ou não causar mudanças significativas, o que tornaria o seu uso inoportuno e desnecessário. Assim, constata-se 
uma falta de consistência nos dados obtidos, em razão da não repetitividade da performance.

Como regra geral, pressupõe-se que os fabricantes de herbicidas adicionem, quando necessário, adjuvantes que auxiliem na ação dos defensivos sobre o controle das invasoras. O glyphosate contém em sua formulação comercial o surfatante não iônico amina graxa etoxilada. Neste trabalho, o referido herbicida em volume de aplicação de 280 1/ha, não mostrou necessidade de acréscimo de outros adjuvantes para expressar sua eficiência. Desse modo, a formulação comercial do glyphosate, contém uma relação ingrediente ativo/surfatante adequada à aplicações de maior volume.

\section{2. Época de controle do milheto}

A comparação da média de todas as dosagens do herbicida e adjuvantes, em duas épocas de avaliação, mostrou diferença significativa a nível de $5 \%$, conforme a Tabela 6, demonstrando que o efeito do herbicida manifestou-se plenamente no final do período de 30 dias.

Tabela 6. Eficiência de controle do milheto na média de 8 dosagens em 2 épocas em Bandeirantes - MS, 1989.

\begin{tabular}{cc}
\hline Épocas & Eficiência de controle (\%) \\
\hline 30 dias & $83,39 \mathrm{a}$ \\
15 dias & $79,49 \mathrm{~b}$ \\
\hline \hline
\end{tabular}

Médias seguidas pela mesma letra não diferem entre si a nível de $5 \%$ de significância pelo teste de Tukey. 
Esse fato indica um maior cuidado na determinação da necessidade de uso de pós-emergentes, para o controle do milheto, em condições de lavoura. Tem-se observado dificuldade muito grande de manejo do milheto pelos agricultores e técnicos, quando usado como cobertura, devido a possível avaliação precoce, após o manejo com glyphosate.

Conforme Blanco (1985), o grau de competição entre as culturas econômicas e as plantas infestantes, pelos fatores de crescimento como água, nutrientes, luz, espaço e $\mathrm{CO}_{2}$, é determinado por uma interação do complexo entre ambiente, práticas de manejo culturais, densidade populacional, distribuição no terreno, espécies infestantes e cultivadas, assim como o período de competição entre elas.

De acordo com Pitelli (1985), entre os diversos períodos utilizados na avaliação da interferência, o período total de prevenção da interferência (PTPI), definido como o período em que a interferência das infestantes reduzem significativamente a produtividade econômica das culturas, tem uma abrangência mais geral. Os períodos determinados para soja, milho, feijão e algodão variam de 30 a 50 dias, 40 a 45 dias, 20 a 49 dias, 35 a 56 dias, respectivamente.

Essa avaliação pode ser desdobrada, também, em dois outros períodos: PAI e PCPI. Enquanto o período anterior à interferência (PAI) ou de pré-interferência envolve desde a semeadura até a data que a interferência da invasora passa a reduzir significativamente a produtividade da cultura, o período crítico de prevenção da interferência (PCPI) compreende o intervalo onde devem ser adotados as medidas de controle das infestantes, imediatamente antes que os recursos sejam disputados até que não haja mais concorrência com a cultura, ou seja, o restante do período. Em seqüência, os valores encontrados para o PAI foram de: 20 a 30 dias, 15 a 20 dias, 21 a 35 dias, 20 a 40 dias, para soja, milho, feijão e algodão, respectivamente.

Como observado, esses períodos contêm relativa amplitude de variação devido, especificamente, a sua dependência da interação entre fatores ambientais locais da comunidade das infestantes e da espécie cultivada. 
Os dados da Tabela 6 mostram efeitos do produto num período maior, de 30 dias, o que coloca as culturas já citadas, quando implantadas em cima da palhada do milheto, livres da competição no seu período mais sensível da mesma.

Segundo a Sociedade Brasileira da Ciência das Plantas Daninhas (1995), a avaliação do nível de eficácia do controle deve ser realizada, no mínimo até o final do período de prevenção de interferência para a cultura (PTPI). Como o herbicida mostrou todo seu efeito sobre o milheto até a segunda avaliação, aos 30 dias, e como após esse período iniciou a emergência de novas invasoras, uma terceira época de avaliação tornouse desnecessária.

Além disso, a convivência entre as plantas pode ser totalmente modificada com a existência de cobertura vegetal morta ou material orgânico na superfície do solo (Deuber, 1992).

A palha na superficie determina alterações em muitos fatores do solo. Entre os aspectos vantajosos cita-se a diminuição nas pressões de trabalho através da maquinaria utilizada. A energia da chuva que chega até o solo é menor pela ação da palha como anteparo, assim como menor a velocidade e o volume de escorrimento da chuva, em razão do aumento da rugosidade da superficie. $\mathrm{O}$ maior armazenamento de água é a conseqüência desses fatos. Seu aumento no solo proporciona a maior disponibilidade dos nutrientes, facilitando a absorção destes. Como a palha tem baixa condutividade térmica, sua atuação como bom isolante propicia menor amplitude da variação da temperatura do solo e, com isso, uma diminuição das perdas de água tanto na evaporação como na transpiração das plantas. Esses fatores podem acarretar um aumento de 20 a $30 \%$ da água absorvida, assim como uma maior taxa de fixação de nitrogênio pelas plantas. $\mathrm{O}$ menor contato do material vegetal depositado na superfície sem a sua incorporação, que é normalmente praticada nos métodos de cultivo convencionais, propicia uma reciclagem mais lenta e mais eficiente da biomassa e, conseqüentemente, do nitrogênio no sistema.

Como desvantagens pode-se citar um aumento da densidade do solo, uma macroporosidade menor e microporosidade maior. Quando a palha está na superficie, o fluxo ascendente da umidade do solo diminui devido a menor evaporação, prejudicando a 
recuperação do nitrogênio que poderia ocorrer. O aumento de água no solo pode determinar uma lixiviação do nitrato mais rápida, assim como o aumento da denitrificação.

A ação dos aleloquímicos liberados quando da degradação da fitomassa pode influenciar tanto positiva como negativamente as culturas exploradas em seqüência (Almeida, 1985).

Assim, a utilização do milheto como cobertura, bem controlado no seu rebrote, pode auxiliar na inibição da emergência de outras invasoras através, principalmente, da sua atuação competitiva, conforme mostrado por Pereira (1990), quando o milheto mostrou ser a cultura de inverno que mais inibiu, entre 15 outras testadas, o desenvolvimento das infestantes.

\subsection{Diferenças de controle do milheto aos 15 e 30 dias, em diversas dosagens.}

A análise da Tabela 7 confirma a maior eficiência das diversas dosagens aos 30 dias, de 0,25 1/ha até 1,5 1/ha. A partir de 1,751/ha não se observou diferença significativa nas duas épocas de avaliação. Isso coincide com o nível adequado de controle do milheto, estipulado como $90 \%$, ou seja, até a dosagem de $1,5 \mathrm{l} /$ ha a avaliação da aplicação deve ser feita aos 30 dias e não antes, de modo a possibilitar conhecer o nível real de controle do milheto.

Tabela 7. Porcentagem da eficiência de controle do milheto em função de 2 épocas e 8 dosagens de herbicida em Bandeirantes - MS, 1989.

\begin{tabular}{l|llllllll}
\hline \hline Épocas & \multicolumn{7}{|c}{ Dosagens (1/ha) } \\
\hline & 0.25 & 0.50 & 0.75 & 1.00 & 1.25 & 1.50 & 1.75 & 2.00 \\
\hline 15 dias & $42.67 \mathrm{~b}$ & $64.75 \mathrm{~b}$ & $72.10 \mathrm{~b}$ & $80.20 \mathrm{~b}$ & $84.83 \mathrm{~b}$ & $88.96 \mathrm{~b}$ & $93.19 \mathrm{a}$ & $94.13 \mathrm{a}$ \\
30 dias & $58.16 \mathrm{a}$ & $72.03 \mathrm{a}$ & $75.37 \mathrm{a}$ & $\mathbf{8 2 . 5 3 \mathrm { a }}$ & $\mathbf{8 8 . 1 0 \mathrm { a }}$ & $90.83 \mathrm{a}$ & $92.86 \mathrm{a}$ & $95.37 \mathrm{a}$ \\
\hline \hline
\end{tabular}

Médias seguidas pela mesma letra na coluna não diferem entre si ao nível de $5 \%$ de significância pelo Teste de Tukey. 
Os dados da Tabela 7 observados a partir de dosagens mais próximas de um nível satisfatório de controle, de 1,0 1 até 2,0 1/ha, mostram a tendência de controle adequado do rebrote do milheto na dosagem de 1,5 1/ha de glyphosate sozinho ou, em mistura com os adjuvantes, conforme visto nas figuras 2 a 6, construídas com as médias originais. As Figuras 7 a 12 mostram o experimento no campo, por ocasião da $2^{\mathrm{a}}$. avaliação do controle sobre o milheto

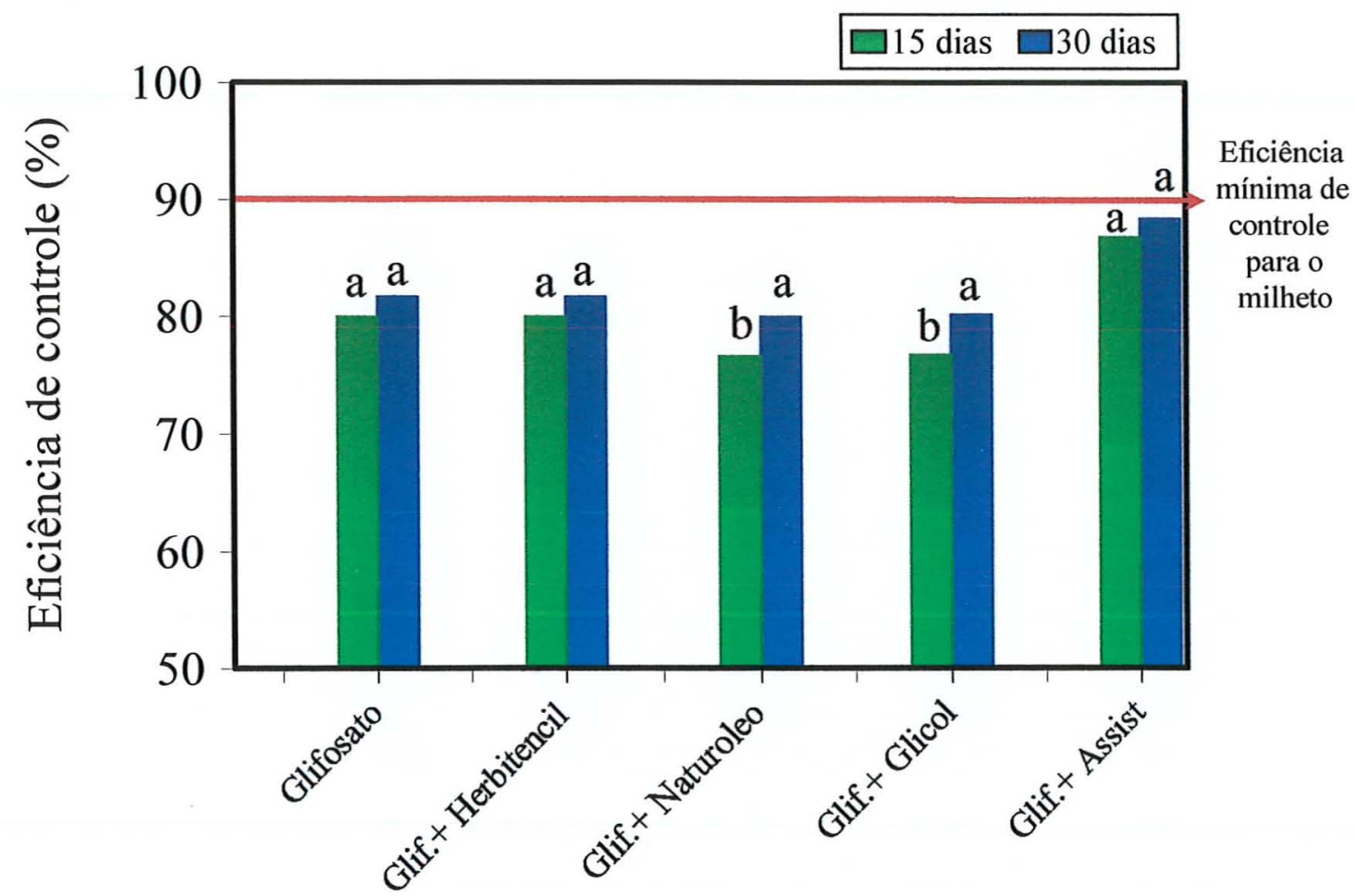

Figura 2 - Eficiência de controle do glyphosate com vários adjuvantes na dosagem de 1,00 l/ha (p.c.) em Bandeirantes - MS, 1989. 


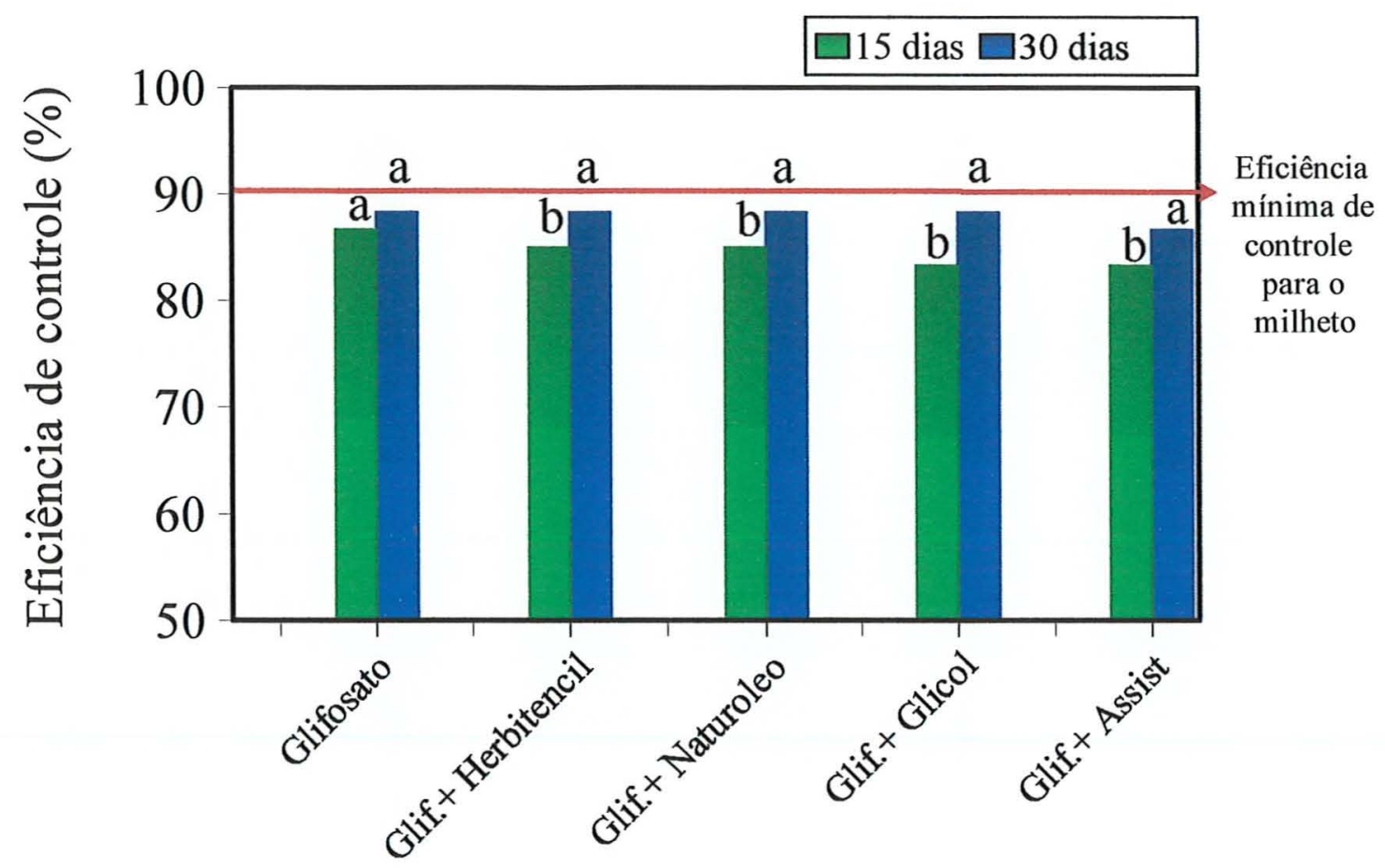

Figura 3 - Eficiência de controle do glyphosate com vários adjuvantes na dosagem de 1,25 l/ha (p.c.) em Bandeirantes - MS,1989.

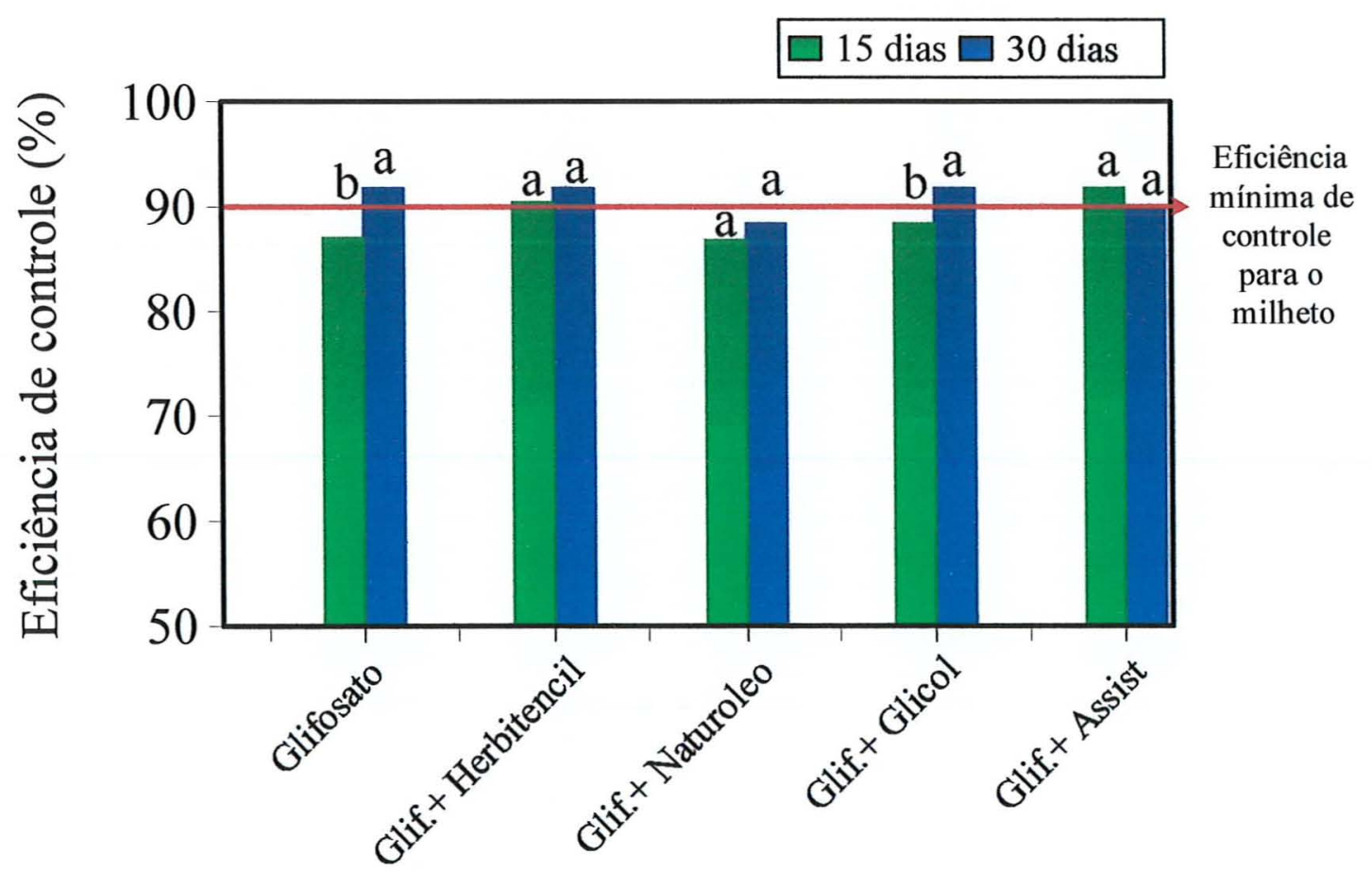

Figura 4 - Eficiência de controle do glyphosate com vários adjuvantes na dosagem de 1,50 l/ha (p.c.) em Bandeirantes - MS, 1989. 
$\square 15$ dias $\square 30$ dias

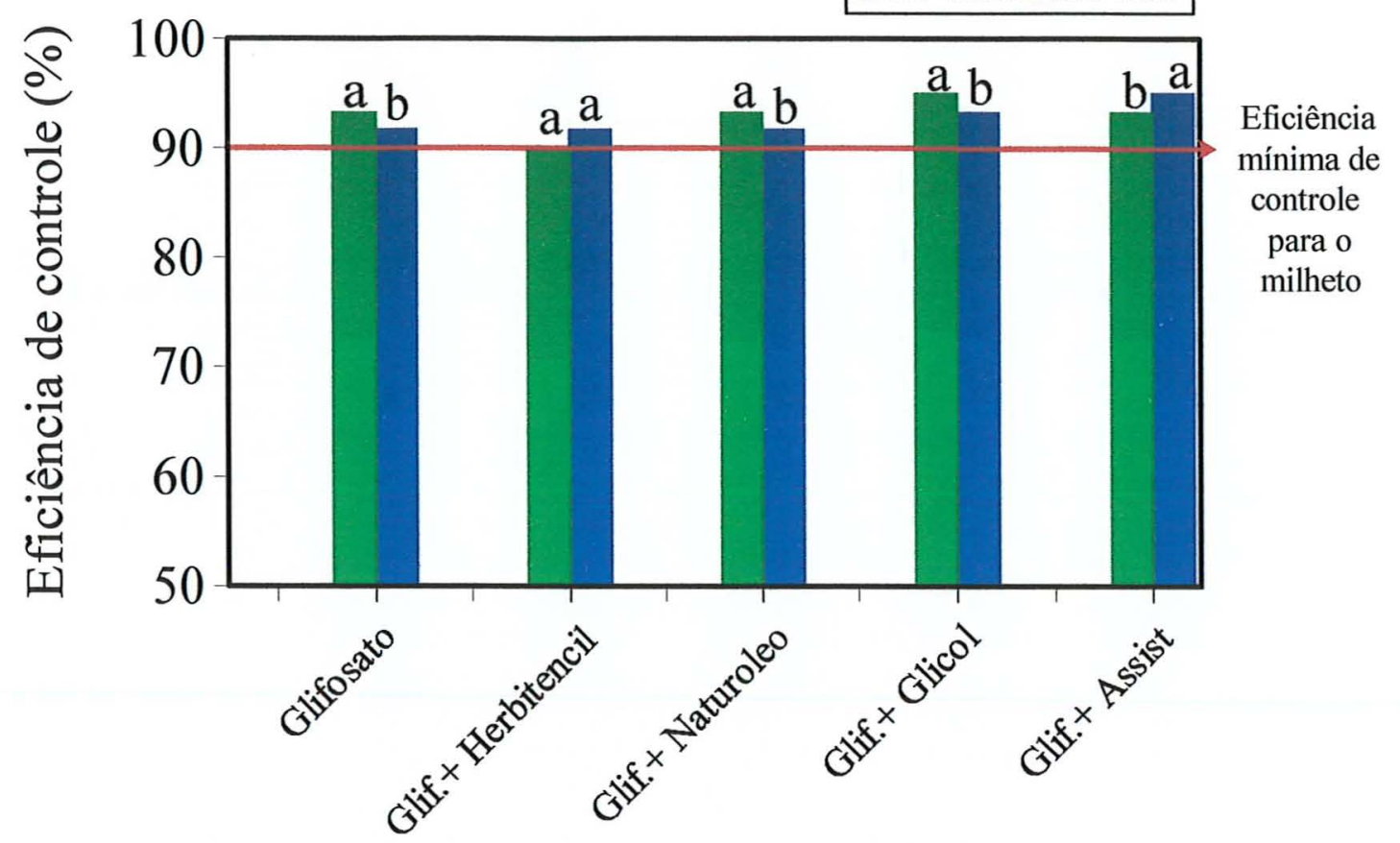

Figura 5 - Eficiência de controle do glyphosate com vários adjuvantes na dosagem de 1,75 l/ha (p.c.) em Bandeirantes - MS, 1989.

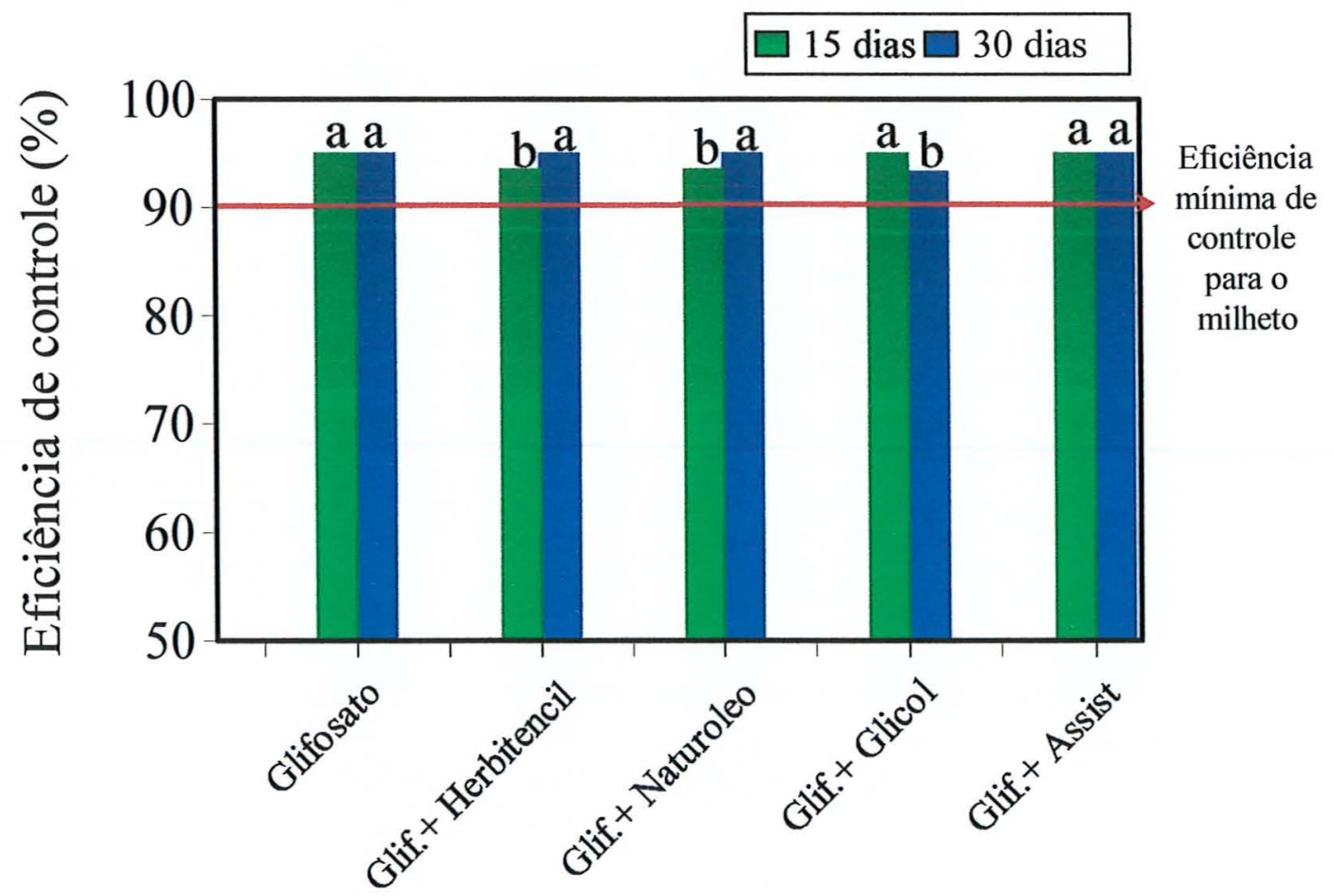

Figura 6 - Eficiência de controle do glyphosate com vários adjuvantes na dosagem de 2,00 l/ha (p.c.) em Bandeirantes - MS, 1989. 
4.4. Correlação de dosagens do herbicida em duas épocas sobre o controle do milheto.

A análise de variância do fator dosagens, em seus oito níveis, na interação com o fator época, em duas ocasiões, foi significativa pelo teste $\mathrm{F}$, conforme constatado na Tabela 4. Em seguida realizou-se a análise de regressão desses dois fatores, mantendo fixo o fator herbicida/surfatante. Os cálculos individualizados para cada tratamento herbicida, glyphosate sozinho ou com adjuvantes, foram realizados conforme apresentados nas Tabelas 8 e 9. Maior detalhamento relativo ao procedimento estatístico pode ser encontrado nas tabelas de número 11 a 50, constantes no Apêndice. 


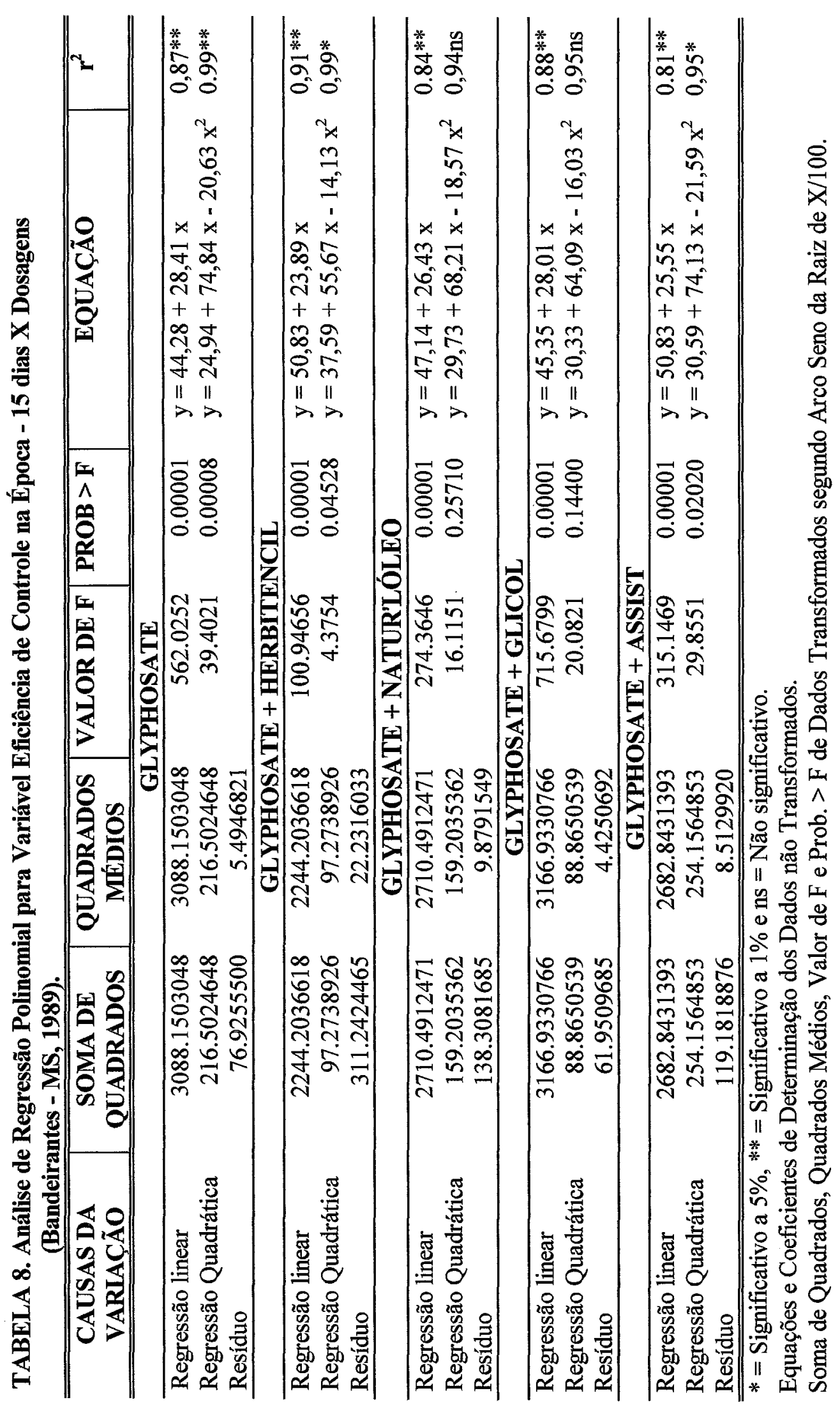




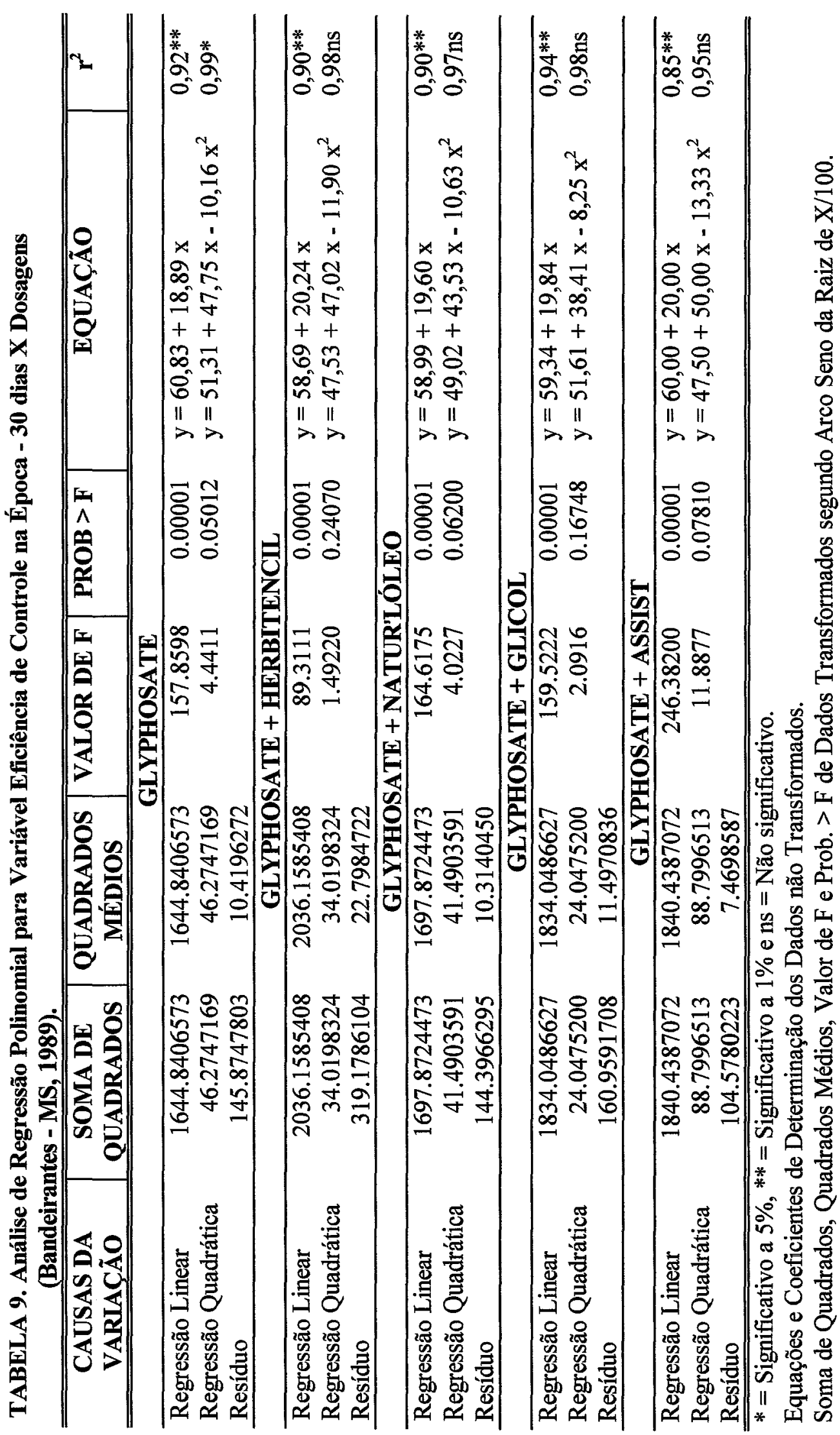


A observação das tabelas 8 e 9 mostra significância nas equações lineares, nas duas épocas e em todos os tratamentos do glyphosate com adjuvantes. Essa resposta linear à aplicação de crescentes doses corresponde a expectativa, pois, a dose máxima de 2,00 1/ha utilizada está dentro de um nível considerado médio para o referido herbicida. Com o uso de altas doses, naturalmente, ocorre uma resposta quadrática, mas em termos práticos, como foi o objetivo deste trabalho, tornam-se desnecessárias.

Para estimar o efeito das oito doses do herbicida, nas duas épocas de avaliação, 15 e 30 dias, foram calculadas as equações de regressão para cada fator herbicida, glyphosate sozinho e também com cada um dos adjuvantes, conforme visualizado nas figuras $13,14,15,16,17,18,19,20,21$ e 22 .

A dose necessária para obter o nível adequado de controle do rebrote do milheto, estipulado como $90 \%$, mostra diferenças entre as misturas testadas. Percebe-se que o glyphosate, isoladamente, necessitou de 1,42 a 1,44 1/ha (p.c.). $O$ acréscimo de Assist mostrou melhor desempenho, precisando de 1,27 1/ha a 1,50 1/ha, enquanto a mistura com Natur'lóleo teve o pior desempenho, necessitando de 1,58 a 1,62 1/ha do herbicida. 


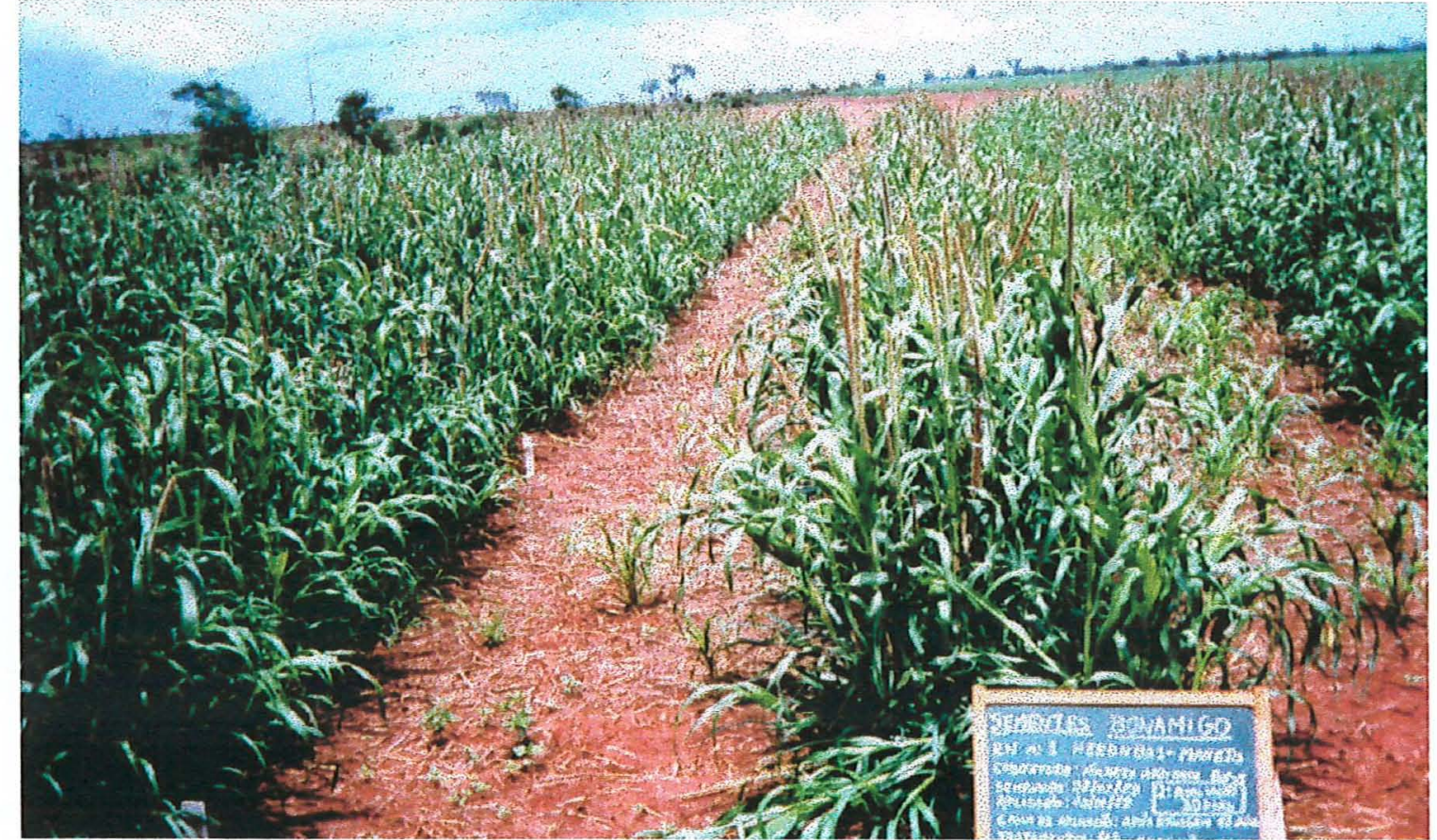

Figura 7 - Vista geral do experimento por ocasião da $2^{\mathrm{a}}$. avaliação em Bandeirantes MS, 1989.

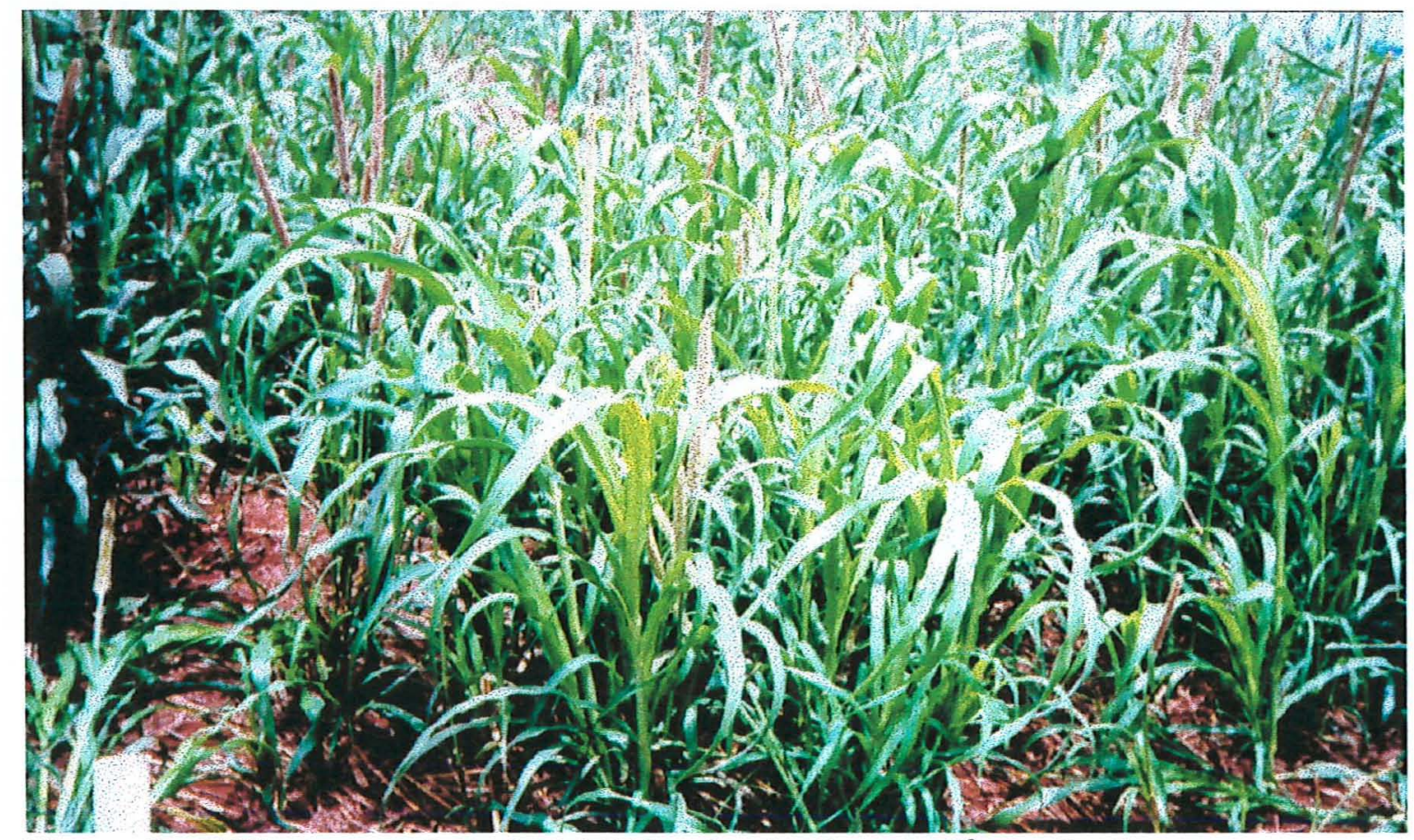

Figura 8 - Milheto com dose de $0,251 /$ ha de glyphosate, $2^{\mathrm{a}}$. avaliação em Bandeirantes - MS, 1989. 


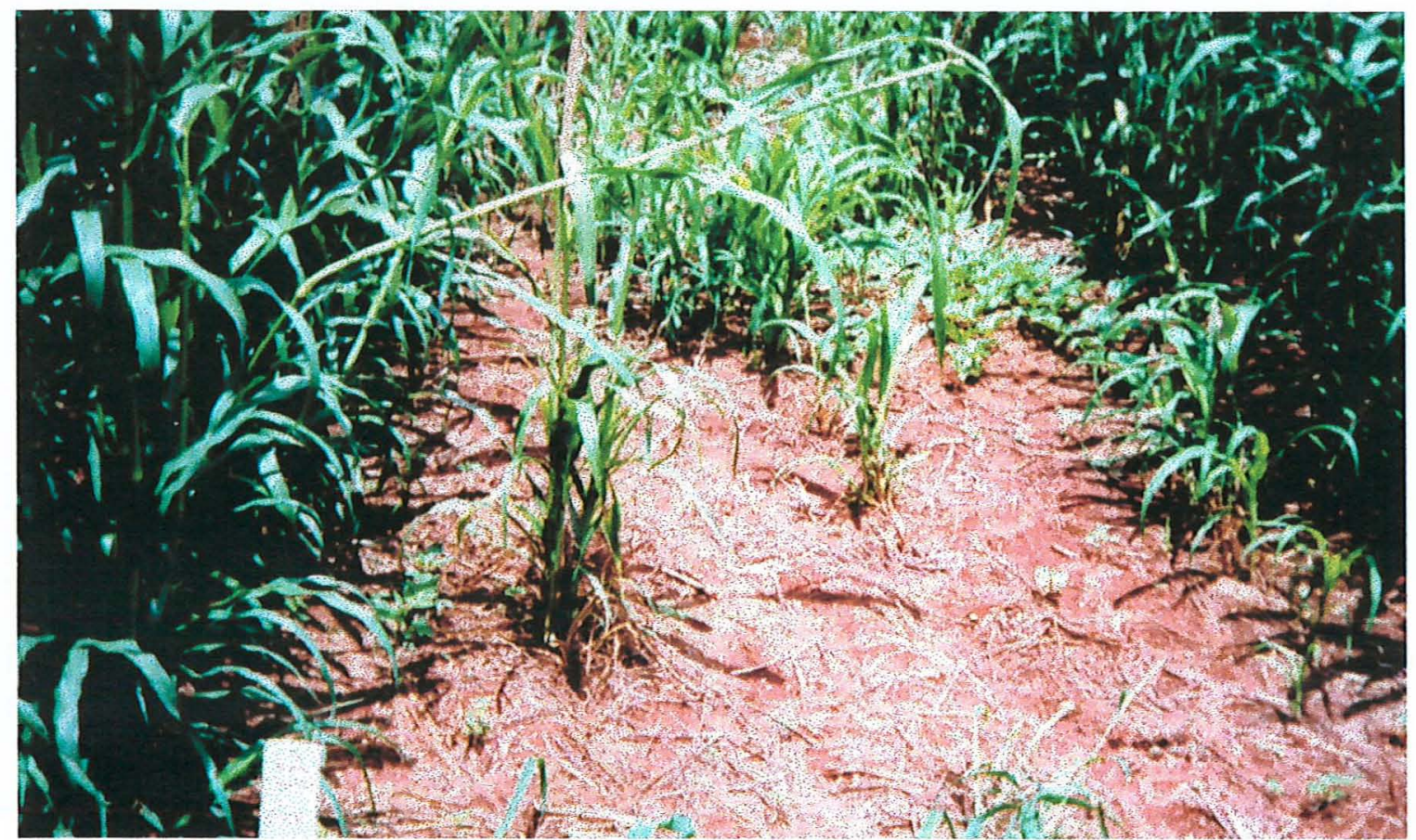

Figura 9 - Milheto com dose de 0.75 l/ha de glyphosate, $2^{\mathrm{a}}$. avaliação em

Bandeirantes - MS,1989.

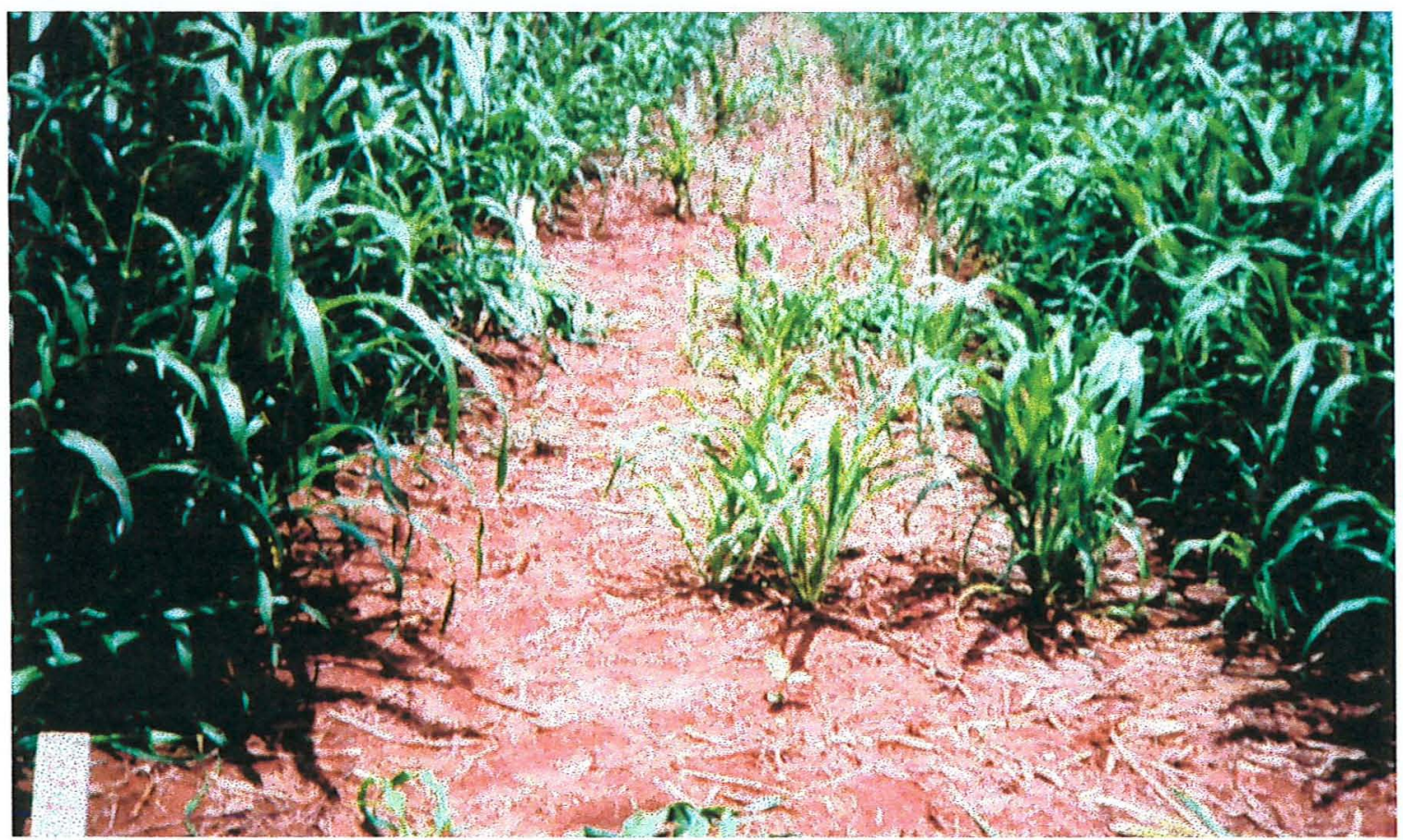

Figura 10 - Milheto com dose de 1,25 1/ha de glyphosate, $2^{\mathrm{a}}$. avaliação em Bandeirantes - MS,1989. 


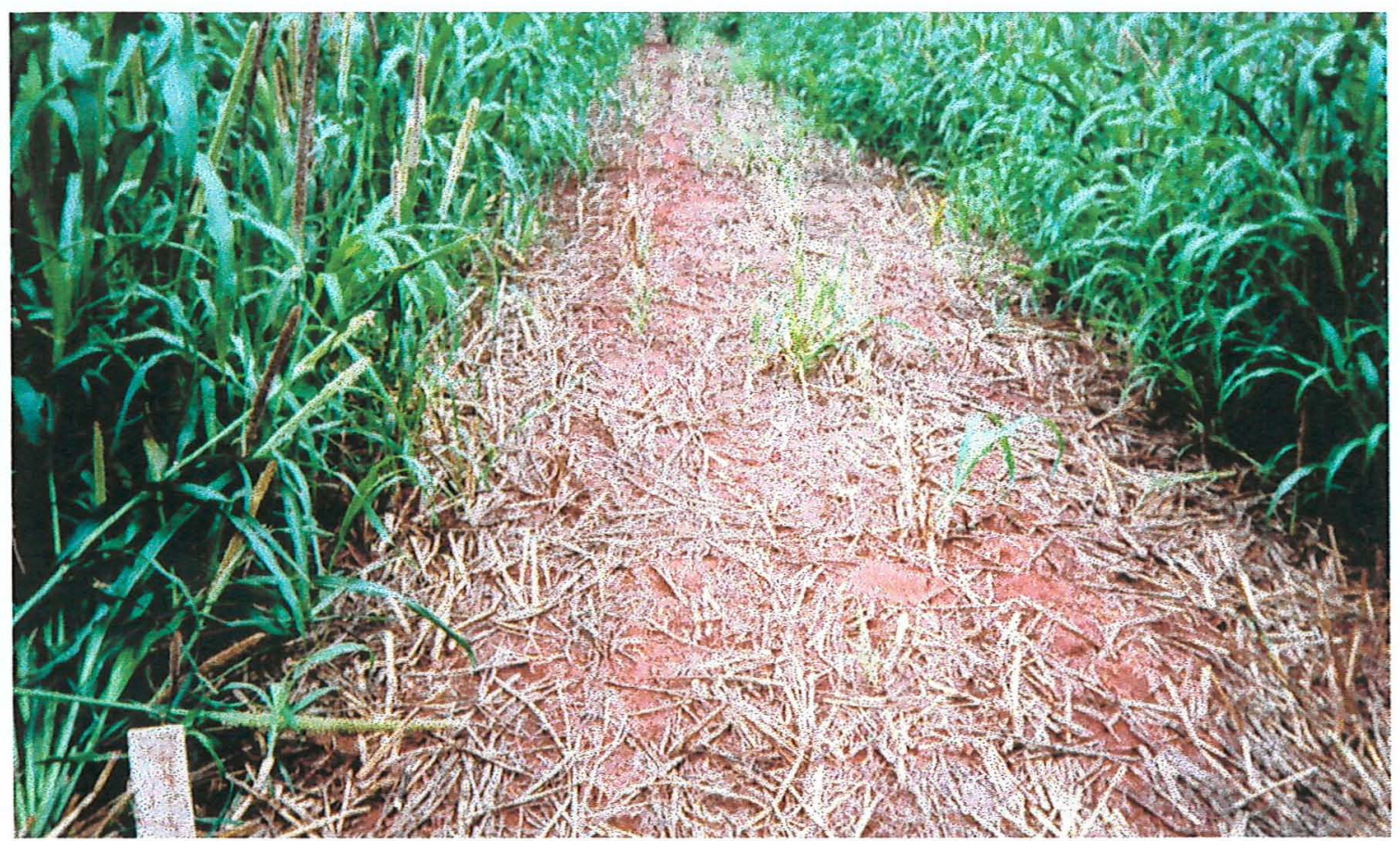

Figura 11 - Milheto com dose de 1,50 l/ha de glyphosate, $2^{\mathrm{a}}$. avaliação em

Bandeirantes - MS,1989.

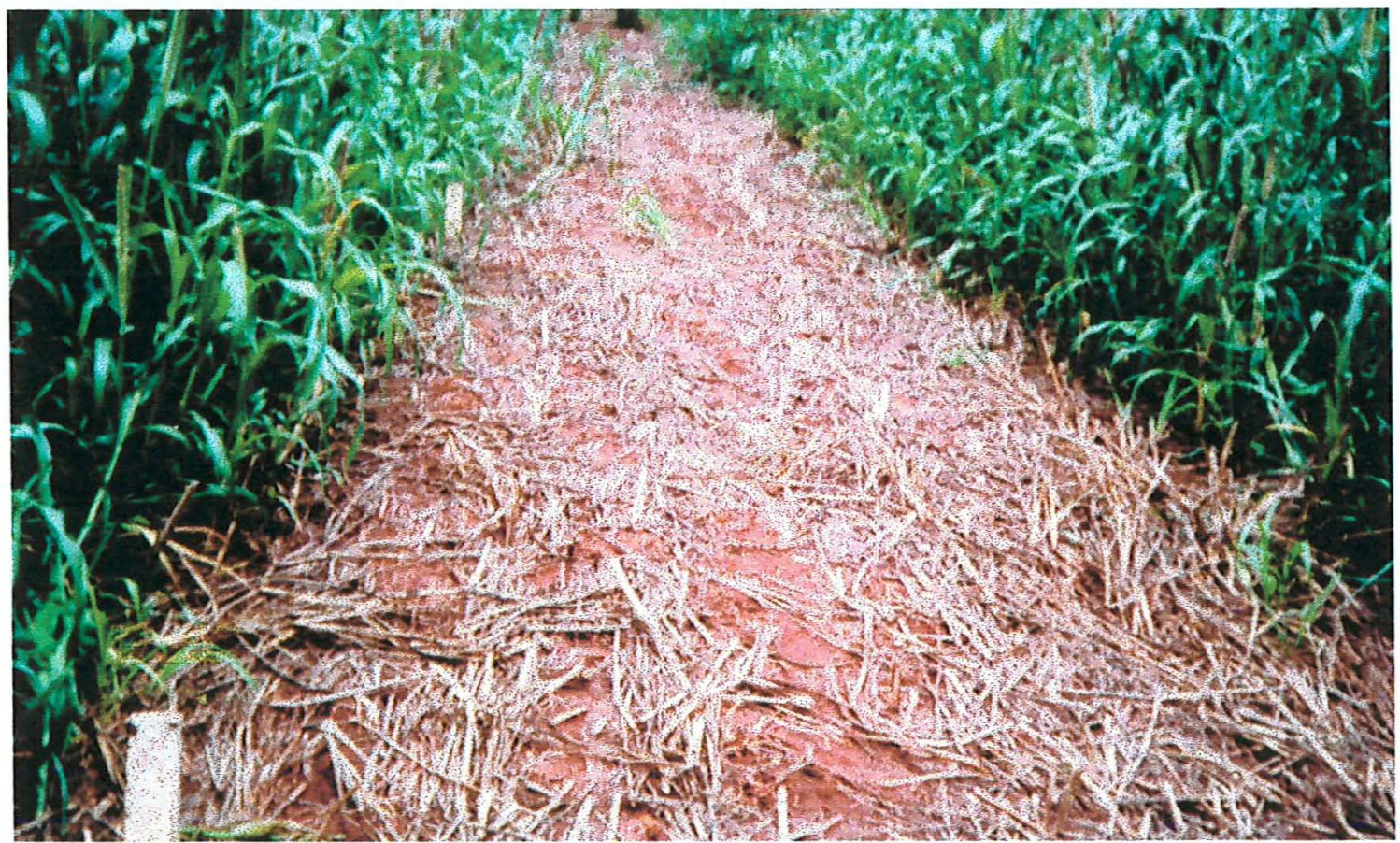

Figura 12 - Milheto com dose de 2,00 l/ha de glyphosate, $2^{\mathrm{a}}$. avaliação em

Bandeirantes - MS,1989. 

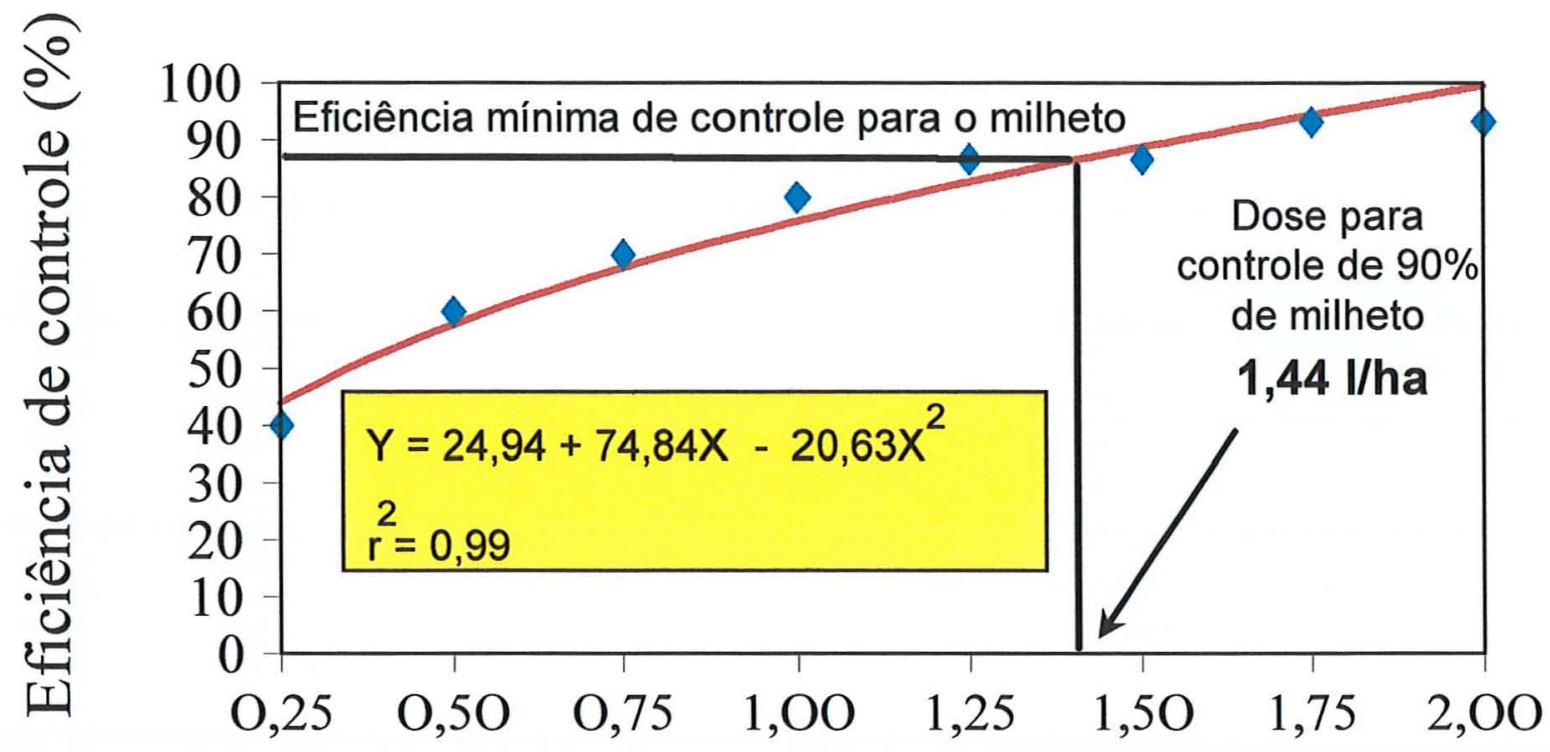

Doses (1/ha)

Figura 13 - Eficiência de controle do glyphosate em função de doses aos 15 dias de avaliação em Bandeirantes - MS, 1989.

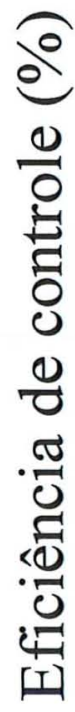

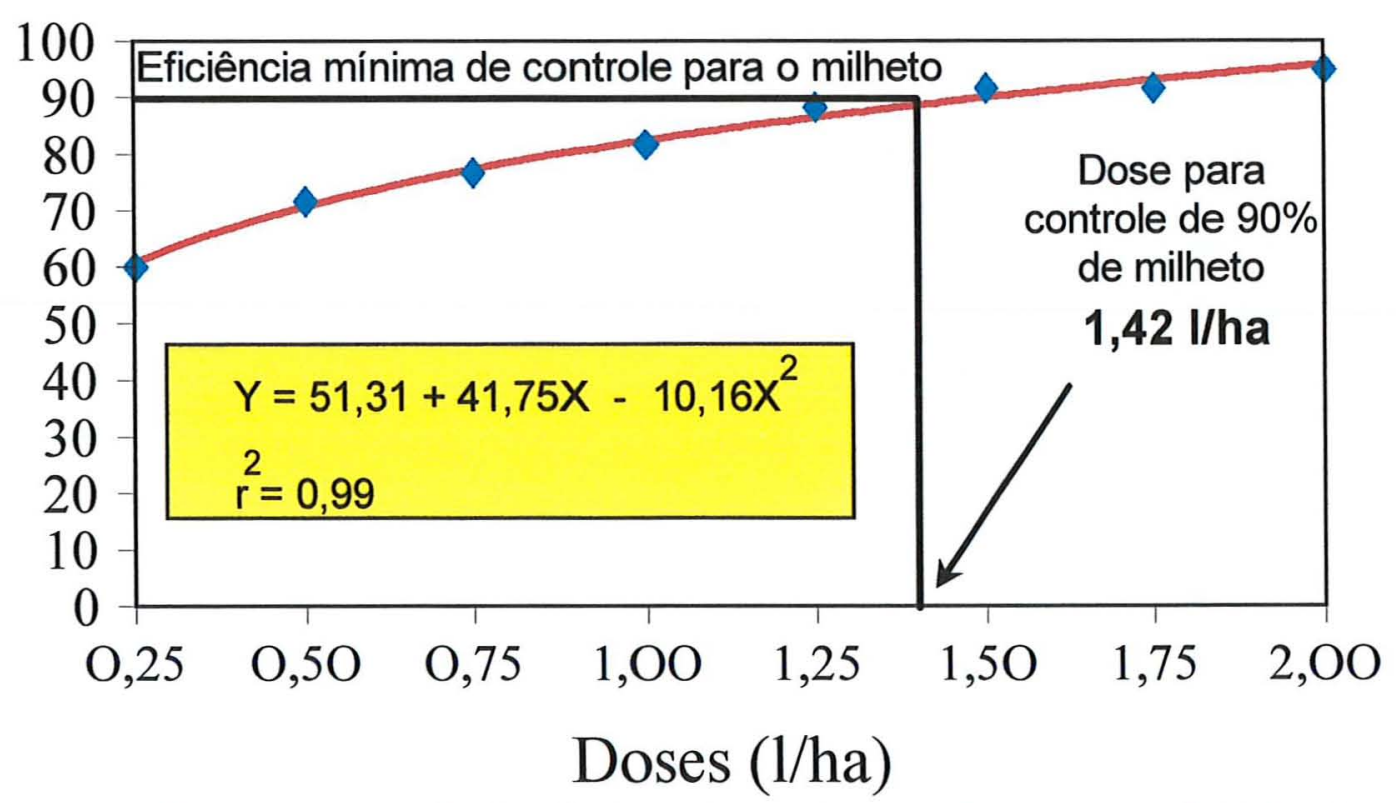

Figura 14 - Eficiência de controle do glyphosate em função de doses aos $\mathbf{3 0}$ dias de avaliação em Bandeirante - MS, 1989. 


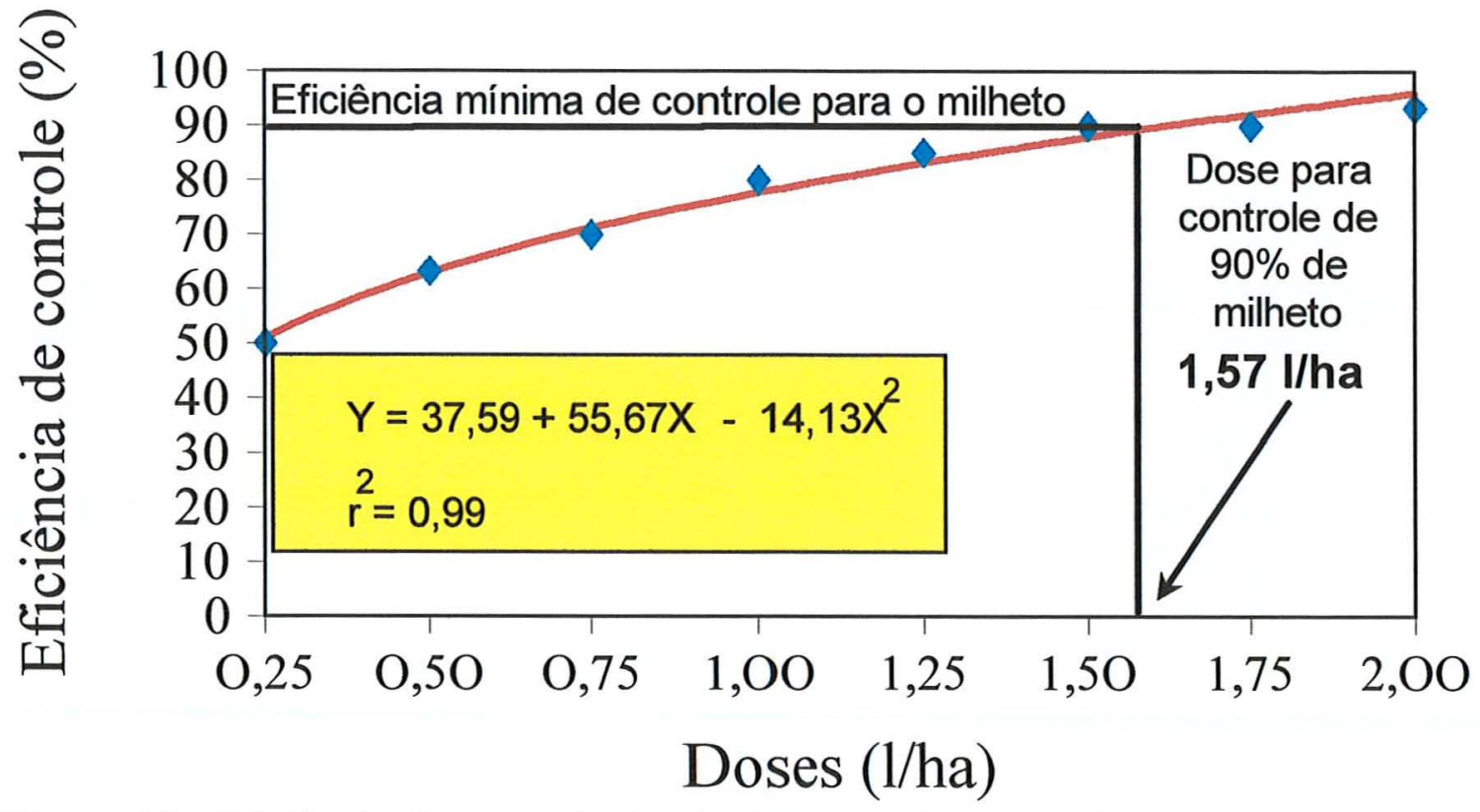

Figura 15 - Eficiência de controle do glyphosate + Herbitencil em função de doses aos 15 dias de avaliação em Bandeirantes - MS, 1989.

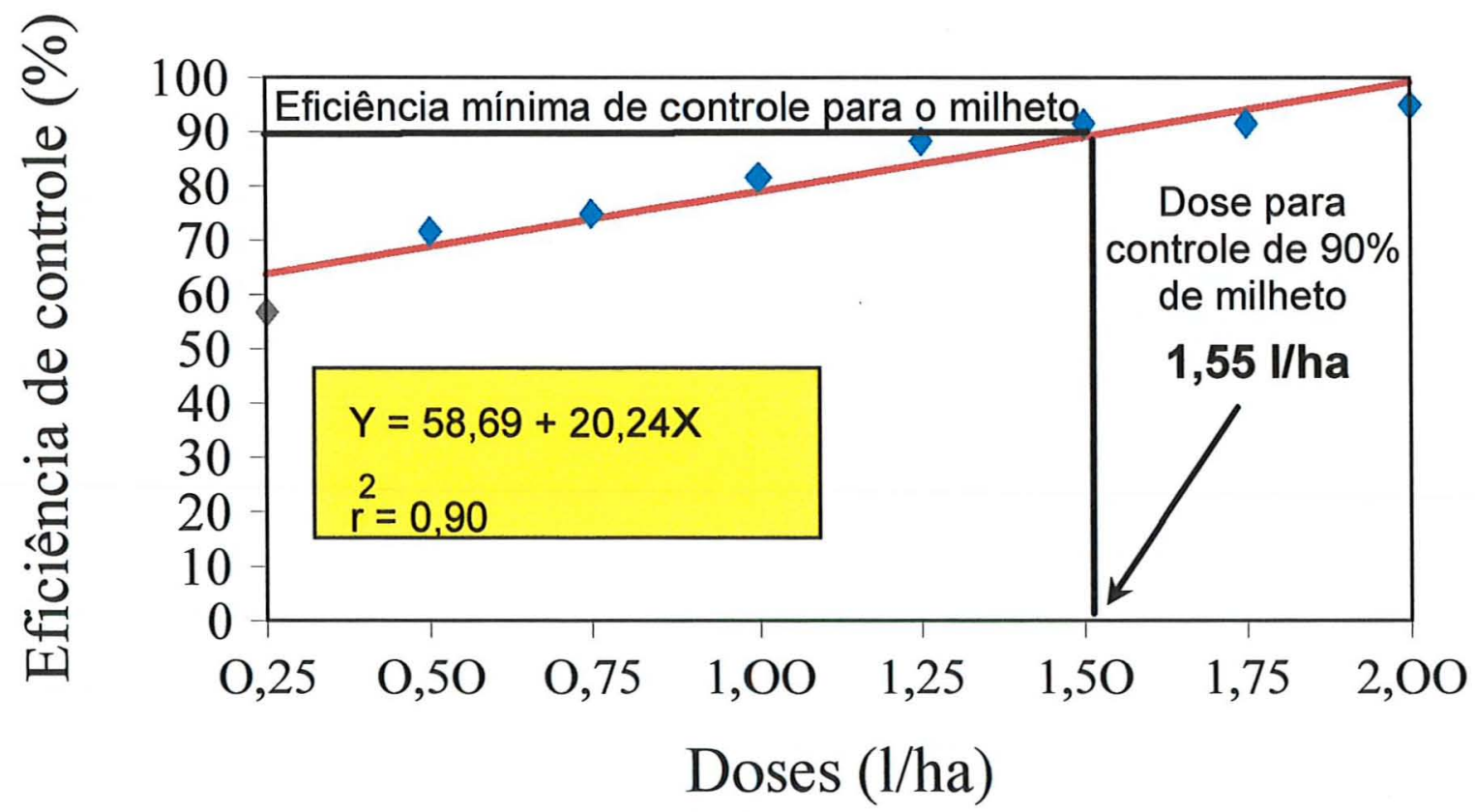

Figura 16 - Eficiência de controle do glyphosate + Herbitencil em função de doses aos 30 dias de avaliação em Bandeirantes - MS, 1989. 

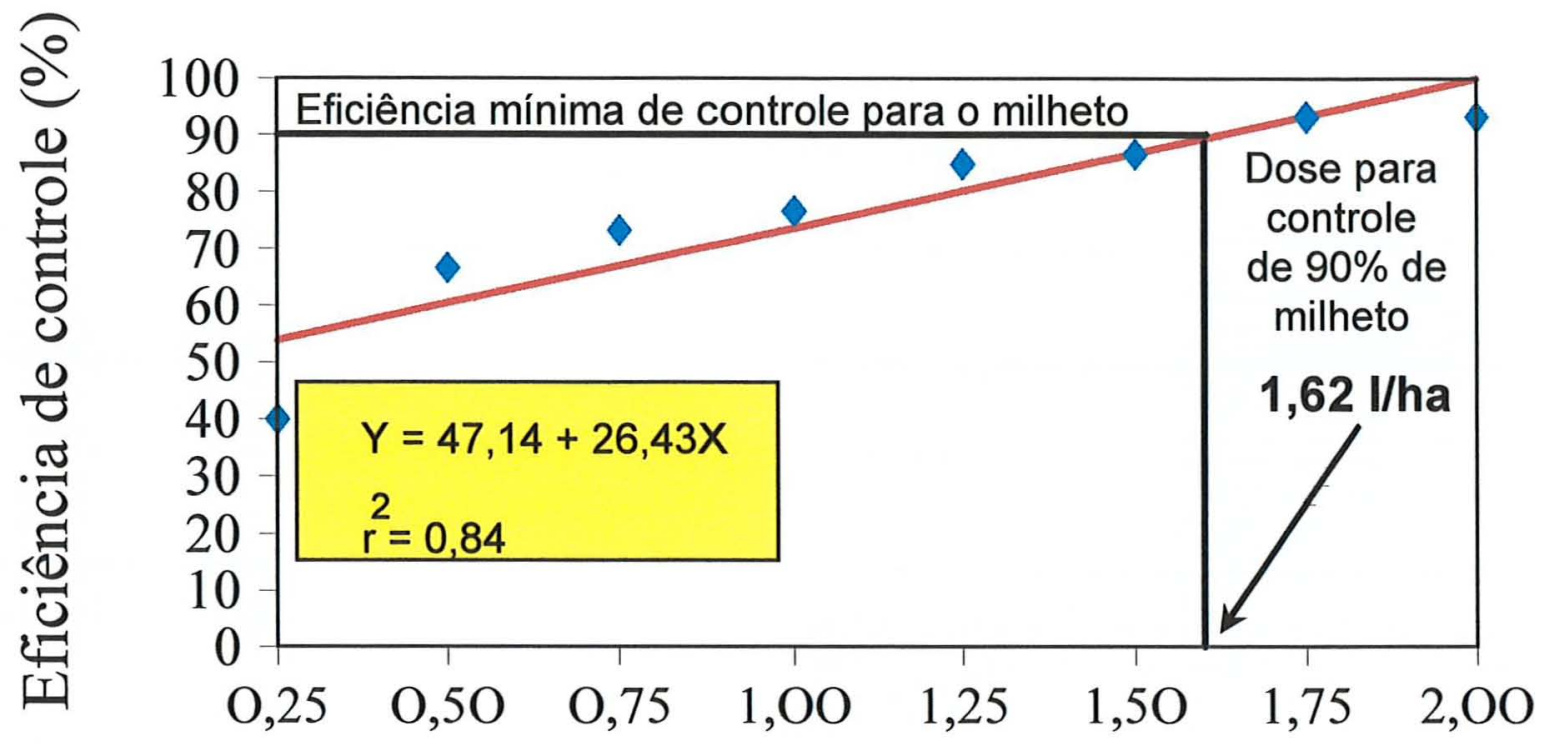

Doses $(1 / \mathrm{ha})$

Figura 17 - Eficiência de controle do glyphosate + Natur'lóleo em função de doses aos 15 dias de avaliação em Bandeirantes - MS, 1989.

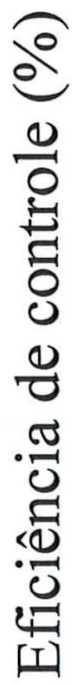

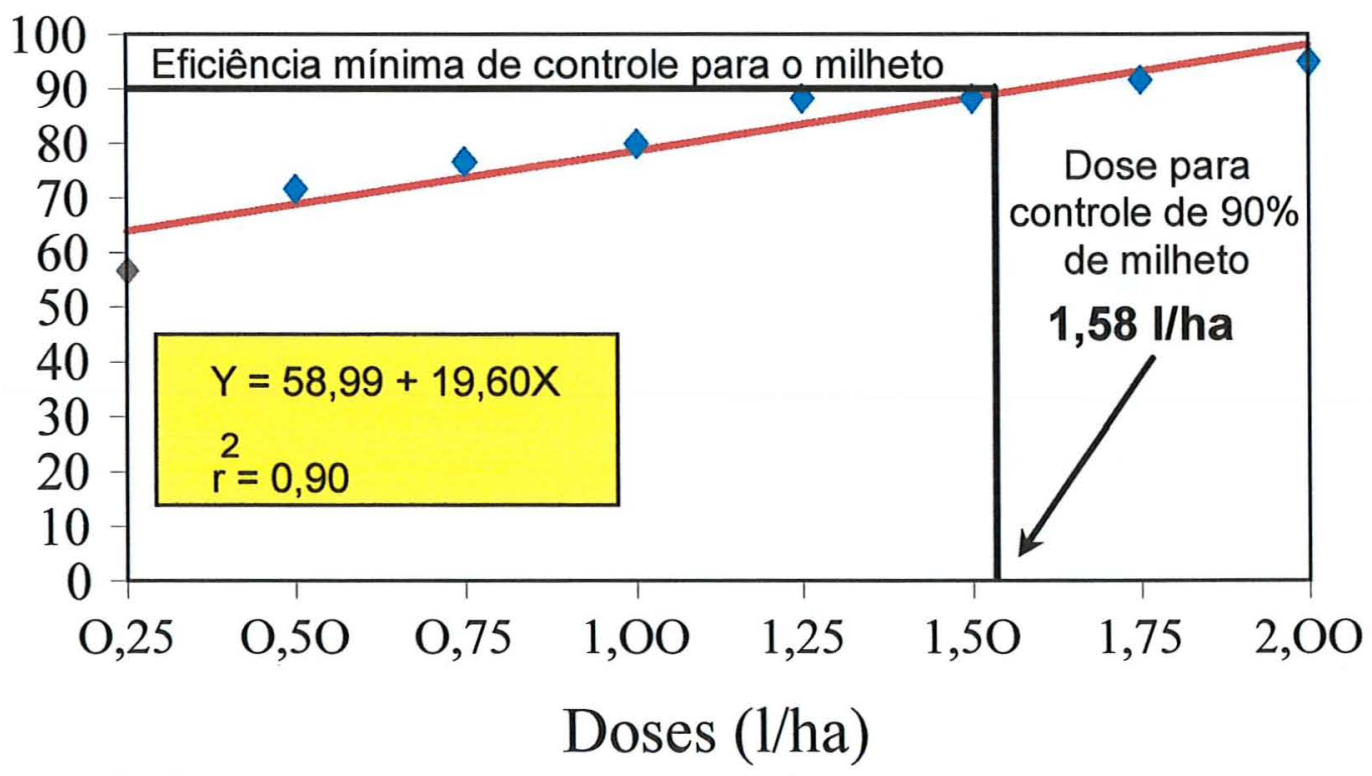

Figura 18 - Eficiência de controle do glyphosate + Natur'lóleo em função de doses aos 30 dias de avaliação em Bandeirantes - MS, 1989. 


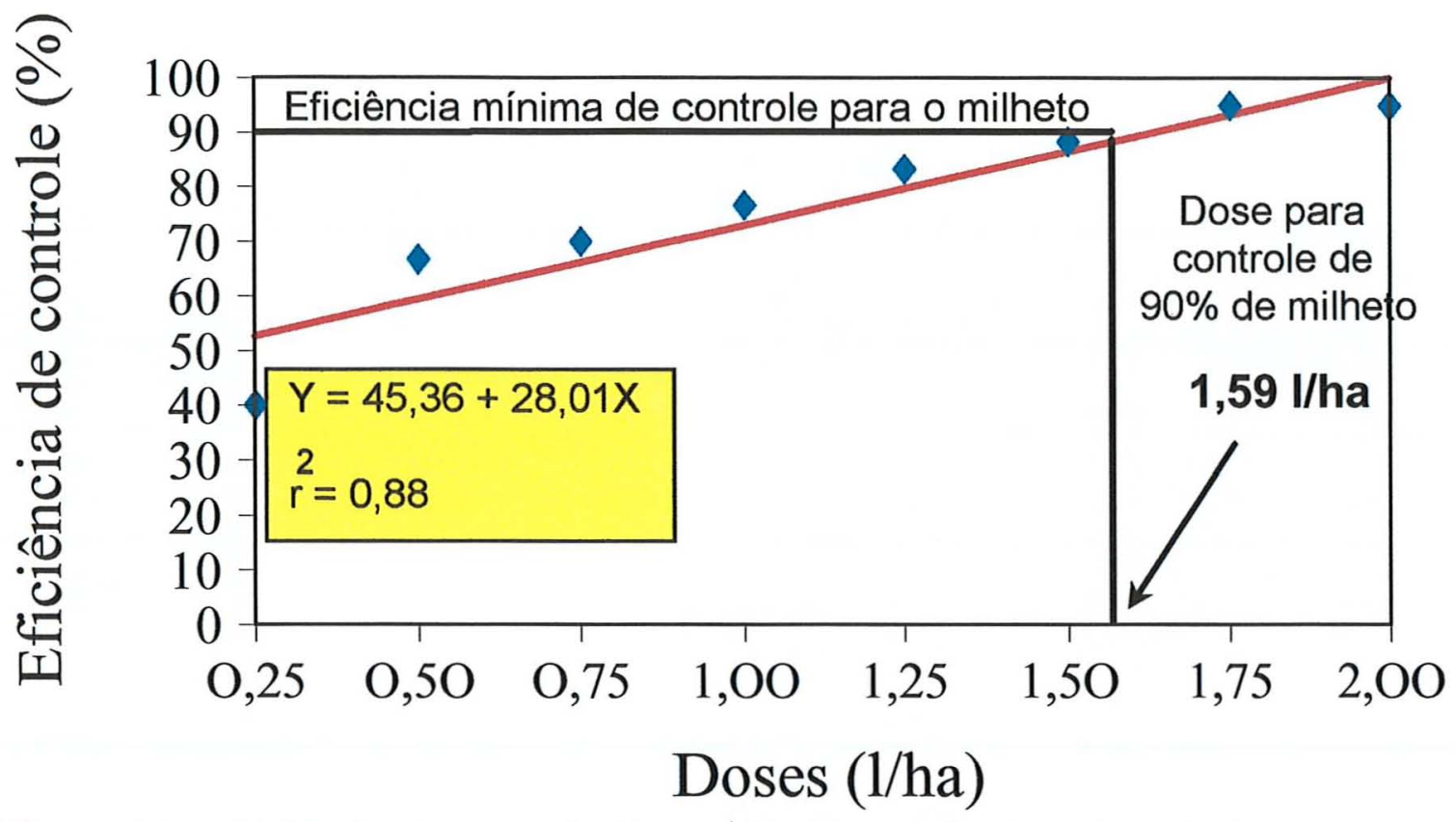

Figura 19 - Eficiência de controle do glyphosate + Glicol em função de doses aos 15 dias de avaliação em Bandeirantes - MS, 1989.
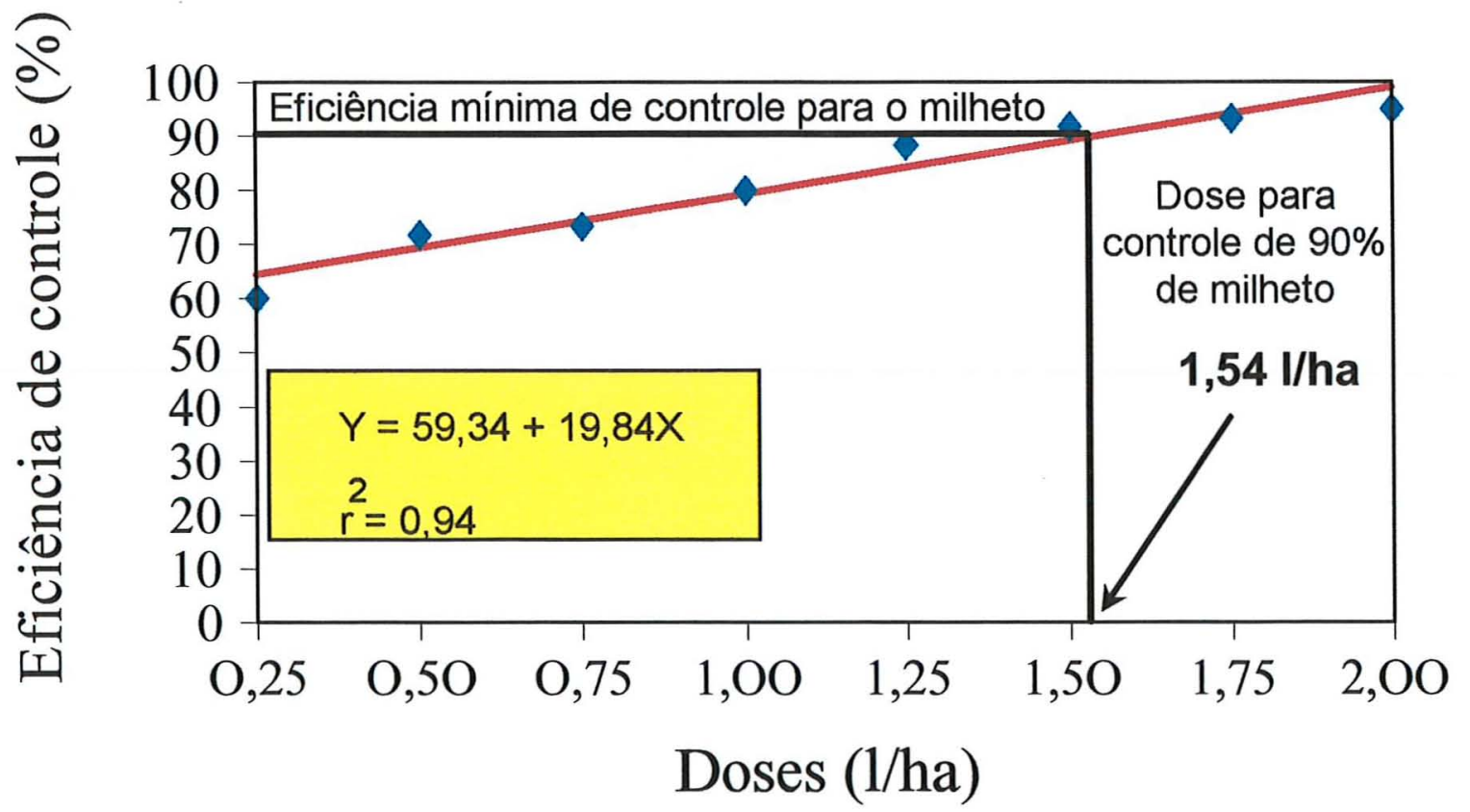

Figura 20 - Eficiência de controle do glyphosate + Glicol em função de doses aos 30 dias de avaliação em Bandeirantes - MS, 1989. 


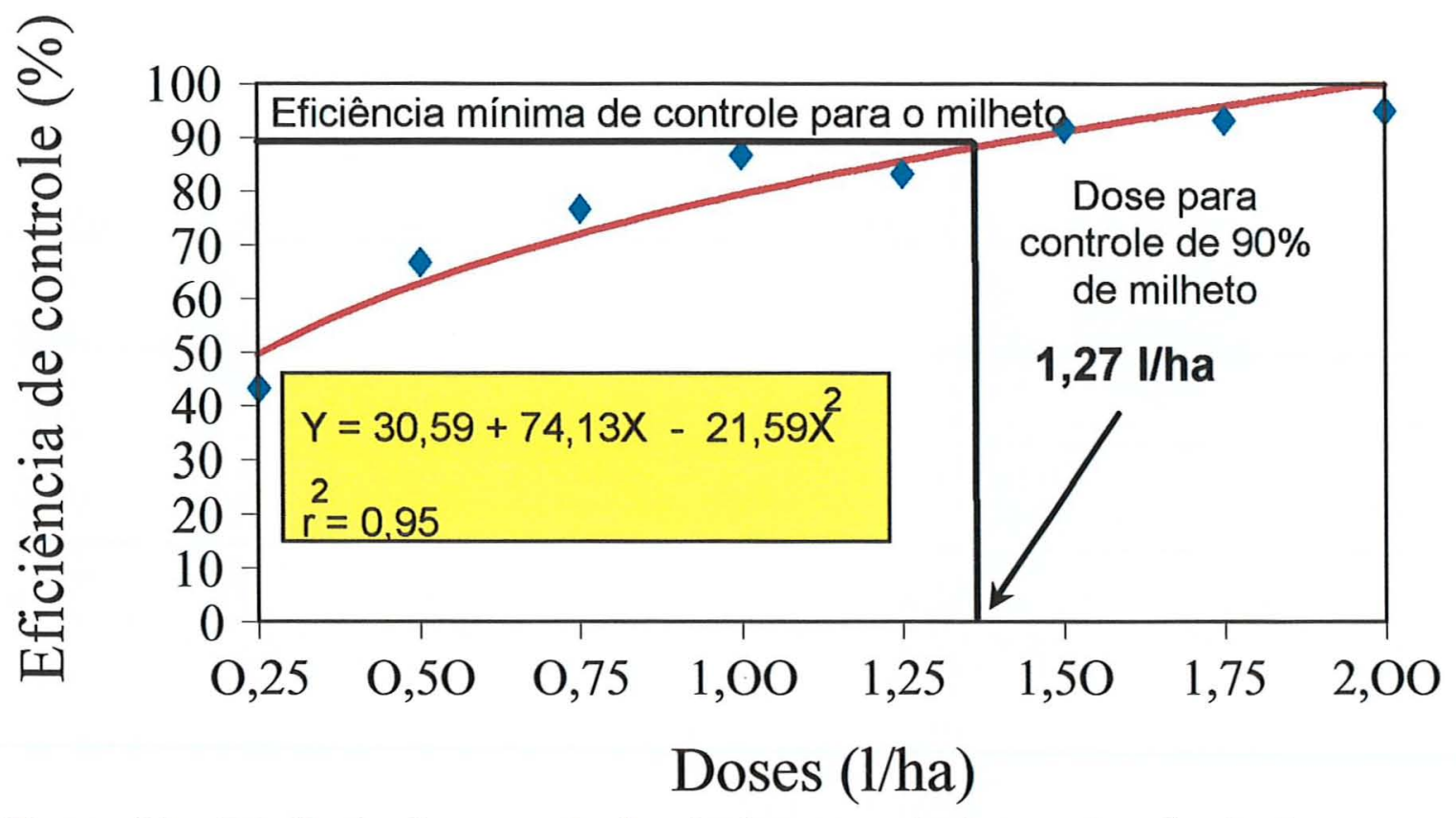

Figura 21 - Eficiência de controle do glyphosate + Assist em função de doses aos 15 dias de avaliação em Bandeirantes - MS, 1989.

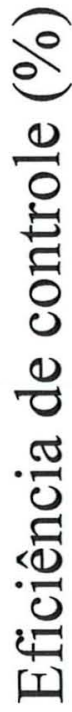

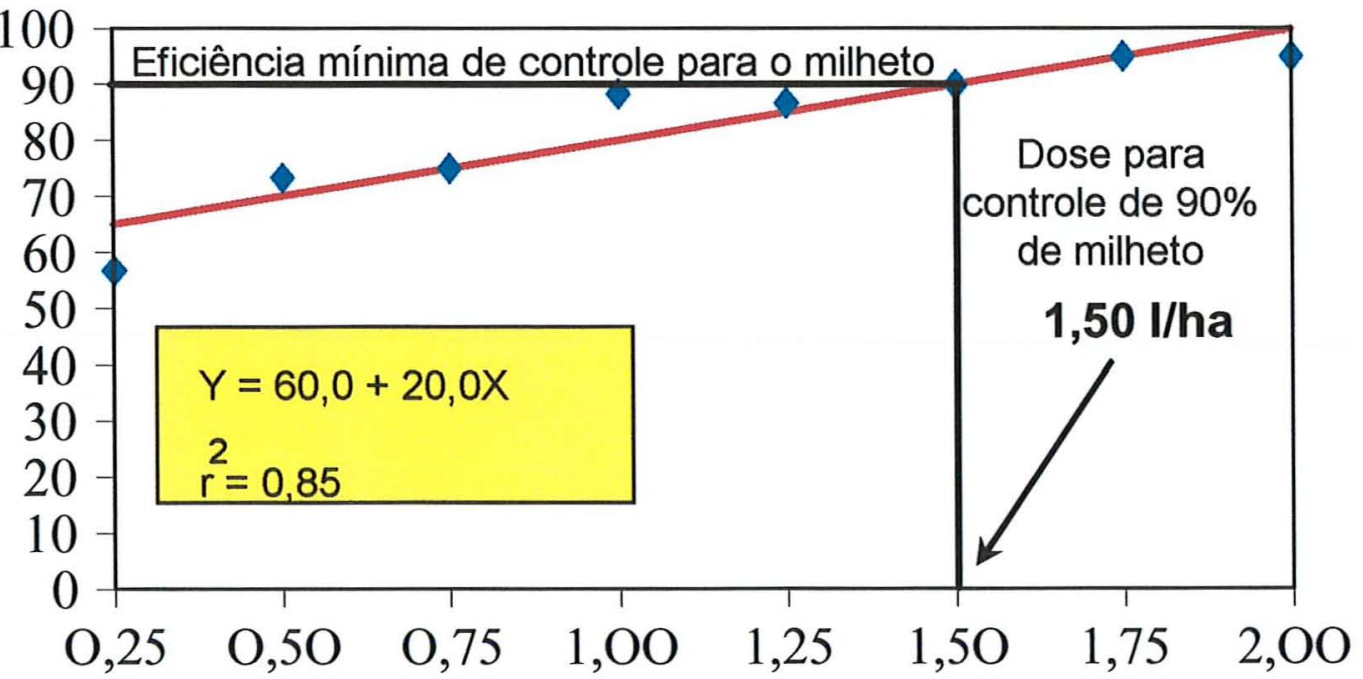

Doses (1/ha)

Figura 22 - Eficiência de controle do glyphosate + Assist em função de doses aos 30 dias de avaliação em Bandeirantes - MS,1989. 
Além da interpretação do comportamento dos dados, a regressão possibilita o conhecimento de valores intermediários, facilitando a determinação de pontos de interesse como um ponto máximo, um ponto de decisão, além de outros (Spadotto \& Luiz, 1994). No entanto, certo cuidado na extrapolação dos dados deve ser verificado, pois conforme Pimentel Gomes (1987), os polinômios são funções pouco apropriadas à representação de fenômenos biológicos. Sua utilização deve-se a simplicidade e à falta de método mais adequado.

O milheto apresenta um comportamento bastante variável em função da disponibilidade maior ou menor de água durante o seu ciclo, dependente da precipitação pluvial inerente a cada região do Cerrado e, da época de sua semeadura.

Nesse sentido, as equações das figuras anteriormente apresentadas, podem ser utilizadas de diversas maneiras. O prolongamento do ciclo do milheto, através de subdoses do glyphosate, em razão do adiamento do momento da semeadura da cultura de verão, pode ser opção preferencial em determinada época ou ano. Todavia, nas épocas onde ocorre atraso das chuvas, dá-se um estreitamento do período de semeadura, e em conseqüência, um escasso tempo para o plantio, necessitando rápido controle do milheto, com o uso de doses maiores. Assim, de acordo com as diferentes situações que ocorrem no campo, dentro do processo produtivo agrícola, a cultura do milheto pode ser manejada, conforme o nível de controle necessário, através da dose calculada adequadamente com as equações citadas. 


\section{CONCLUSÕES}

Os resultados obtidos neste trabalho permitem que se exponha as seguintes conclusões:

a) $\mathrm{O}$ acréscimo de adjuvantes ao herbicida glyphosate não trouxe benefício $\mathrm{em}$ relação ao controle do rebrote do milheto, no volume de calda trabalhado.

b) $O$ período de ação do glyphosate sobre o milheto abrange 30 dias, porque necessita deste período de tempo para manifestar todo seu efeito sobre a espécie.

c) A utilização de doses superiores a 1,50 l/ha (p.c.) de glyphosate mostra-se desnecessária para o controle, em $90 \%$, do rebrote do milheto.

d) As equações de regressão calculadas, para o glyphosate e aditivos, podem auxiliar no manejo do milheto, que devido as diferentes situações encontradas no Cerrado, necessita de instrumentos de apoio que proporcionem a escolha de doses adequadas a cada situação. 


\section{REFERÊNCIAS BIBLIOGRÁFICAS}

ADÁMOLI, J.; MACEDO, J.; AZEVEDO, L.G.; MADEIRA, J. Caracterização da região dos Cerrados. In: GOEDERT, W.J. (Ed.). Solos dos Cerrados: tecnologias e estratégias de manejo. São Paulo: Nobel, 1985. p.33-74.

ALCÂNTARA, P.B.; BUFARAH, G. Plantas forrageiras: gramíneas e leguminosas. São Paulo: Nobel, 1979. 150p.

ALMEIDA, F.S. Influência da cobertura morta do plantio direto na biologia do solo. In: FANCELLI, A.L.; VIDAL TORRADO; MACHADO, J.,(Coord.) Atualização em plantio direto, Campinas: Fundação Cargill, 1985. p.104-144.

ALVIM, P de T. Repensando a teoria da formação dos campos cerrados. In: SIMPÓSIO SOBRE O CERRADO, 8., Brasília, 1996. Anais. Brasília: EMBRAPA-CPAC, 1996. p.56-58.

ANDREWS, D.J.; KUMAR, K.A. Pearl millet for food, feed, and forage. In: PARKS, D.L., (Ed.) Advances in Agronomy. San Diego: Academic Press, 1992. v.48, p.90-139. 
ASSAD, M.L.R.C.L. Recursos biológicos: ocorrência e variabilidade. In: SIMPOSIO SOBRE O CERRADO, 8., Brasília, 1996. Anais. Brasília: EMBRAPA-CPAC, 1996. p.20-24.

AYOADE, J. O. Classificações climáticas e climas regionais. In: Introdução à climatologia para os trópicos. São Paulo: Difel, 1986. cap.11, p.231-234.

BALYAN, R.S.; MALIK, R.K.; BHAN, V.M. Effect of methods of atrazine application on weed control in pearl millet [Pennisetum americanum (L)K.Schum]. Pesticides, v.21, n.3, p.14-16, 1987. Resumo 412 em Sorghum and Millets Abstracts, v.13, n.3, p.53, 1988.

BLANCO. H.G. Ecologia das plantas daninhas:competição de plantas daninhas em culturas brasileiras. In: CREA-SP. Controle integrado de plantas daninhas. 2. ed. São Paulo: CREA, 1985. p.43-75.

BOGDAN, A.V. Pennisetum. In: . Tropical pasture and fodder plants. Londres: Longman, 1977. p.216-243.

BUERKERT, A.; STERN, R.D.; MARSCHNER, H. Post stratification clarifies treatment effects on pearl millet growth in the Sahel. Agronomy Journal, v.87, p.752-761, 1995. 
BURTON, G.W.; WALLACE, A.T.; RACHIE, K.O. Chemical composition and nutritive value of pearl millet [Pennisetum typhoides (Burm.) Stapf and E.C.Hubbard] grain. Crop Science, v.12, p.187-189, 1972.

BURTON, G.W.; POWELL, J.B. Pearl millet breeding and cytogenetics. In: BRADY, N., (Ed.) Advances in Agronomy. San Diego: Academic Press, 1968. v.20, p.4953.

BURTON. G.W. Photoperiodism in pearl millet: Pennisetum typhoides. Crop Science, v.5, p.333-335, 1965.

CAMARGO, P.N. Adjuvantes em formulações de herbicidas. Piracicaba: ESALQ, $1986,82 p$.

CARSON, A.G. Improving weed management in the draft animal-based production of early pearl millet in the Gambia. Tropical Pest Management, v.33, n.4, p.359-363, 1987.

CARVALHO, J.E.B, de. Efeito dos intervalos de simulação de chuva sobre o comportamento do glifosate, sozinho e em mistura com surfactantes e aditivos, no controle da grama-seda [Cynodon dactylon (L.) Pers.]. Piracicaba, 1985. 93p. Tese (Doutorado) - Escola Superior de Agricultura "Luiz de Queiroz", Universidade de São Paulo. 
CARVALHO, J.C. Fatores que influenciam a eficácia dos herbicidas aplicados em pósemergência no controle de espécies de ipomoea e outras plantas daninhas dicotiledôneas na cultura da soja [Glycine $\max$ (L.) Merrill]. Piracicaba, 1989. 135p. Dissertação (Mestrado) - Escola Superior de Agricultura "Luiz de Queiroz", Universidade de São Paulo.

CASELEY, J.C.; COUPLAND, D.; Environmental and plant factors affecting glyphosate uptake, movement and activity. In: GROSSBARD, E. \& ATKINSON, D. (Ed.) The herbicide glyphosate. London: Butterworths, 1985. cap.7, p.92-123.

CHOUDHARY, A.H.; LOGOKE, S.T.O. Weed control in pearl millet in the Savanna Zone of Nigeria. Tropical Pest Management, v.27, n.4. p.465-471, dec. 1981.

CLAPP, J.G.; CHAMBLEE, D.S. Influence of different defoliation systems on the regrowth of pearl millet, hybrid sudangrass, and two sorghum-sudangrass hybrids from terminal, axillary, and basal buds. Crop Science, v.10, p.345-349, 1970.

COLE, D.J. Mode of action of glyphosate: a literature analysis. In: GROSSBARD, E.; ATKINSON, D. (Ed.) The herbicide glyphosate. London: Butterworths, 1985. cap.5, p.48-74.

CUMMINS, D.G.; HARDCASTLE, W.S. Effects of preemergence and postemergence herbicides on pearl millet.. Athens: University of Georgia Agricultural Experiment Stations, 1980. 12p. (Research Report, 354). 
DERPSCH, R.; ROTH, C.H.; SIDIRA, N.; KOPKE, U. Controle da erosão no Paraná, Brasil: sistemas de cobertura do solo, plantio direto e preparo conservacionista do solo. Eschborn: GTZ, 1991. 272p.

DEUBER, R. Ciência das plantas daninhas; fundamentos. Jaboticabal: FUNEP, 1992. $431 p$.

DUARTE, C.M.L. Avaliação de forrageiras perenes de verão e milheto [Pennisetum americanum (L.) Leeke] cv. comum integrados em sistemas de produção animal em pastagens. Porto Alegre, 1980. 150p. Dissertação (M.S.) - Faculdade de Agronomia, Universidade Federal do Rio Grande do Sul.

DUKE, S.O. Effects of herbicides on nonphotosynthetic biosynthetic processes. In: DUKE,S.O. (Ed.) Weed Physiology. Boca Raton: CRC Press, 1985. cap.4, p.93104.

DURIGAN, J.C. Matocompetição e comportamento de baixas doses de herbicidas, na cultura da soja [Glycine $\max$ (L.) Merril]. Piracicaba, 1983. 163p. Tese (Doutorado) - Escola Superior de Agricultura "Luiz de Queiroz" , Universidade de São Paulo.

DURIGAN, J.C. Avaliação da mistura de glifosate e 1,4 D para o controle de plantas daninhas em citros. Ciência das plantas daninhas, v.1, n.1, p.8-10, 1988. 
DURIGAN, J.C. Efeito de adjuvantes na calda e do estádio de desenvolvimento das plantas, no controle do capim-colonião (Panicum maximum) com glyphosate. Planta Daninha, v.10, n.1/2, p.39-44, 1992.

DURIGAN, J.C. Efeitos de adjuvantes na aplicação e eficácia dos herbicidas. Jaboticabal: FUNEP,1993. 42p.

EMPRESA PERNAMBUCANA DE PESQUISA AGROPECUÁRIA-IPA, UNIVERSIDADE FEDERAL DE PERNAMBUCO. Cultura do milheto. Fortaleza: BNB,ETENE. 1982. 95p. (Monografias, 8).

FANCELLI, A.L.; FAVARIN, J.L. O sistema de plantio direto. In: ENCONTRO PAUlista DE Plantio DIRETO, 1., Piracicaba, 1987. Plantio Direto. Piracicaba: ESALQ, 1987. p.9-17.

FAWCETT, J.A.; HARVEY, R.G. Proso millet (Panicum miliaceum) control in corn (Zea mays) with postemergence-directed herbicides. Weed Sciences, v.36, p.215-220.

FERRARIS, R.; NORMAN, M.J.T. Adaptation of pearl millet (Pennisetum typhoides) to coastal New South Wales; 2. productivity under defoliation. Australian $\mathbf{J}$ of Experimental Agriculture and Husbandry, v.13, p.692-699, dec. 1973.

FRANZ, J.E. Discovery, development and chemistry of glyphosate. In: GROSSBARD,E.; ATKINSON,D. (Ed.) The herbicide glyphosate. London: Butterworths, 1985. cap.1, p.3-17. 
FRIBOURG, H.A. The effect of morphology and defoliation intensity on the tillering, regrowth and leafiness of pearl millet, Pennisetum typhoides (Burm.) Stapf. \& C.E. Hubb. In: INTERNATIONAL GRASSLAND CONGRESS,9., São Paulo, 1965. Anais. São Paulo: Departamento da Produção Animal da Secretaria de Agricultura, 1986. v.1, p.489-491.

GARCIA, A.; SILVA, J.F.V. da. Nematóide do cisto da soja. Revista Plantio Direto, v.34, p.21-22, jul./ag. 1996.

GASSEN, D.N. O manejo de pragas no sistema plantio direto. In: EMBRAPA-CNP DE TRIGO et al. (Ed.) Plantio direto no Brasil. Passo Fundo: Aldeia Norte, 1993. cap.11, p.132-133.

GAUTAM, R.C.; KAUSHIK, S.K. Technologies to step up pearl millet yield. Indian Farming, p.13-14, jan. 1992.

GAZZIERO, D.L.P.; FLECK, N.G. Efeito de três herbicidas pós-emergentes aplicados em diferentes horas do dia sobre ervas daninhas e plantas de soja [Glycine max (L.) Merrill ]. Planta Daninha, v.3, n. 1, p.23-29, 1980.

GHOLVE, S.G.; KULKARNI, P.M.; PATIL, B.V.; PATIL, B.R. Response of ragi (Eleusine coracana), variety B-11 to varying spacing and nitrogen levels under rainfed conditions in transition-2 zones of Maharashtra. Seeds \& Farms, v.11, n.4-5, p.27-28, 1985. Resumo 1001 em Sorghum and Millets Abstracts, v.12, n.12, p.115, 1987. 
GUIMARÃES, S.C. Influência da idade de corte e de aditivos na ação do glyphosate sobre a tiririca (Cyperus rotundus L.). Viçosa, 1981. 87p. Dissertação (M.S.) Universidade Federal de Viçosa.

HANCE, R.J.; HOLLY, K. (Ed.) Weed control handbook: principles. 8 ed. Oxford: Blackwell, 1990. 553p.

HART, R.H. Digestibility, morphology, and chemical composition of pearl millet. Crop Science, v.7: p.581-584, 1967.

HART, R.H. ; BURTON, G.W. Effect of row spacing, seeding rate, and nitrogen fertilization on forage yield and quality of Gahi-1 pearl millet. Agronomy Journal, v.57, p.376-378, 1965.

HENDRIX, J.W.; GUO, B.Z.; AN, Z.-Q. Divergence of mycorrhizal fungal communities in crop production systems. Plant and Soil, v.170, p.131-140, 1995.

IGUE, K.; ALCOVER, M.; DERPSCH, R.; PAVAN, M.A.; MELLA, S.C.; MEDEIROS, G.B. Adubação orgânica. Londrina: IAPAR, 1984. 33p. (Informe da Pesquisa, 59).

JAUHAR, P.P. Cytogenetics and breeding of pearl millet and related species. In: . Progress and topics in cytogenetics. New York: Alan R. Liss, 1981. vol.1, p.1-215. 
KIEHL, E.J. Fertilizantes orgânicos. Piracicaba: Editora Agronômica Ceres, 1985. 492p.

KER, J.C.; RESENDE, M. Recursos edáficos dos cerrados: ocorrência e potencial. In: SIMPÓSIO SOBRE O CERRADO, 8., Brasília, 1996. Anais. Brasília: EMBRAPA-CPAC, 1996. p.15-19.

KISHORE, G.M.; PADGETTE, S.R.; FRALEY, R.T. History of herbicide-tolerant crops, methods of development and current state of the art; emphasis on glylosate tolerance. Weed Technology, v.6, n.3, p.626-634, jul./sep. 1992.

KLINK, C..A. Relação entre o desenvolvimento agrícola e a biodiversidade. In: SIMPÓSIO SOBRE O CERRADO, 8., Brasília, 1996. Anais. Brasília: EMBRAPA-CPAC, 1996. p.25-27.

KNOCHE, M.; BUKOVAC, M.J. Interaction of surfactant and leaf surface in glyphosate absorption. Weed Science, v.41, n.1, p.87-93, jan./mar. 1993.

MAROCHI, A.I. Conquiste o futuro com a tecnologia presente: tecnologia de aplicação. Castro: Fundação ABC, 1996. 36p.

MATO GROSSO DO SUL. Secretaria de Planejamento e Coordenação Geral, Fundação Instituto Brasileiro de Geografia e Estatística. Macrozoneamento geoambiental do Estado de Mato Grosso do Sul. Campo Grande: FIPLAN, 1989. 242p. 
MEDEIROS, R.B. Formação e manejo de pastagens para a região do Planalto Médio e Missões. Porto Alegre: Secretaria de Agricultura/Governo do Estado do Rio Grande do Sul, 1977. 48p.

MEDEIROS, R.B. ; SAIBRO, J.C. Efeito do $\mathrm{N}$ e da população de plantas sobre o rendimento de MS, teor e produção de PB de forrageiras anuais de estação quente:(2) cv. comum de milheto [Pennisetum typhoides (Burm)]*. In: REUNIÃO ANUAL DA SOCIEDADE BRASILEIRA DE ZOOTECNIA,10., Porto Alegre, 1973. Resumos. Porto Alegre: SBZ, 1973. p.367.

MEDINA, H.P. Constituição física. In: MONIZ, A.C., (Ed.) Elementos de pedologia. São Paulo: Ed. da Universidade de São Paulo-Polígono, 1972. cap.1, p.11-28.

MICHELS, K.; ARMBRUST, D.V.; ALLISON, B.E.; SIVAKUMAR, M.V.K. Wind and windblown sand damage to pearl millet. Agronomy Journal, v.87, p.620-626, 1995.

NALEWAJA, J.D.; MATYSIAK, R.; FREEMAN, T.P. 2,4-D and salt combinations affect glyphosate phytotoxicity. Weed Science, v.6, n.2, p.332-327, ap./jun. 1992a.

NALEWAJA, J.D.; MATYSIAK, R.; FREEMAN, T.P. Spray droplet residual of glyphosate in various carriers. Weed Science, v.6, n.3, p.561-566, jul./sep.1992b.

NALEWAJA, J.D.; MATYSIAK, R.; FREEMAN, T.P. Spray droplet residual of glyphosate in various carriers. Weed Science, v.40, p.576-589, 1992c. 
NDAHI, W.B. Herbicide evaluation in millet in the Northern Guinea and Sudan Savannah of Nigeria. Tropical Pest Management, v.30, n.4, p.351-355, dec. 1984.

PEREIRA, F. de A.R.; GAZZIERO, D.L.P.; BONAMIGO, L.A. Avaliação de espécies com potencial para a produção de cobertura morta em áreas de cerrado. In: Resultados de pesquisa de soja 1985/86. Londrina: EMBRAPA-CNPSo, 1987(a). p.432-434. (Documentos, 20).

PEREIRA, F. de A.R.; GAZZIERO, D.L.P.; BONAMIGO, L.A. Avaliação de espécies com potencial para a produção de cobertura morta em áreas de cerrado. In: Resultados de pesquisa de soja 1985/86. Londrina: EMBRAPA-CNPSo, 1987(b). p.435-438. (Documentos, 20).

PEREIRA, F. de A.R. Avaliação de herbicidas na cultura de soja em áreas de cerrado do Mato Grosso do Sul. Campo Grande: EMPAER, 1989. 33p. (Documentos, 28).

PEREIRA, F. de A.R. Cultivo de espécies visando a obtenção de cobertura vegetal do solo na entressafra da soja [Glycine max (L.) Merril] no cerrado. Botucatu, 1990. 83p. Dissertação (M.S.) - Faculdade de Ciências Agronômicas do Campus de Botucatu-UNESP.

PEREIRA, M.H. Carta ao Presidente da República. Jornal do Plantio Direto, v.25, n.1, jan./fev. 1995. 
PIMENTEL GOMES, F. Curso de estatística experimental. 12 ed. Piracicaba: ESALQ/USP, 1987, 467p.

PITELLI, R.A. Interferência de plantas daninhas em culturas agrícolas. Informe Agropecuário, v.11, n.129, p.16-27, set. 1985.

PURSEGLOVE, J.W. Gramineae: Pennisetum. In: Tropical crops; monocotyledons 1. New York: John Wiley \& Sons, 1972. p.204-213.

RAIJ, B. van. A capacidade de troca de cátions das frações orgânica e mineral em solos ('). Bragantia, v.28, n.8, p. 85-112, 1969.

RAO, S.A.; MENGESHA, M.H.; REDDY, C.R. Pearl millet ( $P$. americanum) germplasm from Senegal. Indian Journal of Genetics and Plant Breeding, v.46, n.2, p.413-422, 1986. Resumo 730 em Sorghum and Millets Abstracts, v.13, n.5, p.92, 1988 .

RESK, D.V.S. Manejo de solos e sustentabilidade dos sistemas agrossilvipastoris na região dos cerrados. In: SIMPÓSIO SOBRE O CERRADO, 8., Brasília, 1996. Anais. Brasília: EMBRAPA-CPAC, 1996. p.81-89.

RICHARD Jr, E.P.; GOSS, J.R.; ARNTZEN, C.J. Glyphosate does not inhibit photosynthetic electron transport and phosphorylation in pea (Pisum sativum) chloroplasts. Weed Science, v.27, n.6, p.684-688. 
RODRIGUES, B.N.; ALMEIDA, F.S.de. Guia de herbicidas. 3.ed. Londrina: dos autores, 1995. 675p.

ROHDE, G.M. Uma breve história do arroz. Lavoura Arrozeira, v.48, n.419, p.3-6, FENARROZ/1995.

SCHEFFER, S.M.; SAIBRO, J.C. de; RIBOLDI, J. Efeito do nitrogênio, métodos de semeadura e regimes de corte no rendimento e qualidade da forragem e da semente de milheto. Pesquisa Agropecuária Brasileira, v.20, n.3, p.309-317, mar. 1985.

SIVAPRASAD, B.; SARMA, K.S.S. Seedling emergence of chickpea (Cicer arietinum), pigeon pea (Cajanus cajan) and pearl millet (Pennisetum typhoides); effect of differential soil crusting, as induced by raindrop size, and depth of sowing. Plant and Soil, v.104, n.2, p.263-268, 1987.

SOCIEDADE BRASILEIRA DA CIÊNCIA DAS PLANTAS DANINHAS. Procedimentos para instalação, avaliação e análise de experimentos com herbicidas. Londrina: SBCPD, 1995. 42p.

SPADOTTO, C.A.; LUIZ, A.J.B. Estatística: uso da análise de regressão. Ciência das Plantas Daninhas, v.2, n.1, p.15-17, 1994. 
TURNER, D.J.; LOADER, M.P.C . Effect of ammonium sulphate and other additives upon the phytotoxicity of glyphosate to Agropyron repens (L.)Beauv. Weed Research, v.20, p.140-146, 1980

TURNER, D.J. Effects on glyphosate performance of formulation, additives and mixing with other herbicides. In: GROSSBARD, E.; ATKINSON, D. (Ed.) The herbicide glyphosate. London: Butterworths, 1985. cap.15, p.221-240.

VICTÓRIA FILHO, R. Controle químico de plantas daninhas. In: CREA-SP. Controle integrado de plantas daninhas. 2. ed. São Paulo: CREA, 1985. p.77-102.

WILLS, G.D. Factors affecting toxicity and translocation of glyphosate in cotton (Gossypium hirsutum). Weed Science, v.26, n.5, p.509-513, sep. 1978.

WILSON, R.G. Wild proso millet. Lincoln: Cooperative Extension-Institute of Agriculture and Natural Resources-University of Nebraska, 1992. 2p.

WODAGENEH, A.; MATHEWS, G.A. Addition of oil pesticide sprays; downwind movement of droplets. Tropical pest management, v.27, n.4, p.501-504.

ZHANG, D.; HAN, X.L. First analysis of photosynthetic traits in various crops under different ecotopes. Yunnam Agricultural Science and Technology, n.6, p.3-5, 1987. Resumo 719 em Sorghum and Millets Abstracts, v.13, n.5, p.91, 1988. 
APÊNDICE 
TABELA 10. Precipitação diária, em mm, ano de 1989, em Bandeirante - MS

\begin{tabular}{|c|c|c|c|c|c|c|c|c|c|c|c|c|}
\hline \multirow[t]{2}{*}{ Dia } & \multicolumn{12}{|c|}{ Mês } \\
\hline & Jan. & Fev. & Mar. & Abr. & Mai. & Jun. & Jul. & $\mathrm{Ag}$. & Set. & Out & Nov. & Dez. \\
\hline 01 & 0 & 0 & 0 & 0 & 0 & 0 & 0 & 0 & 5 & 0 & 0 & 12 \\
\hline 02 & 0 & 0 & 0 & 0 & 40 & 0 & 2 & 0 & 0 & 0 & 0 & 0 \\
\hline 03 & 6 & 0 & 0 & 0 & 25 & 0 & 0 & 0 & 0 & 12 & 13 & 20 \\
\hline 04 & 3 & 0 & 0 & 0 & 35 & 0 & 0 & 52 & 0 & 0 & 0 & 25 \\
\hline 05 & 8 & 8 & 0 & 0 & 0 & 0 & 0 & 0 & 0 & 8 & 0 & 0 \\
\hline 06 & 80 & 0 & 0 & 0 & 0 & 0 & 0 & 0 & 0 & 0 & 0 & 5 \\
\hline 07 & 0 & 40 & 0 & 20 & 0 & 0 & 0 & 0 & 0 & 0 & 0 & 2 \\
\hline 08 & 18 & 6 & 3 & 0 & 0 & 42 & 0 & 0 & 0 & 0 & 0 & 8 \\
\hline 09 & 0 & 9 & 0 & 0 & 0 & 28 & 0 & 0 & 0 & 0 & 30 & 10 \\
\hline 10 & 17 & 1 & 0 & 28 & 0 & 12 & 0 & 0 & 3 & 0 & 0 & 10 \\
\hline 11 & 9 & 0 & 12 & 8 & 0 & 0 & 0 & 0 & 0 & 45 & 0 & 20 \\
\hline 12 & 23 & 0 & 15 & 1 & 0 & 0 & 0 & 0 & 0 & 0 & 0 & 2 \\
\hline 13 & 8 & 29 & 0 & 20 & 0 & 0 & 0 & 0 & 0 & 0 & 0 & 0 \\
\hline 14 & 0 & 5 & 0 & 0 & 0 & 0 & 0 & 0 & 0 & 0 & 0 & 2 \\
\hline 15 & 50 & 24 & 0 & 0 & 0 & 0 & 0 & 0 & 0 & 0 & 0 & 0 \\
\hline 16 & 18 & 12 & 28 & 0 & 0 & 0 & 0 & 0 & 0 & 0 & 0 & 0 \\
\hline 17 & 0 & 15 & 0 & 0 & 0 & 0 & 0 & 0 & 0 & 0 & 0 & 33 \\
\hline 18 & 20 & 10 & 0 & 0 & 0 & 0 & 0 & 0 & 0 & 0 & 0 & 45 \\
\hline 19 & 0 & 10 & 12 & 10 & 0 & 0 & 0 & 0 & 0 & 0 & 0 & 0 \\
\hline 20 & 0 & 8 & 8 & 0 & 0 & 0 & 3 & 0 & 0 & 0 & 0 & 0 \\
\hline 21 & 0 & 24 & 5 & 0 & 0 & 0 & 0 & 12 & 0 & 0 & 0 & 0 \\
\hline 22 & 0 & 8 & 0 & 0 & 0 & 0 & 0 & 26 & 0 & 0 & 0 & 0 \\
\hline 23 & 0 & 9 & 0 & 0 & 0 & 0 & 0 & 0 & 10 & 0 & 0 & 0 \\
\hline 24 & 0 & 37 & 0 & 8 & 0 & 0 & 0 & 0 & 0 & 1 & 0 & 3 \\
\hline 25 & 0 & 0 & 0 & 0 & 0 & 0 & 0 & 0 & 0 & 2 & 0 & 0 \\
\hline 26 & 18 & 0 & 5 & 0 & 0 & 0 & 0 & 0 & 0 & 103 & 0 & 1 \\
\hline 27 & 19 & 28 & 22 & 0 & 0 & 0 & 0 & 45 & 0 & 0 & 0 & 13 \\
\hline 28 & 0 & 0 & 0 & 0 & 0 & 10 & 0 & 0 & 0 & 0 & 0 & 73 \\
\hline 29 & 21 & & 0 & 30 & 0 & 0 & 20 & 0 & 0 & 8 & 68 & 12 \\
\hline 30 & 0 & & 10 & 0 & 0 & 0 & 20 & 0 & 0 & 0 & 12 & 18 \\
\hline 31 & 30 & & 0 & & 0 & & 0 & 12 & & 16 & & 3 \\
\hline Total & 348 & 283 & 120 & 125 & 100 & 92 & 45 & 147 & 18 & 195 & 123 & 317 \\
\hline
\end{tabular}

Total do ano: $1.913 \mathrm{~mm}$ 
ANÁLISE VARIÂNCIA E DE REGRESSÃO POLINOMIAL FIXANDO NIVEIS DOS FATORES HERBICIDA E ÉPOCA. DADOS TRANSFORMADOS SEGUNDO ARCO SENO DA RAIZ DE X/ 100

TABELA 11. Análise de variância fixando o nível glyphosate do fator herbicida e nível 15 dias do fator época.

\begin{tabular}{lrrrrr}
\hline \hline CAUSAS DA VARIAÇ̃̃OO & G.L. & S.Q. & Q.M. & VALOR F & PROB.>F \\
\hline Blocos & 2 & 20.3029095 & 10.1514548 & 1.8475 & 0.19301 \\
Doses & 7 & 3345.5847247 & 477.9406750 & 86.9824 & $0.00001^{* *}$ \\
Resíduo & 14 & 76.9255500 & 5.4946821 & & \\
\hline \hline Total & 23 & 3442.8131842 & & & \\
\hline
\end{tabular}

Média geral $=62.278145$

Coeficiente de variação $=3.764 \%$

TABELA 12.Análise de variância da regressão polinomial para os níveis de doses.

\begin{tabular}{lrrrrr}
\hline \hline CAUSAS DA VARIAÇÃO & G.L. & \multicolumn{1}{c}{ S.Q. } & \multicolumn{1}{c}{ Q.M. } & VALOR F & PROB.>F \\
\hline Regressão linear & 1 & 3088.1503048 & 3088.1503048 & 562.02529 & $0.00001^{* *}$ \\
Regressão quadrática & 1 & 216.5024648 & 216.5024648 & 39.40218 & $0.00008^{* *}$ \\
Regressão cúbica & 1 & 9.9262533 & 9.9262533 & 1.80652 & 0.19810 \\
Desvios de regressão & 4 & 31.0057018 & 7.7514254 & 1.41071 & 0.28089 \\
Resíduo & 14 & 76.9255500 & 5.4946821 & & \\
\hline \hline
\end{tabular}

TABELA 13. Equações polinomiais para dados não transformados.

\begin{tabular}{|c|c|c|c|c|c|c|}
\hline * & * & $\mathrm{X}$ & * & $\mathrm{X}^{\wedge} 2$ & * & $\mathrm{X}^{\wedge} 3$ \\
\hline$* \mathrm{Y}=$ & $44.285714 *$ & 28.4126984 * & & & $*$ & * \\
\hline$* \mathrm{Y}=$ & $24.940476 *$ & 74.8412698 * & & -20.63492063 & & $=$ \\
\hline$* \mathrm{Y}=$ & $16.190476 *$ & 111.2554113 * & & -58.81673882 & & 11.313131313 \\
\hline
\end{tabular}

TABELA 14. Médias ajustadas pelas equações de regressão.

\begin{tabular}{lccccc}
\hline \hline Níveis & Médias Obs. & Médias Orig. & Linear & Quadrática & Cúbica \\
\hline 0.250 & 40.0000 & 40.0000 & 51.3889 & 42.3611 & 40.5051 \\
0.500 & 60.0000 & 60.0000 & 58.4921 & 57.2024 & 58.5281 \\
0.750 & 70.0000 & 70.0000 & 65.5952 & 69.4643 & 71.3203 \\
1.000 & 80.0000 & 80.0000 & 72.6984 & 79.1468 & 79.9423 \\
1.250 & 86.6667 & 86.6667 & 79.8016 & 86.2500 & 85.4545 \\
1.500 & 86.6667 & 86.6667 & 86.9048 & 90.7738 & 88.9177 \\
1.750 & 93.3333 & 93.3333 & 94.0079 & 92.7183 & 91.3925 \\
2.000 & 93.3333 & 93.3333 & 101.1111 & 92.0833 & 93.9394 \\
\hline \hline Coeficiente de determinação: & & 0.8714 & 0.9863 & 0.9939
\end{tabular}


TABELA 15. Análise de variância fixando o nível glyphosate do fator herbicida e nível 30 dias do fator época.

\begin{tabular}{lrrrrr}
\hline \hline CAUSAS DA VARIAÇÃO & G.L. & \multicolumn{1}{c}{ S.Q. } & \multicolumn{1}{c}{ Q.M. } & VALOR F & PROB.>F \\
\hline Blocos & 2 & 1.0474840 & 0.5237420 & 0.0503 & 0.95122 \\
Doses & 7 & 1710.7127696 & 244.3875385 & 23.4545 & $0.00002^{* *}$ \\
Resíduo & 14 & 145.8747803 & 10.4196272 & & \\
\hline \hline Total & 23 & 1857.6350339 & & & \\
\hline
\end{tabular}

Média geral $=66.068878$

Coeficiente de variação $=4.886 \%$

TABELA 16. Análise de variância da regressão polinomial para os níveis de doses.

\begin{tabular}{lrrrrl}
\hline \hline CAUSAS DA VARIAÇÃO & G.L. & \multicolumn{1}{c}{ S.Q. } & \multicolumn{1}{c}{ Q.M. } & VALOR F & PROB.>F \\
\hline Regressão linear & 1. & 1644.8406573 & 1644.8406573 & 157.85984 & $0.00001^{* *}$ \\
Regressão quadrática & 1 & 46.2747169 & 46.2747169 & 4.44111 & $0.05012^{\text {ns }}$ \\
Regressão cúbica & 1 & 0.1641571 & 0.1641571 & 0.01575 & 0.89739 \\
Desvios de regressão & 4 & 19.4332383 & 4.8583096 & 0.46627 & 0.76140 \\
Resíduo & 14 & 145.8747803 & 10.4196272 & & \\
\hline \hline
\end{tabular}

TABELA 17. Equações polinomiais para dados não transformados.

\begin{tabular}{|c|c|c|c|c|c|c|c|}
\hline * & $*$ & $X$ & * & $\mathrm{X}^{\wedge} 2$ & * & $X^{\wedge} 3$ & $*$ \\
\hline$* \mathrm{Y}=$ & $60.833333 *$ & 18.8888889 & & & * & & $\bar{*}$ \\
\hline$* \mathrm{Y}=$ & $51.309524 *$ & 41.7460317 & & -10.15873016 & & & $*$ \\
\hline$* \mathrm{Y}=$ & $48.809524 *$ & 52.1500722 & & -21.06782107 & & 3.232323232 & $2 *$ \\
\hline
\end{tabular}

TABELA 18. Médias ajustadas pelas equações de regressão.

\begin{tabular}{llllll}
\hline \hline Níveis & Médias Obs. & Médias Orig. & Linear & Quadrática & Cúbica \\
\hline 0.250 & 60.0000 & 60.0000 & 65.5556 & 61.1111 & 60.5808 \\
0.500 & 71.6667 & 71.6667 & 70.2778 & 69.6429 & 70.0216 \\
0.750 & 76.6667 & 76.6667 & 75.0000 & 76.9048 & 77.4351 \\
1.000 & 81.6667 & 81.6667 & 79.7222 & 82.8968 & 83.1241 \\
1.250 & 88.3333 & 88.3333 & 84.4444 & 87.6190 & 87.3918 \\
1.500 & 91.6667 & 91.6667 & 89.1667 & 91.0714 & 90.5411 \\
1.750 & 91.6667 & 91.6667 & 93.8889 & 93.2540 & 92.8752 \\
2.000 & 95.0000 & 95.0000 & 98.6111 & 94.1667 & 94.6970 \\
\hline \hline \multicolumn{7}{l}{ Coeficiente de determinação: } & & 0.9225 & 0.9892 & 0.9907
\end{tabular}


TABELA 19. Análise de variância fixando o nível glyphosate + herbitencil do fator herbicida e nível 15 dias do fator época.

\begin{tabular}{lccccl}
\hline \hline CAUSAS DA VARIAÇÃO & G.L. & \multicolumn{1}{c}{ S.Q. } & Q.M. & VALOR F & PROB.>F \\
\hline Blocos & 2 & 20.6979273 & 10.3489636 & 0.4655 & 0.64198 \\
Doses & 7 & 2361.0965286 & 337.2995041 & 15.1721 & $0.00007^{* *}$ \\
Resíduo & 14 & 311.2424465 & 22.2316033 & & \\
\hline \hline Total & 23 & 2693.0369024 & & & \\
\hline
\end{tabular}

Média geral $=63.030819$

Coeficiente de variação $=7.481 \%$

TABELA 20. Análise de variância da regressão polinomial para os níveis de doses.

\begin{tabular}{|c|c|c|c|c|c|}
\hline CAUSAS DA VARIAÇÃO & G.L & S.Q. & & $\overline{\text { VALOR F }}$ & $\overline{\text { PROB. }>\mathrm{F}}$ \\
\hline $\operatorname{Reg}$ & 1 & $\overline{2244.2036618}$ & 2244.2036618 & 100.94655 & $0.00001 * *$ \\
\hline ica & 1 & 97.2738926 & 97.2738926 & 548 & $528^{* *}$ \\
\hline cúbica & 1 & 0.0092495 & 0.0092495 & 0.00042 & 0.98177 \\
\hline Desvios de regressão & 4 & 19.6097248 & 4.9024312 & 0.22052 & 0.92111 \\
\hline Resíduo & 14 & 311.2424465 & 22.2316033 & & \\
\hline
\end{tabular}

TABELA 21. Equações polinomiais para dados não transformados.

\begin{tabular}{|c|c|c|c|c|c|c|}
\hline$*$ & $*$ & $\mathrm{X}$ & $\mathrm{X}^{\wedge} 2$ & * & $\mathrm{X}^{\wedge} 3$ & $*$ \\
\hline$* \mathrm{Y}=$ & $50.833333 *$ & 23.8888889 & & * & & * \\
\hline$* \mathrm{Y}=$ & $37.589286 *$ & 55.6746032 & -14.12698413 & $*$ & & * \\
\hline$* \mathrm{Y}=$ & $35.714286 *$ & 63.4776335 & -22.30880231 & & 2.424242424 & $*$ \\
\hline
\end{tabular}

TABELA 22. Médias ajustadas pelas equações de regressão.

\begin{tabular}{llllll}
\hline \hline Níveis & Médias Obs. & Médias Orig. & Linear & Quadrática & Cúbica \\
\hline 0.250 & 50.0000 & 50.0000 & 56.8056 & 50.6250 & 50.2273 \\
0.500 & 63.3333 & 63.3333 & 62.7778 & 61.8948 & 62.1789 \\
0.750 & 70.0000 & 70.0000 & 68.7500 & 71.3988 & 71.7965 \\
1.000 & 80.0000 & 80.0000 & 74.7222 & 79.1369 & 79.3074 \\
1.250 & 85.0000 & 85.0000 & 80.6944 & 85.1091 & 84.9387 \\
1.500 & 90.0000 & 90.0000 & 86.6667 & 89.3155 & 88.9177 \\
1.750 & 90.0000 & 90.0000 & 92.6389 & 91.7560 & 91.4719 \\
2.000 & 93.3333 & 93.3333 & 98.6111 & 92.4306 & 92.8283 \\
\hline \hline
\end{tabular}


TABELA 23. Análise de variância fixando o nível glyphosate + herbitencial do fator herbicida e nível 30 dias do fator época.

\begin{tabular}{lrrrrr}
\hline CAUSAS DA VARIAÇ̃̃O & G.L. & \multicolumn{1}{c}{ S.Q. } & \multicolumn{1}{c}{ Q.M. } & \multicolumn{2}{c}{ VALOR F PROB.>F } \\
\hline Blocos & 2 & 22.0986410 & 11.0493205 & 0.4847 & 0.63064 \\
Doses & 7 & 2116.3713771 & 302.3387682 & 13.2614 & $0.00011^{* *}$ \\
Resíduo & 14 & 319.1786104 & 22.7984722 & & \\
\hline \hline Total & 23 & 2457.6486286 & & & \\
\hline
\end{tabular}

Média geral $=65.994026$

Coeficiente de variação $=7.235 \%$

TABELA 24. Análise de variância da regressão polinomial para os níveis de doses.

\begin{tabular}{lrrrrl}
\hline \hline CAUSAS DA VARIAÇÃO & G.L. & \multicolumn{1}{c}{ S.Q. } & \multicolumn{1}{c}{ Q.M. } & VALOR F & PROB.>F \\
\hline Regressão linear & 1 & 2036.1585408 & 2036.1585408 & 89.31118 & $0.00001^{* *}$ \\
Regressão quadrática & 1 & 34.0198324 & 34.0198324 & 1.49220 & $0.24077^{\text {ns }}$ \\
Regressão cúbica & 1 & 7.9973388 & 7.9973388 & 0.35078 & 0.56910 \\
Desvios de regressão & 4 & 38.1956652 & 9.5489163 & 0.41884 & 0.79377 \\
Resíduo & 14 & 319.1786104 & 22.7984722 & & \\
\hline \hline
\end{tabular}

TABELA 25. Equações polinomiais para dados não transformados.

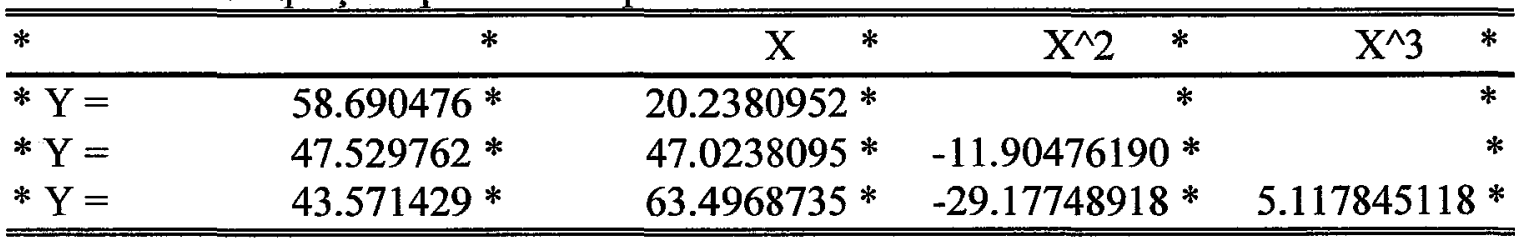

TABELA 26. Médias ajustadas pelas equações de regressão.

\begin{tabular}{llllll}
\hline \hline Níveis & Médias .Obs. & Médias. Orig. & Linear & Quadrática & Cúbica \\
\hline 0.250 & 56.6667 & 56.6667 & 63.7500 & 58.5417 & 57.7020 \\
0.500 & 71.6667 & 71.6667 & 68.8095 & 68.0655 & 68.6652 \\
0.750 & 75.0000 & 75.0000 & 73.8690 & 76.1012 & 76.9408 \\
1.000 & 81.6667 & 81.6667 & 78.9286 & 82.6488 & 83.0087 \\
1.250 & 88.3333 & 88.3333 & 83.9881 & 87.7083 & 87.3485 \\
1.500 & 91.6667 & 91.6667 & 89.0476 & 91.2798 & 90.4401 \\
1.750 & 91.6667 & 91.6667 & 94.1071 & 93.3631 & 92.7633 \\
2.000 & 95.0000 & 95.0000 & 99.1667 & 93.9583 & 94.7980 \\
\hline \hline
\end{tabular}


TABELA 27. Análise de variação fixando o nível glyphosate + natur'l óleo do fator herbicida e nível de 15 dias do fator época.

\begin{tabular}{lrrrrl}
\hline \hline CAUSAS DA VARIACAO & G.L. & \multicolumn{1}{c}{ S.Q. } & \multicolumn{1}{c}{ Q.M. } & \multicolumn{1}{c}{ VALOR F PROB.>F } \\
\hline Blocos & 2 & 9.4345504 & 4.7172752 & 0.4775 & 0.63485 \\
Doses & 7 & 3005.0862582 & 429.2980369 & 43.4549 & $0.00001^{* *}$ \\
Resíduo & 14 & 138.3081685 & 9.8791549 & & \\
\hline Total & 23 & 3152.8289771 & & & \\
\hline \hline
\end{tabular}

Média geral $=62.589214$

Coeficiente de variação $=5.022 \%$

TABELA 28. Análise de variância da regressão polinomial para os níveis de doses.

\begin{tabular}{lrrrrr}
\hline \hline CAUSAS DA VARIACAO & G.L. & \multicolumn{1}{c}{ S.Q. } & \multicolumn{1}{c}{ Q.M. } & VALOR F & PROB.>F \\
\hline Regressão linear & 1 & 2710.4912471 & 2710.4912471 & 274.36469 & $0.00001^{* * *}$ \\
Regressão quadrática & 1 & 159.2035362 & 159.2035362 & 16.11510 & $0.57145^{\text {ns }}$ \\
Regressão cúbica & 1 & 45.6429582 & 45.6429582 & 4.62013 & 0.17473 \\
Desvios de regressão & 4 & 89.7485166 & 22.4371292 & 2.27116 & 0.11293 \\
Resíduo & 14 & 138.3081685 & 9.8791549 & & \\
\hline \hline
\end{tabular}

TABELA 29. Equações polinomiais para dados não transformados.

\begin{tabular}{lrrrrr}
\hline \hline$*$ & $*$ & $\mathrm{X} *$ & $\mathrm{X}^{\wedge} 2$ & $*$ & $\mathrm{X}^{\wedge} 3$ \\
\hline$* \mathrm{Y}=$ & $47.142857^{*}$ & $26.4285714^{*}$ & $*$ & $*$ \\
$* \mathrm{Y}=$ & $29.732143^{*}$ & $68.2142857^{*}$ & $-18.57142857^{*}$ & $*$ \\
$* \mathrm{Y}=$ & $14.523810^{*}$ & $131.5055315^{*}$ & $-84.93506494^{*}$ & $19.663299663 *$ \\
\hline \hline
\end{tabular}

TABELA 30. Médias ajustadas pelas equações de regressão.

\begin{tabular}{lllccc}
\hline \hline Níveis & Médias Obs. & Médias Orig. & Linear & Quadrática & Cúbica \\
\hline 0.250 & 40.0000 & 40.0000 & 53.7500 & 45.6250 & 42.3990 \\
0.500 & 66.6667 & 66.6667 & 60.3571 & 59.1964 & 61.5007 \\
0.750 & 73.3333 & 73.3333 & 66.9643 & 70.4464 & 73.6724 \\
1.000 & 76.6667 & 76.6667 & 73.5714 & 79.3750 & 80.7576 \\
1.250 & 85.0000 & 85.0000 & 80.1786 & 85.9821 & 84.5996 \\
1.500 & 86.6667 & 86.6667 & 86.7857 & 90.2679 & 87.0418 \\
1.750 & 93.3333 & 93.3333 & 93.3929 & 92.2321 & 89.9278 \\
2.000 & 93.3333 & 93.3333 & 100.0000 & 91.8750 & 95.1010 \\
\hline \hline
\end{tabular}


TABELA 31. Análise de variância fixando o nível glyphosate + naturll óleo do fator herbicida e nível de 30 dias do fator época.

\begin{tabular}{lccccc}
\hline \hline CAUSAS DA VARIACAO & G.L. & \multicolumn{1}{c}{ S.Q. } & Q.M. & VALOR F & PROB.>F \\
\hline Blocos & 2 & 8.5148677 & 4.2574338 & 0.4128 & 0.67426 \\
Doses & 7 & 1784.5307930 & 254.9329704 & 24.7171 & $0.00002^{* *}$ \\
Resíduo & 14 & 144.3966295 & 10.3140450 & & \\
\hline Total & 23 & 1937.4422902 & & & \\
\hline
\end{tabular}

Média geral $=65.260017$

Coeficiente de variação $=4.921 \%$

TABELA 32. Análise de variância da regressão polinomial para os níveis de doses.

\begin{tabular}{lrrrrr}
\hline \hline CAUSAS DA VARIACAO & G.L. & \multicolumn{1}{c}{ S.Q. } & \multicolumn{1}{c}{ Q.M. } & VALOR F & PROB.>F \\
\hline Regressão linear & 1 & 1697.8724473 & 1697.8724473 & 164.61751 & $0.00001^{* *}$ \\
Regressão quadrática & 1 & 41.4903591 & 41.4903591 & 4.02270 & $0.06202^{\text {ns }}$ \\
Regressão cúbica & 1 & 15.1404978 & 15.1404978 & 1.46795 & 0.24454 \\
Desvios de regressão & 4 & 30.0274889 & 7.5068722 & 0.72783 & 0.58946 \\
Resíduo & 14 & 144.3966295 & 10.3140450 & & \\
\hline \hline
\end{tabular}

TABELA 33. Equações polinomiais para dados não transformados.

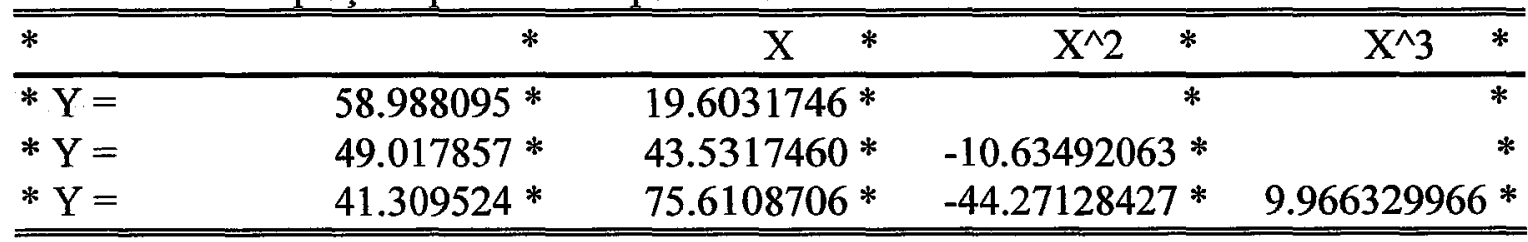

TABELA 34. Médias ajustadas pelas equações de regressão.

\begin{tabular}{|c|c|c|c|c|c|}
\hline Níveis & Médias Obs. & Médias Orig. & Linear & Quadrática & Cúbica \\
\hline 0.250 & 56.6667 & 56.6667 & 63.8889 & 59.2361 & 57.6010 \\
\hline 0.500 & 71.6667 & 71.6667 & 68.7897 & 68.1250 & 69.2929 \\
\hline 0.750 & 76.6667 & 76.6667 & 73.6905 & 75.6845 & 77.3196 \\
\hline 1.000 & 80.0000 & 80.0000 & 78.5913 & 81.9147 & 82.6154 \\
\hline 1.250 & 88.3333 & 88.3333 & 83.4921 & 86.8155 & 86.1147 \\
\hline 1.500 & 88.3333 & 88.3333 & 88.3929 & 90.3869 & 88.7518 \\
\hline 1.750 & 91.6667 & 91.6667 & 93.2937 & 92.6290 & 91.4610 \\
\hline 2.000 & 95.0000 & 95.0000 & 98.1944 & 93.5417 & 95.1768 \\
\hline
\end{tabular}


TABELA 35. Análise de variância fixando o nível glyphosate + glicol do fator herbicida e nível 15 dias do fator época.

\begin{tabular}{lrrrrl}
\hline CAUSAS DA VARIACAO & G.L. & \multicolumn{1}{c}{ S.Q. } & \multicolumn{1}{c}{ Q.M. } & VALOR F & PROB.>F \\
\hline Blocos & 2 & 13.8013460 & 6.9006730 & 1.5594 & 0.24396 \\
Doses & 7 & 3388.8466044 & 484.1209435 & 109.4042 & $0.00001^{* *}$ \\
Resíduo & 14 & 61.9509685 & 4.4250692 & & \\
\hline Total & 23 & 3464.5989189 & & & \\
\hline
\end{tabular}

Média geral $=62.781136$

Coeficiente de variação $=3.351 \%$

TABELA 36. Análise de variância da regressão polinomial para os níveis de doses.

\begin{tabular}{lrrrrr}
\hline \hline CAUSAS DA VARIACAO & G.L. & \multicolumn{1}{c}{ S.Q. } & \multicolumn{1}{c}{ Q.M. } & VALOR F & PROB.>F \\
\hline Regressão linear & 1 & 3166.9330766 & 3166.9330766 & 715.67990 & $0.00001^{* *}$ \\
Regressão quadrática & 1 & 88.8650539 & 88.8650539 & 20.08218 & $0.14406^{\text {ns }}$ \\
Regressão cúbica & 1 & 24.0114946 & 24.0114946 & 5.42624 & 0.66361 \\
Desvios de regressão & 4 & 109.0369793 & 27.2592448 & 6.16019 & 0.54772 \\
Resíduo & 14 & 61.9509685 & 4.4250692 & & \\
\hline \hline
\end{tabular}

TABELA 37. Equações polinomiais para dados não transformados.

\begin{tabular}{|c|c|c|c|c|c|c|c|}
\hline * & $*$ & $\mathrm{X}$ & $*$ & $\mathrm{X}^{\wedge} 2$ & * & $\mathrm{X}^{\wedge} 3$ & * \\
\hline$* \mathrm{Y}=$ & $45.357143^{*}$ & 28.0158730 & & & $*$ & & * \\
\hline$* \mathrm{Y}=$ & $30.327381 *$ & 64.0873016 & & -16.03174603 & $3 *$ & & * \\
\hline * $\mathrm{Y}=$ & $18.452381 *$ & 113.5064935 & & -67.84992785 & & 15.353535354 & 4* \\
\hline
\end{tabular}

TABELA 38. Médias ajustadas pelas equações de regressão.

\begin{tabular}{lllllc}
\hline \hline Níveis & Médias Obs. & Médias Orig. & Linear & Quadrática & Cúbica \\
\hline 0.250 & 40.0000 & 40.0000 & 52.3611 & 45.3472 & 42.8283 \\
0.500 & 66.6667 & 66.6667 & 59.3651 & 58.3631 & 60.1623 \\
0.750 & 70.0000 & 70.0000 & 66.3690 & 69.3750 & 71.8939 \\
1.000 & 76.6667 & 76.6667 & 73.3730 & 78.3829 & 79.4625 \\
1.250 & 83.3333 & 83.3333 & 80.3770 & 85.3869 & 84.3074 \\
1.500 & 88.3333 & 88.3333 & 87.3810 & 90.3869 & 87.8680 \\
1.750 & 95.0000 & 95.0000 & 94.3849 & 93.3829 & 91.5837 \\
2.000 & 95.0000 & 95.0000 & 101.3889 & 94.3750 & 96.8939 \\
\hline \hline Coeficiente de determinação: & & 0.8800 & 0.9520 & 0.9666
\end{tabular}


TABELA 39. Análise de variância fixando o nível glyphosate + glicol do fator mistura e nível 30 dias do fator época.

\begin{tabular}{|c|c|c|c|c|c|}
\hline CAUSAS DA VARIACAO & G.L. & S.Q. & Q.M. & VALOR F & PROB. $>F$ \\
\hline Blocos & 2 & 1.4891478 & 0.7445739 & 0.0648 & 0.93729 \\
\hline Doses & 7 & 1894.4040770 & 270.6291539 & 23.5389 & $0.00002^{* *}$ \\
\hline Resíduo & 14 & 160.9591708 & 11.4970836 & & \\
\hline Total & 23 & 2056.8523957 & & & \\
\hline
\end{tabular}

Média geral $=65.878593$

Coeficiente de variação $=5.147 \%$

TABELA 40. Análise de variância da regressão polinomial para os níveis de doses.

\begin{tabular}{lrrrrr}
\hline \hline CAUSAS DA VARIACAO & G.L. & \multicolumn{1}{c}{ S.Q. } & \multicolumn{1}{c}{ Q.M. } & VALOR F & PROB.>F \\
\hline Regressão linear & 1 & 1834.0486627 & 1834.0486627 & 159.52295 & $0.00001^{* *}$ \\
Regressão quadrática & 1 & 24.0475200 & 24.0475200 & 2.09162 & $0.16745^{\text {ns }}$ \\
Regressão cúbica & 1 & 6.7273357 & 6.7273357 & 0.58513 & 0.53717 \\
Desvios de regressão & 4 & 29.5805586 & 7.3951396 & 0.64322 & 0.64286 \\
Resíduo & 14 & 160.9591708 & 11.4970836 & & \\
\hline \hline
\end{tabular}

TABELA 41. Equações polinomiais para dados não transformados.

\begin{tabular}{lrrrrr}
\hline \hline & $*$ & $\mathrm{X} *$ & $\mathrm{X}^{\wedge} 2$ & $*$ & $\mathrm{X}^{\wedge} 3$ \\
\hline$* \mathrm{Y}=$ & $59.345238 *$ & $19.8412698 *$ & & $*$ \\
$* \mathrm{Y}=$ & $51.607143 *$ & $38.4126984 *$ & $-8.25396825 *$ & $*$ \\
$* \mathrm{Y}=$ & $53.690476 *$ & $29.7426647 *$ & $0.83694084 *$ & $-2.693602694^{*}$ \\
\hline \hline
\end{tabular}

TABELA 42. Médias ajustadas pelas equações de regressão.

\begin{tabular}{llllll}
\hline \hline Níveis & Médias Obs. & Médias Orig. & Linear & Quadrática & Cúbica \\
\hline 0.250 & 60.0000 & 60.0000 & 64.3056 & 60.6944 & 61.1364 \\
0.500 & 71.6667 & 71.6667 & 69.2659 & 68.7500 & 68.4343 \\
0.750 & 73.3333 & 73.3333 & 74.2262 & 75.7738 & 75.3319 \\
1.000 & 80.0000 & 80.0000 & 79.1865 & 81.7659 & 81.5765 \\
1.250 & 88.3333 & 88.3333 & 84.1468 & 86.7262 & 86.9156 \\
1.500 & 91.6667 & 91.6667 & 89.1071 & 90.6548 & 91.0967 \\
1.750 & 93.3333 & 93.3333 & 94.0675 & 93.5516 & 93.8672 \\
2.000 & 95.0000 & 95.0000 & 99.0278 & 95.4167 & 94.9747 \\
\hline \hline
\end{tabular}


TABELA 43. Análise de variância fixando o nível glyphosate + assist do fator herbicida e nível 15 dias do fator época.

\begin{tabular}{lrrrrl}
\hline \hline CAUSAS DA VARIACAO & G.L. & \multicolumn{1}{c}{ S.Q. } & \multicolumn{1}{c}{ Q.M. } & VALOR F & PROB.>F \\
\hline Blocos & 2 & 19.2929453 & 9.6464727 & 1.1331 & 0.35080 \\
Doses & 7 & 3066.7633817 & 438.1090545 & 51.4636 & $0.00001^{* *}$ \\
Resíduo & 14 & 119.1818876 & 8.5129920 & & \\
\hline \hline Total & 23 & 3205.2382146 & & & \\
\hline
\end{tabular}

Média geral $=64.687172$

Coeficiente de variação $=4.510 \%$

TABELA 44. Análise de variância da regressão polinomial para os níveis de doses.

\begin{tabular}{lrrrrr}
\hline \hline CAUSAS DA VARIACAO & G.L. & \multicolumn{1}{c}{ S.Q. } & \multicolumn{1}{l}{ Q.M. } & VALOR F & PROB.>F \\
\hline Regressão linear & 1 & 2682.8431393 & 2682.8431393 & 315.14691 & $0.00001^{* *}$ \\
Regressão quadrática & 1 & 254.1564853 & 254.1564853 & 29.85513 & $0.02020^{* *}$ \\
Regressão cúbica & 1 & 58.9503135 & 58.9503135 & 6.92475 & 0.01883 \\
Desvios de regressão & 4 & 70.8134436 & 17.7033609 & 2.07957 & 0.13756 \\
Resíduo & 14 & 119.1818876 & 8.5129920 & & \\
\hline \hline
\end{tabular}

TABELA 45. Equações polinomiais para dados não transformados.

\begin{tabular}{lrrrrr}
\hline \hline$*$ & $*$ & $*$ & $\mathrm{X}^{\wedge} 2$ & $*$ & $\mathrm{X}^{\wedge} 3$ \\
\hline$* \mathrm{Y}=$ & $50.833333 *$ & $25.5555556 *$ & & $*$ & $*$ \\
$* \mathrm{Y}=$ & $30.595238 *$ & $74.1269841 *$ & $-21.58730159 *$ & $*$ \\
$* \mathrm{Y}=$ & $13.928571 *$ & $143.4872531^{*}$ & $-94.31457431 *$ & $21.548821549 *$ \\
\hline \hline
\end{tabular}

TABELA 46. Médias ajustadas pelas equações de regressão.

\begin{tabular}{llllll}
\hline \hline Níveis & Médias Obs. & Médias Orig. & Linear & Quadrática & Cúbica \\
\hline 0.250 & 43.3333 & 43.3333 & 57.2222 & 47.7778 & 44.2424 \\
0.500 & 66.6667 & 66.6667 & 63.6111 & 62.2619 & 64.7872 \\
0.750 & 76.6667 & 76.6667 & 70.0000 & 74.0476 & 77.5830 \\
1.000 & 86.6667 & 86.6667 & 76.3889 & 83.1349 & 84.6501 \\
1.250 & 83.3333 & 83.3333 & 82.7778 & 89.5238 & 88.0087 \\
1.500 & 91.6667 & 91.6667 & 89.1667 & 93.2143 & 89.6789 \\
1.750 & 93.3333 & 93.3333 & 95.5556 & 94.2063 & 91.6811 \\
2.000 & 95.0000 & 95.0000 & 101.9444 & 92.5000 & 96.0354 \\
\hline \hline Coeficiente de determinação: & & 0.8062 & 0.9500 & 0.9817
\end{tabular}


TABELA 47. Análise de variância fixando o nível glyphosate + assist do fator herbicida e nível 30 dias do fator época.

\begin{tabular}{lrrrrl}
\hline \hline CAUSAS DA VARIACAO & G.L. & \multicolumn{1}{c}{ S.Q. } & \multicolumn{1}{c}{ Q.M. } & \multicolumn{1}{c}{ VALOR F } & PROB.>F \\
\hline Blocos & 2 & 20.1981171 & 10.0990585 & 1.3520 & 0.29037 \\
Doses & 7 & 2026.4797639 & 289.4971091 & 38.7554 & $0.00001^{* *}$ \\
Resíduo & 14 & 104.5780223 & 7.4698587 & & \\
\hline Total & 23 & 2151.2559032 & & & \\
\hline
\end{tabular}

Média geral $=66.545135$

Coeficiente de variação $=4.107 \%$

TABELA 48. Análise de variância da regressão polinomial para os níveis de doses.

\begin{tabular}{lcrrrr}
\hline \hline CAUSAS DA VARIACAO & G.L. & S.Q. & Q.M. & VALOR F & PROB.>F \\
\hline Regressão linear & 1 & 1840.4387072 & 1840.4387072 & 246.38200 & $0.00001^{* *}$ \\
Regressão quadrática & 1 & 88.7996513 & 88.7996513 & 11.88773 & $0.07811^{\text {ss }}$ \\
Regressão cúbica & 1 & 10.0203184 & 10.0203184 & 1.34143 & 0.26555 \\
Desvios de regressão & 4 & 87.2210869 & 21.8052717 & 2.91910 & 0.05952 \\
Resíduo & 14 & 104.5780223 & 7.4698587 & & \\
\hline
\end{tabular}

TABELA 49. Equações polinomiais para dados não transformados.

\begin{tabular}{|c|c|c|c|c|c|c|}
\hline * & * & $\mathrm{X}$ & $\mathrm{X}^{\wedge} 2$ & $*$ & $\mathrm{X}^{\wedge} 3$ & $*$ \\
\hline$* \mathrm{Y}=$ & $60.000000 *$ & 20.0000000 & & * & & * \\
\hline * $\mathrm{Y}=$ & $47.500000 *$ & 50.0000000 & -13.3333333 & $3 *$ & & * \\
\hline$* \mathrm{Y}=$ & $40.000000 *$ & 81.2121212 & -46.06060600 & & $9.69696969^{\prime}$ & $7 *$ \\
\hline
\end{tabular}

TABELA 50. Médias ajustadas pelas equações de regressão.

\begin{tabular}{llllll}
\hline \hline Níveis & Médias Obs. & Médias Orig. & Linear & Quadrática & Cúbica \\
\hline 0.250 & 56.6667 & 56.6667 & 65.0000 & 59.1667 & 57.5758 \\
0.500 & 73.3333 & 73.3333 & 70.0000 & 69.1667 & 70.3030 \\
0.750 & 75.0000 & 75.0000 & 75.0000 & 77.5000 & 79.0909 \\
1.000 & 88.3333 & 88.3333 & 80.0000 & 84.1667 & 84.8485 \\
1.250 & 86.6667 & 86.6667 & 85.0000 & 89.1667 & 88.4848 \\
1.500 & 90.0000 & 90.0000 & 90.0000 & 92.5000 & 90.9091 \\
1.750 & 95.0000 & 95.0000 & 95.0000 & 94.1667 & 93.0303 \\
2.000 & 95.0000 & 95.0000 & 100.0000 & 94.1667 & 95.7576 \\
\hline \hline
\end{tabular}

